\title{
The Impact of
}

\section{Antenatal Breastfeeding}

Education on

\section{Young Women's Breastfeeding}

\section{Self-efficacy and Breastfeeding}

\section{Rates}

\section{By \\ Nicola Jane Jackson}

A thesis submitted to the Victoria University of Wellington in fulfilment of the

requirements for the degree of

Master of Midwifery

Victoria University of Wellington 


\section{Acknowledgements}

This has been a journey and one I couldn't have completed without help from many people along the way. The work wouldn't have taken place without the participation and time given by forty one young women and I would like to acknowledge and thank them for this. Special thanks to my family who had many weekends over the last year with an absent partner and mother. Russell, for keeping the home fires burning, never complaining about the extra workload on him, and to my four wonderful children. Thanks to my wider family and good friends for editing services and support, meals, childcare and understanding. Also to my work colleagues, whom I hope I have not put off post-graduate study! Thanks to the New Zealand College of Midwives for obtaining and distributing funding. Last but not least, thanks to my supervisor Dr Joan Skinner, who like a true midwife, gave good guidance and showed patience, particularly when this baby was overdue. 


\section{Abstract}

Title: The impact of antenatal breastfeeding education on young women's breastfeeding self-efficacy and breastfeeding rates.

Background: Despite the known benefits of breastfeeding to the mother, baby and society as a whole, young women's breastfeeding rates are generally poor compared to older mothers. Effective antenatal education has been identified as one way to improve these rates. Whether or not antenatal breastfeeding education for young women can make a significant impact on their breastfeeding success is of paramount concern in this research.

An important and modifiable variable, identified in the literature as influencing breastfeeding outcomes, is self-efficacy (confidence in ability to breastfeed). This breastfeeding self-efficacy in young mothers is of great interest due to this group and their infants being vulnerable in terms of breastfeeding initiation and continuation.

Aim: This study aimed to identify the effects of antenatal breastfeeding education on the self-efficacy, experience and duration of breastfeeding for young women. It also aimed to replicate aspects of prior research in this area conducted overseas to see if those findings could be generalized to a New Zealand setting.

Method: A repeated measure design using an existing validated tool was utilised to quantify breastfeeding self-efficacy, prior to and following, an antenatal breastfeeding education session for young pregnant women aged less than 25 years old.

Findings: Breastfeeding antenatal education improved breastfeeding selfefficacy scores in urban young women less than 25 years of age. The Breastfeeding Self-efficacy Scale (short form), was found to be a reliable tool to test this. Whilst initiation rates were high in this group, there was no statistically 
significant link with breastfeeding self-efficacy and the duration and continuation of breastfeeding.

Conclusion: Whilst breastfeeding antenatal education was shown to increase breastfeeding self-efficacy, there are many confounding factors influencing breastfeeding initiation and continuation for young women. The findings have contributed to the knowledge about breastfeeding patterns of young New Zealand women. It may be that despite international findings, an increased breastfeeding self-efficacy in this setting doesn't impact on the rates of breastfeeding of urban New Zealand young mothers. Further research with an increased sample size and comparison groups is warranted.

Key Words: antenatal, prenatal, pre-natal, education, breastfeeding and support, attitudes to breastfeeding, adolescents, teenagers and breastfeeding self-efficacy. 


\section{Table of Contents}

Acknowledgements

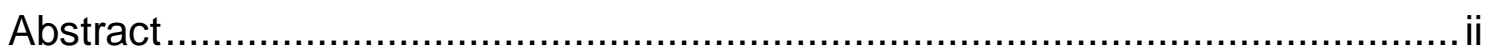

Table of Contents ................................................................................ iv

Lists of tables and figures ................................................................... viii

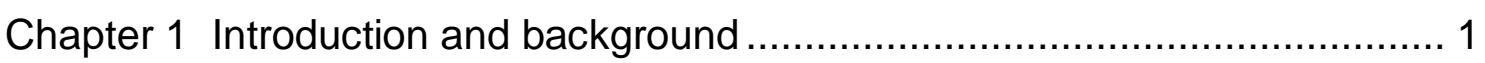

Adolescent breastfeeding practices ........................................................... 3

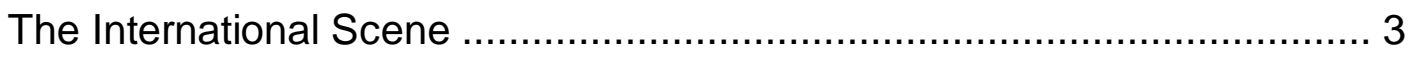

Breastfeeding within the New Zealand Context ........................................... 4

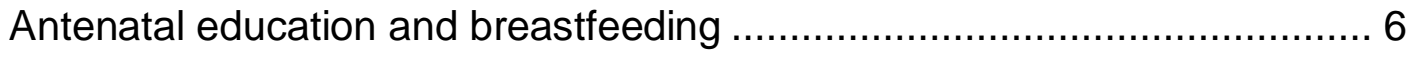

Adolescent mothers and breastfeeding education ..................................... 7

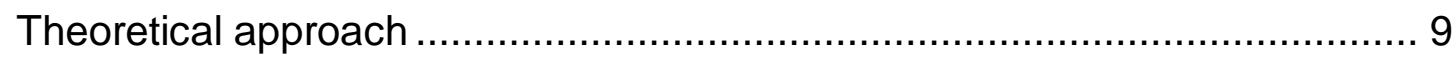

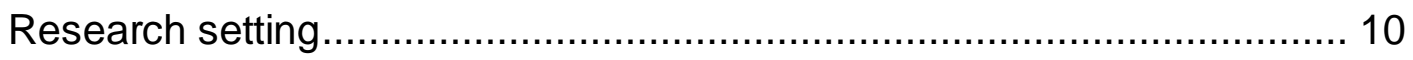

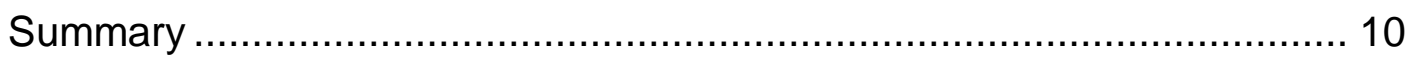

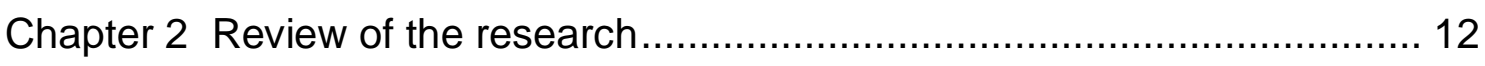

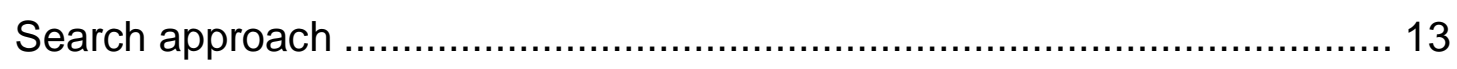

The effectiveness of antenatal breastfeeding education .............................. 15

New Zealand breastfeeding research .................................................... 15

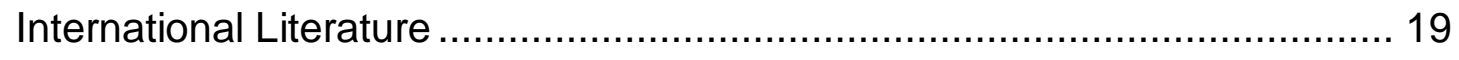

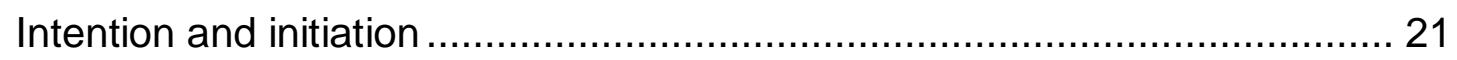

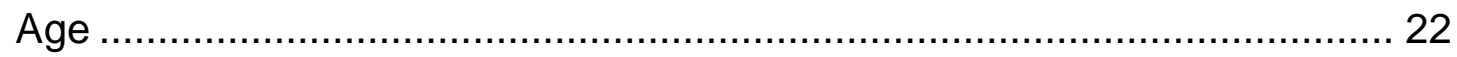

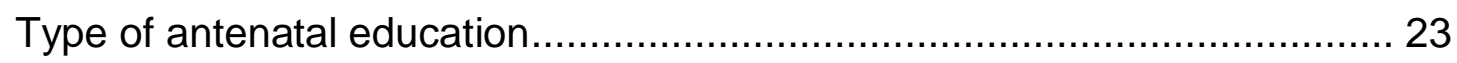

Timing, format and delivery of antenatal breastfeeding education ............... 25

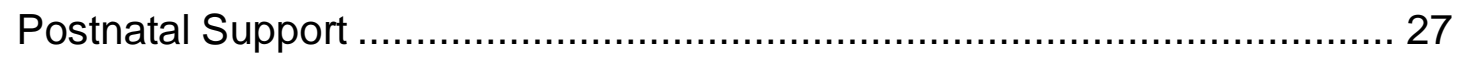

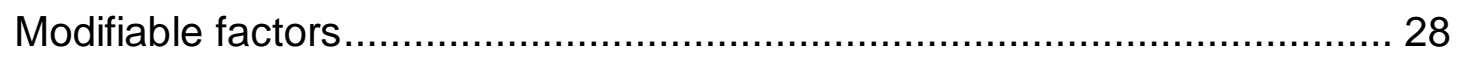




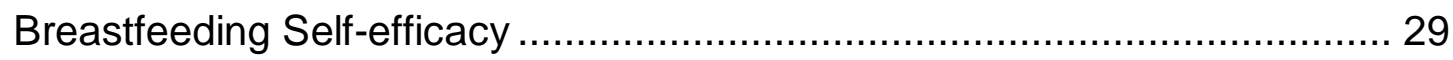

The Breastfeeding Self Efficacy Scale ...................................................... 30

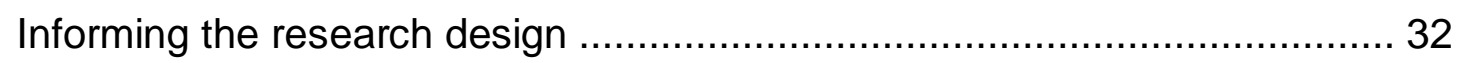

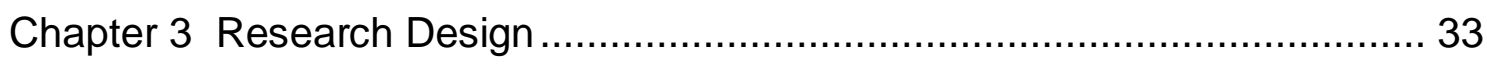

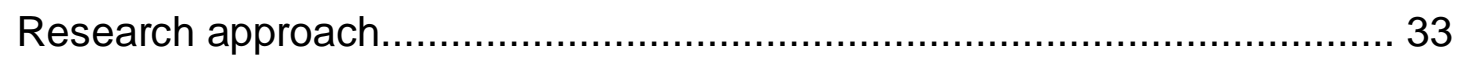

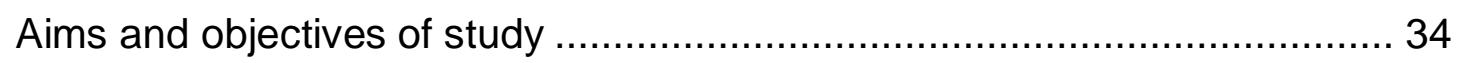

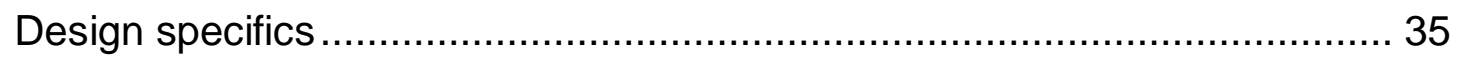

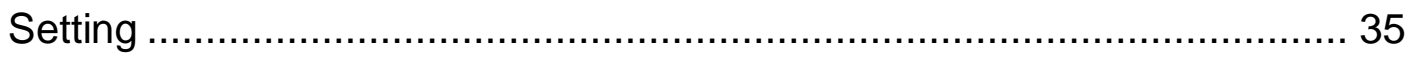

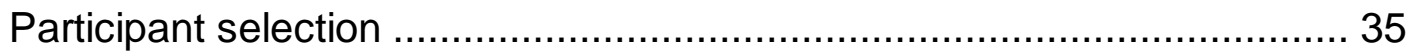

Preparation of educators, participant recruitment and administration of

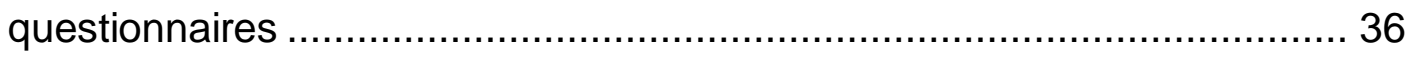

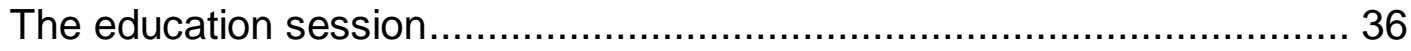

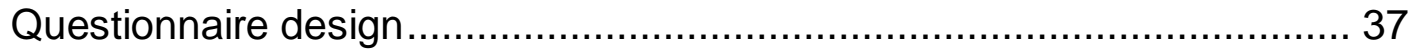

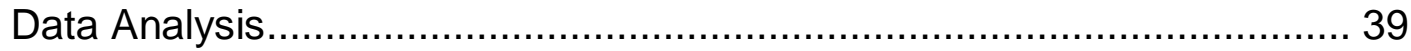

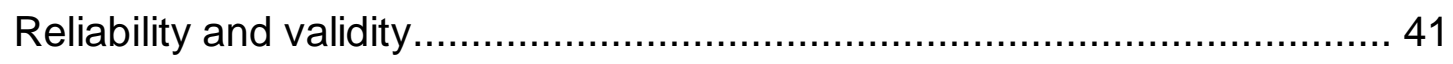

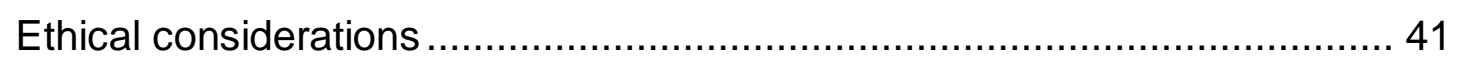

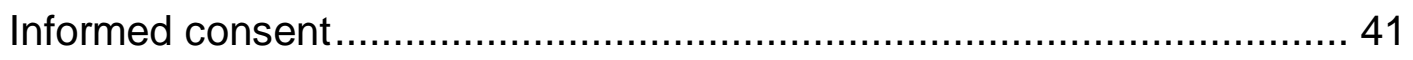

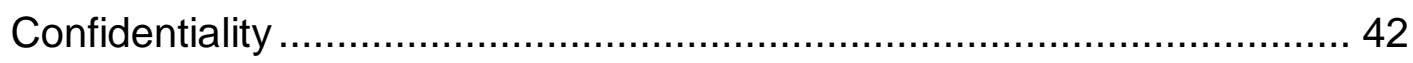

Treaty of Waitangi and Māori Participants ............................................ 43

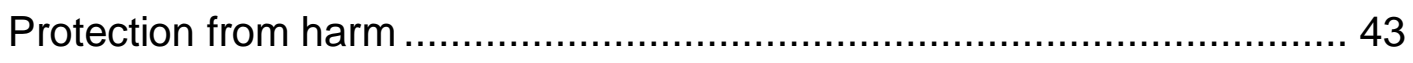

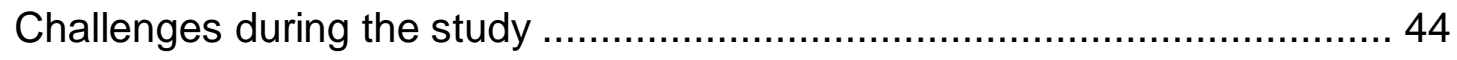

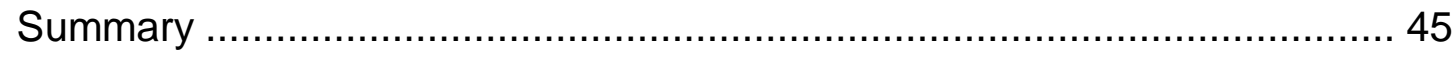

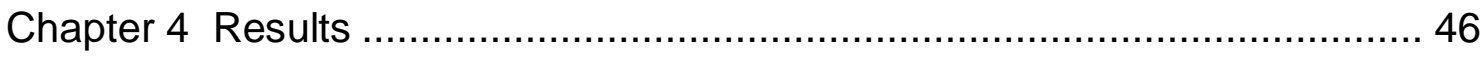

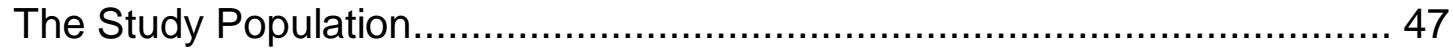

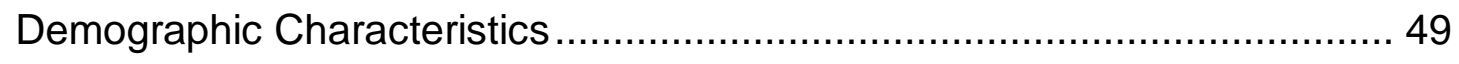

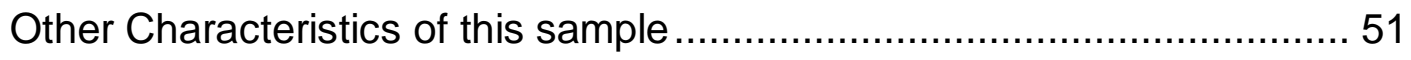

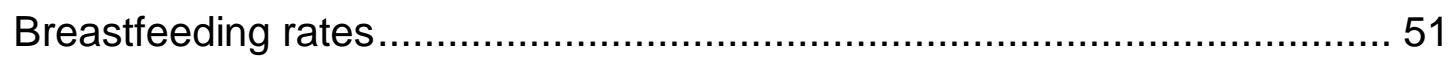


Reliability of the Breastfeeding Self-efficacy Scale

Impact of breastfeeding education on Breastfeeding Self-Efficacy scores. 52

Baseline BSES-sf scores 52

Change in breastfeeding self-efficacy and its relationship to breastfeeding success. 54

Factors influencing the duration of breastfeeding …................................... 55

Reasons for cessation of breastfeeding .................................................. 57

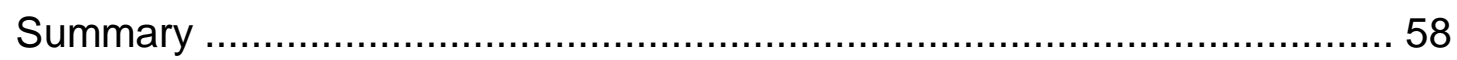

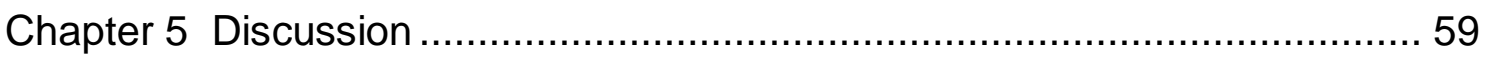

Breastfeeding self-efficacy and breastfeeding success. ............................... 60

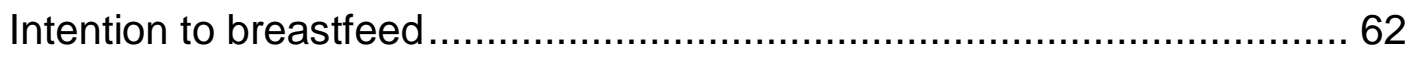

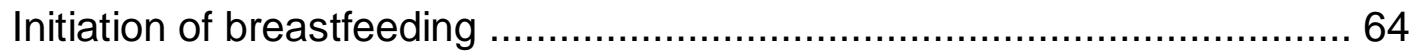

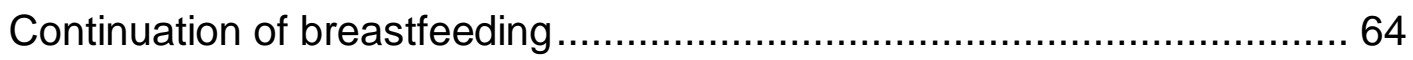

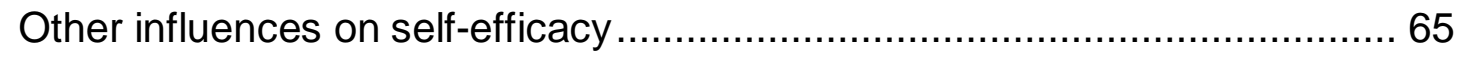

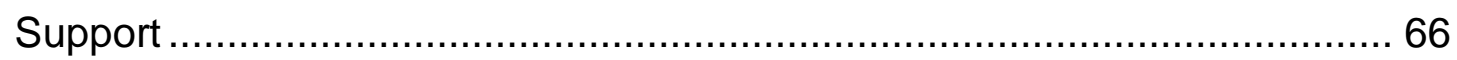

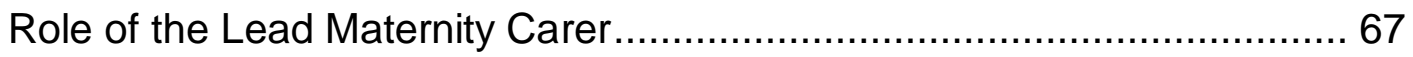

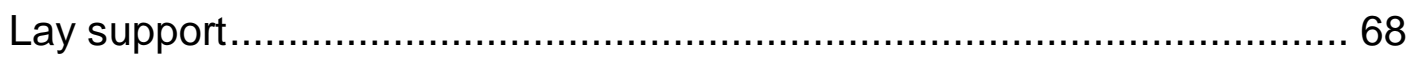

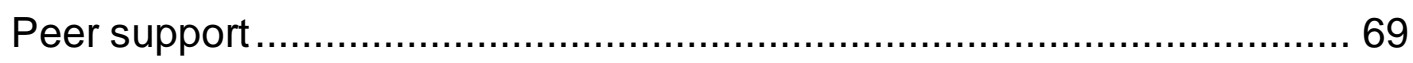

Appropriate support for Māori women ...................................................... 70

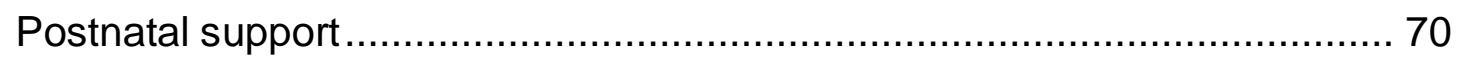

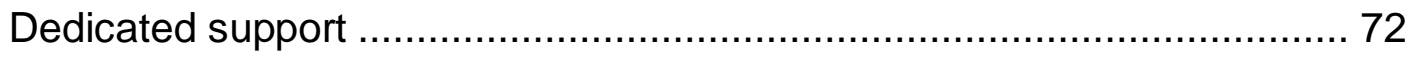

The quality and type of antenatal education ……....................................... 72

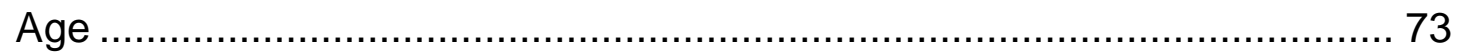

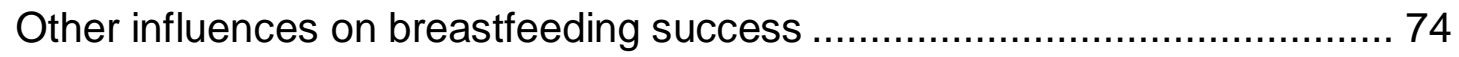

Modifiable and non-modifiable influences............................................. 74

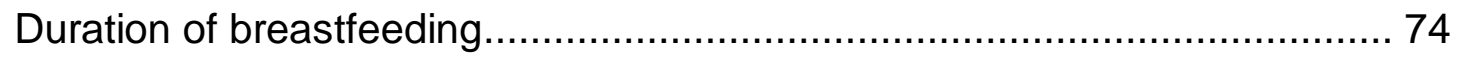

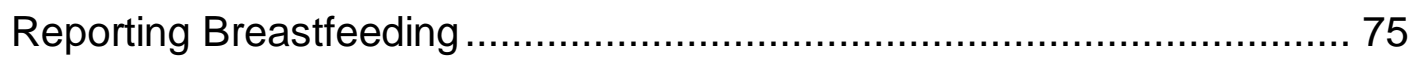




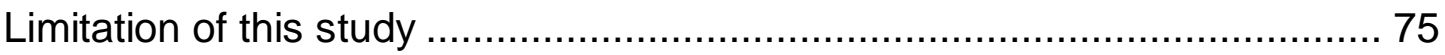

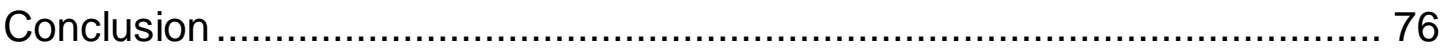

Significance and recommendations ................................................ 77

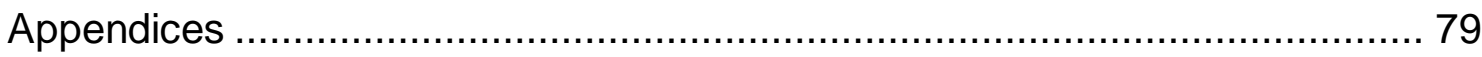

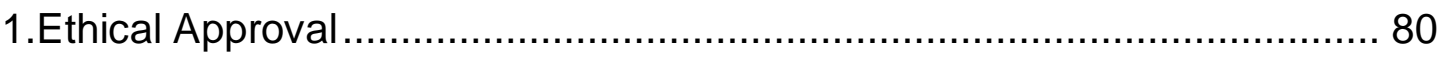

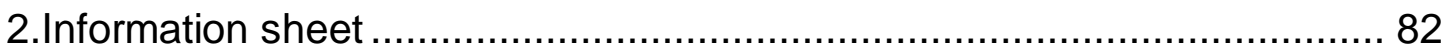

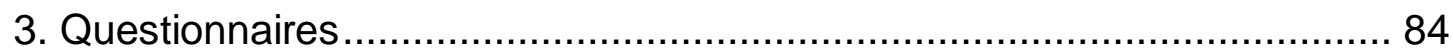

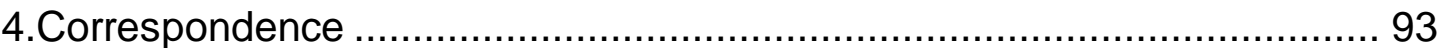

4.1 Cindy Lee Dennis .................................................................. 93

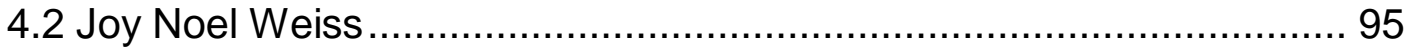

5.Summary BSES-sf included studies with Cronbachs Alpha Coefficient..... 97

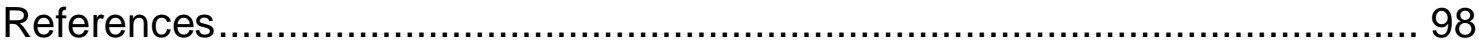




\section{Lists of tables and}

\section{figures}

Table 1: Distribution of live births by ethnicity and maternal age Hutt Valley and Capital and Coast District Health Boards and nationally. Dataset 2006-2010

Table 2: $\quad$ Timing and contents of questionnaires

Table 3: Participant age, ethnicity, marital status, education level and household income

Table 4: Breastfeeding rates at 6 and 12 weeks for under and over 20 year olds

Table 5: Breastfeeding self-efficacy scores before and after antenatal breastfeeding education for women of 15-19 and 20-25 years

Table 6: Baseline BSE scores taken before antenatal breastfeeding class for age, education, income and ethnicity

Table 7: Change in BSES and relationship to breastfeeding at 6 and 12 weeks

Table 8: Mean breastfeeding self-efficacy scores for women under and over 20 years for variables potentially influencing breastfeeding duration

Table 9: Examples of reasons for cessation of breastfeeding as cited in PN2 and 3 questionnaires

Figure 1: Participant Recruitment 


\section{Chapter 1}

\section{Introduction and}

\section{background}

Young mothers have low rates of breastfeeding both globally and in New Zealand (Sipsma, 2013; Feldman-Winter \& Shaikh, 2007; Dwyer, 2009). This is a matter for concern because of the important benefits which this group of women and babies are missing. Breastfeeding promotion is commonly undertaken in mainstream antenatal education classes where mothers, particularly adolescent mothers, are often absent. The link between antenatal education and breastfeeding among these women provides a useful opportunity to explore potential interventions. One such intervention might be targeted education to enhance breastfeeding self-efficacy.

Breastfeeding self-efficacy is defined as the confidence a woman has in her ability to breastfeed her baby (Dennis, 1999). It is based on Bandura's (1977) social learning theory, and self-efficacy enhancement is often a goal in interventions in other settings, designed to change people's health related actions and behaviours. Hence, it can have an important effect on potentially changing health behaviour such as breastfeeding. The aim of my research is to determine whether antenatal breastfeeding education can improve breastfeeding self-efficacy and in turn improve breastfeeding in young women. Using a repeated measure design, I have attempted to see if focused breastfeeding education for this particular group enhanced their breastfeeding self-efficacy. A secondary aim was to look at whether education also impacted on initiation and duration of breastfeeding by this group of young women.

My interest in this subject emerged from my own experience as a midwife in antenatal education. Educational programmes in which I am involved have youth-specific courses, and I have always enjoyed these. However, my 
awareness of the comparatively high youth pregnancy rates and low breastfeeding duration for this group in New Zealand, has led me to consider the effect of antenatal breastfeeding education on these young mothers and their feeding intentions and outcomes.

This study focuses on women under 25 years of age which includes adolescents, who are my particular interest and focus. Here there needs to be clarification around age definitions because young person and teenager and adolescent are commonly used interchangeably in the literature and indeed definitions of age vary depending on the organisations referring to young people. In Western society part of the human life span called adolescence, is described as the period of time between being a child and becoming an adult and lasts approximately ten years. The Oxford online dictionary of English language defines adolescence as the period of development "following the onset of puberty during which a young person develops from a child into an adult" ("Adolescence," n.d). Despite these definitions even government departments in New Zealand use variations and different age bands, for example the Office of Ethnic Affairs describes the youth population as 12-25 years, the Ministry of Youth Affairs also uses 12-24 years but Statistics New Zealand divides it into $15-19$ years and 20-24 years. The United Nations has definitions for early adolescence being 10-14 years and late adolescence 15-19 years. It defines youth as 15-24 years and young people as 10-24 years (UNFPA, 2005). Therefore the reader can see that defining the exact age of an adolescent can be challenging and this will be further considered in the discussion chapter.

In the course of considering the role of education, I became aware of the concept of breastfeeding self-efficacy. Pivotal work in Canada with adolescents, found breastfeeding self-efficacy scores were a reliable predictor of breastfeeding initiation and duration in adolescent mothers (Dennis, Heaman, \& Mossman, 2011). However, there are few other studies specifically focusing on how self-efficacy in antenatal education impacts on this group. This prompted me to replicate elements of Dennis et al (2011) and Noel-Weiss, Bassett, and Cragg (2006a) studies in my own setting to specifically answer the question: "Does antenatal education on breastfeeding increase young women's breastfeeding self-efficacy and improve breastfeeding rates?" 


\section{Adolescent breastfeeding practices}

\section{The International Scene}

The United Nations Children's Fund (UNICEF) reports adolescents are 50\% less likely to breastfeed than older mothers (UNICEF, 2007). This is supported by in-country data where adolescents continue to have the lowest rates of breastfeeding initiation, for instance in the United States (Feldman-Winter \& Shaikh, 2007). Similar trends have been noted in other countries, such as the United Kingdom, where breastfeeding initiation, and also continuation, are the lowest among young mothers, particularly if they have dropped out of school (Dykes, Moran, Burt, \& Edwards, 2003). Whilst provisional figures from the USA for 2007 indicate the rates have shown some improvement to $51 \%$ for adolescents compared to $71 \%$ for mothers aged $20-29$ years and $79 \%$ for mothers thirty years and older, the continuation rates in the United States keep on declining with rates being 19, 36 and 50\% respectively, for breastfeeding at six months (Centers for Disease Control and Prevention, 2008). FeldmanWinter \& Shaikh (2007) have cited data from the World Health Organisation Global Databank on breastfeeding showing this also, but point out that readers need to be aware that at the time the database was not comprehensive due to differing definitions, methods or indicators used by each country contributing to the database.

However one significant influence on this reporting and overall worldwide breastfeeding rates, has been the impact of the Baby Friendly Hospital Initiative. The Baby-Friendly Hospital Initiative (BFHI) was a global effort launched in 1991 by the World Health Organisation (WHO) and United Nations Children's Fund (UNICEF) to implement practices that protect, promote and support breastfeeding. It was launched in response to the Innocenti Declaration which was produced and adopted by participants at the WHO/UNICEF policymakers' meeting on "Breastfeeding in the 1990s" (A Global Initiative, co-sponsored by the United States Agency for International Development and the Swedish International Development Authority (SIDA), held at the Spedaledegli Innocenti, Florence, Italy, in 1990). Internationally hospitals can become accredited as 
being 'Baby Friendly' after meeting strict criteria to promote, support and protect breastfeeding.

In order to protect, promote and support breastfeeding, the Innocenti declaration called for governments to ensure that every facility providing maternity services fully practised all ten of the 'Ten Steps to Successful Breastfeeding' set out in the joint WHO/UNICEF statement, "Protecting, promoting and supporting breastfeeding: the special role of maternity services" (UNICEF, 2005).

\section{Breastfeeding within the New Zealand Context}

These same steps are therefore central in many New Zealand Ministry of Health documents and initiatives (Ministry of Health, 2006 (revised 2008), 2008; National Breastfeeding Advisory Committee of New Zealand, 2009). The New Zealand Breastfeeding Authority was contracted in 1999 by the then Health Funding Authority, to establish BFHI in New Zealand and this along with the New Zealand National Strategic Plan of Action for Breastfeeding 2008-2012, was developed to meet these steps and address the issue of poor breastfeeding rates and early weaning (Jackson, 2005; Ministry of Health, 2009; New Zealand Breastfeeding Authority, 2012; World Health Organisation and Unicef, 2005).

The establishment of the BFHI in New Zealand has resulted in $98 \%$ of New Zealand hospitals holding accreditation to this internationally recognized programme and this has impacted positively on breastfeeding rates in New Zealand since its initiation (Jackson, 2005; National Breastfeeding Advisory Committee of New Zealand, 2009; New Zealand Breastfeeding Authority, 2012). This is substantiated by the exclusive breastfeeding rates on discharge from BFHI accredited maternity services of $84.4 \%$. Further to these impressive figures of breastfeeding on discharge from maternity facilities, (which don't include homebirth breastfeeding rates), the majority of babies in New Zealand were either exclusively or fully breastfed $(79.7 \%)$ at two weeks of age (Ministry of Health, 2010) with $65 \%$ exclusively or fully breastfeeding at 6 weeks and $55 \%$ at 3 months but dropping to $26 \%$ at 6 months (Central Cancer Network, 2010; Royal New Zealand Plunket Society, 2010). 
However, whilst overall rates in New Zealand compare favourably to international rates, there is still concern in this country over continuation and rates of early weaning of infants. This is in contrast with the World Health Organisations' recommendation of exclusive breastfeeding until six months of age (World Health Organisation and Unicef, 2003).

Another area of concern is the reduction in the rates of exclusive breastfeeding by young women until their babies are six months of age. The rates of breastfeeding by young mothers (under 25 years) in New Zealand are difficult to find. Whilst the 20 local District Health Boards (DHBs) report on adolescent birth rates, the breastfeeding rates and age of baby, are more commonly broken down by ethnicity and age of the baby rather than by age of the mother. Despite the lack of specific data on breastfeeding for this age group of women, what we do know is that in New Zealand, birth rates for young women (15-24 years) have gradually increased, reaching a peak of 32.4 per 1,000 in 2008 and that 2006 figures placed New Zealand second highest for youth births (at 28.4 per 1000) compared to other OECD countries (Craig et al., 2011; Johnson \& Denny, 2007; New Zealand Parliamentarians' Group on Population and Development, 2007; UNICEF, 2007).

With regard to the birth rates in the areas this study has taken place, rates in Capital and Coast DHB were lower than the New Zealand rate throughout 2000-2010, while rates in Hutt Valley DHB were more similar. Birth rates of young women were higher for Māori and Pacifika women compared to European and Asian/Indian women in both district health boards. This is in keeping with national figures where Māori women tend to give birth at a younger age than the other ethnicities shown, with approximately $35 \%$ of all Māori women giving birth aged 22 years or younger (Ministry of Health, 2010). Craig et al. (2011) reports on the state of health of children in the two district health boards in this study and shows the distribution of live births by ethnicity and maternal age. (Table 1) 
Table 1: Distribution of live births by ethnicity and maternal age Hutt Valley and Capital and Coast District Health Boards and nationally. Source Craig et al, 2011 pg. 47. Dataset 2006-2010.

\begin{tabular}{|l|l|l|l|l|l|l|}
\hline & $\begin{array}{l}\text { Number } \\
\text { of births }\end{array}$ & $\begin{array}{l}\text { \% of } \\
\text { births }\end{array}$ & $\begin{array}{l}\text { Number } \\
\text { of births }\end{array}$ & $\begin{array}{l}\text { \% of } \\
\text { births }\end{array}$ & $\begin{array}{l}\text { Number } \\
\text { of births }\end{array}$ & $\begin{array}{l}\text { \% of } \\
\text { births }\end{array}$ \\
\hline Ethnicity & $\begin{array}{l}\text { Hutt } \\
\text { Valley }\end{array}$ & $\begin{array}{l}\text { Capital } \\
\text { and } \\
\text { Coast }\end{array}$ & & $\begin{array}{l}\text { New } \\
\text { Zealand }\end{array}$ & \\
\hline Asian/India & 214 & 10.0 & 508 & 12.7 & 7,451 & 11.5 \\
\hline European & 1,021 & 47.5 & 2,139 & 53.5 & 30,016 & 46.4 \\
\hline Māori & 611 & 28.4 & 804 & 20.1 & 18,893 & 29.2 \\
\hline Other & 36 & 1.7 & 117 & 2.9 & 1045 & 1.6 \\
\hline TOTAL & 2,149 & 100.0 & 3,995 & 100.0 & 64,666 & 100.0 \\
\hline $\begin{array}{l}\text { Maternal } \\
\text { Age }\end{array}$ & & & & & & \\
\hline$<20$ yrs & 158 & 7.3 & 180 & 4.5 & 4,533 & 7.0 \\
\hline $\mathbf{2 0 - 2 4}$ & 408 & 19 & 469 & 11.7 & 11,994 & 18.5 \\
\hline $\mathbf{2 5 - 2 9}$ & 514 & 23.9 & 755 & 18.9 & 16,087 & 24.9 \\
\hline $\mathbf{3 0 - 3 4}$ & 624 & 29.0 & 1,334 & 33.4 & 17,898 & 27.7 \\
\hline $\mathbf{3 5 +}$ yrs & 447 & 20.8 & 1,260 & 31.5 & 14,187 & 21.9 \\
\hline TOTAL & 2,151 & 100.0 & 3,998 & 100.0 & 64,699 & 100.0 \\
\hline
\end{tabular}

These figures therefore give us a number of potential young breastfeeding mothers if not an actual rate of breastfeeding. Given our high rates of birth in this young age group, and the known benefits of breastfeeding, in the context of this research, it is important to ask whether antenatal education on breastfeeding actually effects breastfeeding behaviour for this group of women.

\section{Antenatal education and breastfeeding}

Effective antenatal education has been identified as an important influence on feeding decisions and intentions for all age groups (Dwyer, 2009; Lumbiganon et al., 2012; Ministry of Health, 2009; Renfrew et al., 2005). However some of the identified barriers to accessing these classes are the cost associated with them, location, accessibility and cultural appropriateness to women and families 
accessing them. Therefore, the goals set out in New Zealand's national plan around antenatal education, include Collaboration between the Ministry of Health and District Health Boards "to assess and plan for improving access to antenatal education" (Ministry of Health, 2009, p. 9). In this country antenatal education is provided by various community groups, sometimes privately run and some courses are provided by District Health Boards. Short and long term objectives include improving free access to targeted antenatal education about breastfeeding with a focus on programmes specifically for young, Māori and Pacific women and their whānau [traditional extended family]. The aim of targeting these groups, which include the adolescent mother, through education, is because they represent sectors of the community shown to be least likely to breastfeed despite the fact that their infants may gain most advantage from being breastfed.

The strategic plan also called for a change in our breastfeeding culture. This is supported by the Innocenti Declaration which states that "Efforts should be made to increase women's confidence in their ability to breastfeed. Such empowerment involves the removal of constraints and influences that manipulate perceptions and behaviour towards breastfeeding, often by subtle and indirect means" (UNICEF, 2005). This potential to increase women's selfconfidence to breastfeed through antenatal education is very clear here.

\section{Adolescent mothers and breastfeeding education}

In New Zealand, anecdotally the uptake of antenatal education by adolescents is deemed to be low compared to older women. There is little evidence to support this supposition, most likely because adolescents are poor attendees so there have been fewer opportunities to study the effectiveness of antenatal education on breastfeeding for this group (Dwyer, 2009). Other reasons for low attendance cited are poor access, and lack of programmes designed specifically to meet their needs (Dwyer, 2009; Martis, 2005; New Zealand Breastfeeding Authority, 2012). Martis (2005) and Fraser (2008) in their research, explored the needs of New Zealand teens in terms of their antenatal education and support needs as young mothers. Martis (2005) found pregnant adolescents wanted to participate in and guide antenatal education programme 
development. As well as traditional antenatal educational informational needs, the emotional needs and education around relationship issues, conflict resolution and self-esteem building, were identified as equally important to the group of teenagers in her study. This increased emotional support need was echoed by Fraser (2008), who found key relationships with family, peers and like-minded mothers was also central to supporting teenage mothers.

These studies provide background to understanding the needs of this group and their stage of development, made more complex by pregnancy. In summary they suggest that young women in this age group are often grappling with the transition from childhood to adulthood. They are generally egocentric and their conversation may vary from verbalising concrete thoughts to communicating actual or make believe situations. Acceptance by peers is important as is body image, and these things impact on their self-esteem. What educators need to remember is becoming pregnant doesn't necessarily speed up these developmental tasks of adolescence as they still need to move through them. Also this group has specific needs compared to adult mothers. These are around feeling safe and not being judged and that their emotional development is just as significant. This is as important as optimal care, and courses tailored to young parents should optimize breastfeeding promotion by recognising the unique developmental tasks of adolescence.

This aspect of development is discussed further in the literature, particularly in relation to recommendations for promotion of breastfeeding with adolescents and how it needs to be taken into account. Descriptive studies highlight many ways trialled to address this issue, for example dedicated breastfeeding support groups for young women which incorporate education and ongoing support, support by group or phone, by peers, health professional or lay persons (Greenwood \& Littlejohn, 2002; Lavender, Thompson, \& Wood, 2005b; Pobocik et al., 2000). The situation of poor uptake is a concern because teenage parents and their children are known to be at risk of medical, psychological, developmental and social problems (Fraser, 2008; Johnson \& Denny, 2007; McLeod, Pullon, \& Cookson, 2002; Silvers et al., 2012; UNICEF, 2007a; Volpe, 2002). 
Breastfeeding by young mothers is seen as one way to reduce some of these risks for the mother and her infant. I became curious about reasons for the poor breastfeeding rates in this group, their attitudes to breastfeeding and their confidence to breastfeed. One would assume that more breastfeeding education and knowledge a young woman had antenatally, would impact on these rates. But how does it do this? I was interested in getting some evidence to support the idea that a mother with higher self-confidence would initiate and continue to breastfeed her baby, and whether antenatal education on breastfeeding impacts on this confidence level.

The aim of this research therefore was to ascertain whether antenatal breastfeeding education within a structured antenatal education course improved breastfeeding self-efficacy and whether this in turn impacts positively on breastfeeding rates for young women. The objectives were;

1. To examine the relationship between breastfeeding self-efficacy and antenatal education.

2. To examine the relationship between self-efficacy and breastfeeding duration.

3. To examine self-efficacy in relation to other influences on the young mothers' breastfeeding experience.

4. To determine whether there is a difference in self-efficacy and outcomes between $15-19$ year olds and 20-25 year olds.

\section{Theoretical approach}

The theoretical approach to this study arises from the work by Dennis who describes maternal breastfeeding self-efficacy as the confidence a woman has in her ability to breastfeed her baby (Dennis, 1999). Dennis has contributed much to the literature on this theory with regard to breastfeeding (Blyth, 2002; Creedy et al., 2003; Dennis, 1999, 2002a, 2003; Dennis et al., 2011). This literature found breastfeeding confidence antenatally and postnatally is positively associated with, and predictive of, breastfeeding duration. Dennis developed and validated a Breastfeeding Self-Efficacy Scale - Short form (BSES-sf). As this tool has been used extensively and has been 
psychometrically tested, particularly with adolescents (Dennis et al., 2011), it seemed to be worth using this as a measure to see if the findings could be replicated in a New Zealand adolescent population and was therefore used, with permission, in this research (appendix 4). A repeated measure design was used to examine breastfeeding self-efficacy and the impact of antenatal breastfeeding education on this. Forty women were recruited from antenatal classes specifically for youth, in two urban locations. Using the Breastfeeding Self-efficacy Scale (short form) BSES-sf, developed by Dennis (2003), selfefficacy before and after a breastfeeding education session was measured. In addition women were followed up three times postnatally to record BSES-sf scores at 1-2 weeks and breastfeeding status until 3 months post-partum. Further detail of Dennis's work, the methodology and method which frames and enables this research are described in Chapter three.

\section{Research setting}

The setting for this research were youth friendly venues where antenatal courses targeted towards young women less than 25 years old are held. Background of the company BirthEd which provided the education sessions, and recruitment of young mothers attending their classes, will be described in more detail in the research design chapter. The ability to access this group easily through my work as a midwife educator for BirthEd, permitted me, as the researcher, to look for evidence to support the view that breastfeeding selfefficacy is one of the most significant variables influencing breastfeeding initiation and duration. It allowed me to meet the aims and objectives of the research by attempting to answer the question on whether antenatal education on breastfeeding did increase breastfeeding self-efficacy and improve breastfeeding rates in this group.

\section{Summary}

The concept of breastfeeding self-efficacy in young mothers is of great interest due to this group and their infants being vulnerable in terms of breastfeeding initiation and continuation. This is verified by both international and New Zealand literature indicating this is a hard to reach group with low breastfeeding 
rates. By using an existing validated tool previously used on this age group, measurement of self-efficacy was used to determine whether antenatal education on breastfeeding did enhance breastfeeding self-efficacy and whether this in turn improved outcomes. This will add to the body of knowledge and valuably inform mothers, healthcare professionals, government and other agencies involved in promoting, protecting and supporting breastfeeding. The next chapter of this thesis is a review of the literature which provides a frame and context and identifies the gaps which prompted this research. Chapter three describes the research. The findings in the chapter following the research design, are presented using graphical and narrative description. The final chapter discusses these findings and identifies the relationship between the hypothesis, and findings associated with other variables influencing breastfeeding. Finally the implications for practice and future recommendations are given. 


\section{Chapter 2}

\section{Review of the}

\section{research}

Whether antenatal breastfeeding education for young women can make a significant impact on breastfeeding success is central to this research. A review of relevant research was undertaken with these aims: to identify current knowledge, identify gaps in knowledge and assist in refining the question and research approach.

The research review had three focus areas. Firstly I looked at research on the effectiveness of antenatal education on breastfeeding rates in general (including intervention and descriptive studies). I then focused on New Zealand research studies (all of which were descriptive). This included an examination of whether any research had looked specifically at New Zealand's Māori and Pacific women, as these populations have both lower breastfeeding rates and higher pregnancy rates for young women. I then looked at any research that examined the relationship between young women's breastfeeding and antenatal education.

What was commonly expressed was that for young people, the attitudes towards breastfeeding played an important role in whether breastfeeding was successful or not. Self-efficacy was identified as a key concept in relation to attitudes and success, and there was a significant body of literature on this topic. This shaped the final stage of the research review, which focused on research studies that examine self-efficacy in relation to both antenatal breastfeeding education and young women. This was pivotal in both refining the research question and in designing the study. 


\section{Search approach}

The literature was examined to firstly assess the effect of antenatal breastfeeding education on breastfeeding rates in general. This involved searching the Cochrane Collaboration, Joanna Briggs Institute (JBI) and the electronic databases PubMed, CINAHL and Psych Info, based on the following keywords, their synonyms and truncations: antenatal $(\mathrm{MeSH})$ prenatal, education or class*, and breastfeeding. Limitations of papers being in the English language and published after 2000 were added to the search. A combined one hundred and four papers were obtained from PubMed and CINAHL searches, along with their bibliographies. After reading the abstracts, papers pertaining to the postnatal period only and those providing background information were excluded (although some are used in the discussion). In total, forty eight studies were reviewed: seven systematic reviews, fourteen randomised controlled trials, two literature reviews and twenty five descriptive studies. The results reinforce this study by providing evidence that antenatal education on breastfeeding is in fact an influencing factor particularly in the initiation of breastfeeding, but that it also influences duration.

Cochrane Collaboration and $\mathrm{JBI}$ revealed two pieces of work respectively, relating to antenatal breastfeeding education. The Cochrane Collaboration had one review on interventions for promoting the initiation of breastfeeding (Dyson, McCormick, \& Renfrew, 2005), and one pertaining to antenatal breastfeeding education (Lumbiganon et al., 2012). JBI had one systematic review comparing structured versus non-structured breastfeeding programmes in acute and primary healthcare settings (Beake, Pellowe, Dykes, Schmied, \& Bick, 2012). The other relevant review protocol from JBI was on the effectiveness of breastfeeding education on maternal breastfeeding self-efficacy and breastfeeding (Yi \& Man, 2011).

I found eleven New Zealand research studies; all were descriptive. As there were so few the date limitation was removed and older studies were included (Basire, Pullon, \& McLeod, 1997; Essex, Smale, \& Geddis, 1995; Ford et al., 1994) to provide context to the research. Two longitudinal studies included breastfeeding success as an outcome for Pacific women (Butler et al, 2004; Schluter et al, 2006); this was of interest because of their known lower 
breastfeeding rates. Māori women also have lower rates of breastfeeding and Glover, Manaena-Biddle, and Waldon (2007) describe barriers to breastfeeding outcomes for Māori. None of the papers specifically researched adolescent or young women in New Zealand, highlighting a gap in the literature.

To be able to meet my research objectives despite this gap, I looked at papers from the international literature that examined the relationship between teen breastfeeding and antenatal education. Articles from indexed journals relevant to the aim of assessing the effect of antenatal breastfeeding education on adolescents, in English and published after 2000, were located and reviewed. This involved searching the electronic databases PubMed, CINAHL and Psych info, using the keywords: breastfeeding or breastfeeding, antenatal (MeSH), antenatal, prenatal, pre-natal, education or class ${ }^{*}$, adolescents or teenagers. Relevant studies by title from retrieved papers' reference lists/bibliographies were examined, again with the limitation of papers published after 2000. A total of forty studies were located. Articles were eliminated from the research review itself if they focused more on the postnatal period than on antenatal breastfeeding education. The remaining studies were of varied methodological approach, including randomised controlled trials, intervention and descriptive studies.

During my investigation of antenatal breastfeeding education, self-efficacy was identified as a key attribute. Therefore a further search was undertaken examining breastfeeding self-efficacy in general and in adolescents. The search included research by the authors who publish most on this subject and in specific journals such as the Journal of Human Lactation. I searched PubMed, CINAHL, and PsychInfo (as it included studies in adolescent-specific journals such as Journal of Adolescent Health). In all, forty six papers were sourced, including two randomised controlled trials. Some of the papers sourced are purely commentary, providing important background regarding the developmental stage of adolescence and context to adolescents growing up in New Zealand. A tool called the Breastfeeding Self Efficacy Scale (short form) BSES-sf, used to measure this breastfeeding self-efficacy has been found to be a reliable predictor of this in at least nine studies (Appendix 5) and became a focus in my research design. 


\section{The effectiveness of antenatal breastfeeding education}

This section examines the literature on the effectiveness of antenatal breastfeeding education in New Zealand. As suggested before, there was very little literature regarding any antenatal education in the New Zealand setting, let alone breastfeeding education or that of breastfeeding education for adolescents. However, reviewing the literature that was available provides context for this research. The international literature was examined in regard to the measures of effectiveness. Complexities identified such as intention, routine care, postnatal impact, age and timing, format and delivery of antenatal breastfeeding interventions, and support will be discussed.

\section{New Zealand breastfeeding research}

Eleven New Zealand (NZ) studies identified were all descriptive, with a focus on factors influencing continuation of breastfeeding. There was no NZ research specifically examining the effectiveness of antenatal breastfeeding education, although four studies alluded to this in their discussions and recommendations. (Vogel et al, 1999; McLeod, 2002; Basire, 1997; Essex, 1995). Firstly, Vogel, Hutchison, and Mitchell's (1999) qualitative study, looking at influences on breastfeeding duration, suggested the need for acceptance of breastfeeding as a societal norm through provision of improved maternity leave, community facilities to support breastfeeding and greater emphasis on breastfeeding education in antenatal education. Secondly, (McLeod et al., 2002) conducted a prospective study with $74 \%$ of the six hundred and sixty five respondents indicating an intention to breastfeed. However $31 \%$ of the women felt unprepared just prior to birthing and the suggestion made was that more information would have improved rates. Thirdly Basire et al. (1997) looked at attitudes to breastfeeding through six focus groups of five to eight women from different socio-economic backgrounds. In relation to antenatal preparation "All of the women said they were given a lot of information on the benefits of breastfeeding at antenatal education classes and in accompanying written material, but little practical advice" (Basire et al., 1997, p. 4), and that there was a focus on the labour and birth and not on the postnatal period. Finally, Essex 
et al (1995) in a longitudinal study looked at prevalence and reasons for discontinuing breastfeeding. Although nearly $94 \%$ of the three thousand six hundred women followed were exclusively breastfeeding, this dropped dramatically to $2.5 \%$ at six months. The authors recommend this decline could be halted with breastfeeding education on managing problems encountered but didn't specify whether this should be antenatally or postnatally (Essex et al., 1995).

Other studies are worth summarising as they make a unique contribution to understanding cultural impact. Manhire, Hagan, and Floyd (2007) and McBrideHenry (2010) describe aspects of the breastfeeding culture in New Zealand. Their qualitative studies through questionnaire and interviews respectively, both found others' expectations, or the perception of these, influence the breastfeeding experience. When breastfeeding, New Zealand woman are open to the responses of those around them from all sectors of society and this sometimes undermines their confidence when faced with breastfeeding difficulties (McBride-Henry, 2010). On the other hand, Manhire et al (2007), found negative influences may be overcome with traits such as persistence and confidence. This is relevant to findings from another section of this literature search with regard to breastfeeding attitudes and will be considered in the discussion. Other aspects of culture relating to New Zealand are related to our unique ethnic make-up and are worth describing in detail.

Data collected suggests Māori and Pacific Island women have lower breastfeeding rates than non-Māori or non-Pacific women (Ministry of Health, 2010). This problem has been explored by two authors focusing on influences on Māori women's' breastfeeding (Ellison-Loschmann, 1997; Glover et al., 2007) and less specifically on the antenatal education needs of Māori in a particular region in New Zealand (Fox, 1997). Two studies had a focus on Pacific Island infants and exclusive breastfeeding rates (Butler, Williams, Tukuitonga, \& Paterson, 2004; Schluter, Carter, \& Percival, 2006). These studies will now be summarised.

Glover and colleagues researched influences that affect Māori women and breastfeeding (2007). A diverse range of thirty mothers and eleven whānau (family) members, identifying themselves as Māori and representative of urban 
and rural women, were interviewed. Only three babies were artificially fed which is thought to be most likely selection bias because women who had breastfed would more likely respond to the recruitment methods used than mothers who had bottle-fed, therefore women who didn't want to breastfeed or had weaned early were under-represented in her study. Of note was the fact that most hadn't accessed antenatal education.

In conclusion the authors comment that that foreign infant care practices have displaced pre-European Māori infant feeding practices to such a degree that Māori women now have the lowest rate of exclusive or full breastfeeding in NZ. She suggests "promotion of breastfeeding to Māori should focus on reestablishing breastfeeding as a tikanga (right cultural practice) rather than a perceived lifestyle choice." (Glover et al, 2007, p. 12). It is proposed that their research provides a new model for understanding how Māori women are diverted from breastfeeding and highlights opportunities for intervention. It is unknown if this model would translate to adolescent Māori, as the age of the participants was not provided but gives insight into the format and delivery of interventions to meet this group known to be at higher risk of not breastfeeding.

Ellison-Loschmann (1997) also examined the influences on Māori women in their decisions to breastfeed. Statistically Māori women have their babies at an earlier age (Ministry of Health, 2010) and their first infant feeding experience at this relatively early age is potentially significant in the decision they will make about feeding subsequent babies. Ellison-Loschmann found family support and role models are an issue as, due to urbanisation, many Māori women may have not witnessed breastfeeding as a normal experience in their own families. Information from family sources is valued over and above what the women receive from anywhere else and this has implications for formal antenatal breastfeeding education.

Fox(1997), using a 'Māori methodology', explored the antenatal educational needs of Māori women and examined a sample of women and midwives in one region of New Zealand. Her research, like Glover et al (2007), is underpinned by the belief that one culture is undermined in relation to a more dominant understanding and explored the colonisation of Māori and the demise of their birthing practices as a reason for non-engagement of Māori in antenatal 
education following a pakeha framework. While not specifically looking at breastfeeding, the participants in her study were asked to sort different statements to discover what Māori women's needs were with regard to antenatal education (Fox, 1997). Similar to Ellison-Loschmann's (1997) findings, $50 \%$ of participants stated they should get breastfeeding information solely from whānau (family). This again has implications for antenatal educators in their planning and gives acclaim to initiatives such as the La Leche League peer counselling programme and Mum4Mum programmes where breastfeeding mothers support other mothers (Fox, 1997; La Leche League, 2008).

Another group in NZ with low breastfeeding rates who would also benefit from more culturally appropriate antenatal education are Pacifika mothers. The longitudinal Pacific Island Family Study of 1398 infants confirmed current national data that Pacific Island breastfeeding rates fall below national targets, and looked at factors associated with not breastfeeding exclusively. Interestingly it was found that newer migrants to New Zealand (NZ) had higher breastfeeding rates than Pacifika women who had resided in NZ for ten years or more. This supports the thought that new immigrants may be more traditional in terms of infant feeding practices and this has a bearing on breastfeeding attitude and rates (Butler et al., 2004). Another factor associated with not breastfeeding exclusively was expectant mothers not seeing the midwife during pregnancy, which the authors felt represented a lost opportunity for discussion on infant feeding and in particular breastfeeding (Schluter et al., 2006). Drawing from Butler et al study, Schluter and colleagues, (2006) report on data from the Pacific Island Families study and find that inadequate education of mothers about the management of breastfeeding problems and the perceived lack of support from employers or educational facilities, are some of the principal reasons for mothers discontinuing exclusive breast-feeding. They cite the concern about insufficient breast milk supply as being common, and suggest addressing these misunderstandings during antenatal classes or visits to health-care professionals could substantially improve exclusive breast-feeding rates amongst the Pacific people (Schluter, 2006).

In summary, there is a culture of breastfeeding in New Zealand where high numbers of women intend to breastfeed and initiate breastfeeding. However New Zealand European women are more likely to be still breastfeeding after 
two weeks compared to Māori and Pacifika mothers. Antenatal care and antenatal education are thought to be important opportunities to give consistent and realistic information about breastfeeding but cultural differences need to be considered as important influences on breastfeeding outcomes. There were no studies specifically addressing adolescents or young women and breastfeeding in New Zealand, thereby identifying a gap in our literature and the need to turn now to the international literature for background to my research.

\section{International Literature}

When I examined the international literature, two reviews from the Cochrane Collaboration were relevant to my research. Although not addressing young women particularly, they are specifically about breastfeeding education and use one or more of the measures to determine effectiveness of antenatal breastfeeding education. These measures are; the rates of initiation, duration and exclusivity of breastfeeding. The first review, specific to education and duration of breastfeeding, found peer counselling, lactation consultation and formal breastfeeding education during pregnancy appeared to increase breastfeeding duration, with peer counselling better than 'routine care' for initiating breastfeeding. What constitutes 'routine care' will be discussed further as a complexity. Despite the large number of women in the studies reviewed and these findings, the authors conclude they are unable to recommend any specific antenatal breastfeeding education because of the variety of interventions and methodologies of the studies (Lumbiganon et al., 2012).

For rates of initiation only however, the second Cochrane Collaboration review found a statistically significant increase (risk ratio (RR) 1.57, 95\% confidence interval $(\mathrm{Cl}) 1.15$ to $2.15, \mathrm{P}=0.005)$ in the number of low income women starting to breastfeed as a result of health education interventions versus routine care in five combined studies with 582 women (Dyson et al., 2005). This finding is substantiated by two of the larger evidence reviews for the United States (US) Preventive Services Task Force (Chung, Raman, Trikalinos, Lau, \& Ip, 2008; Guise et al., 2003). Fairbank et al, (2000) systematic review found informal group health education in the antenatal period increased initiation rates with women in different income groups, but both initiation and duration rates 
were increased for low income women with peer support in the antenatal and postnatal periods, particularly if the women express a wish to breastfeed.

Including the measure of exclusivity, structured antenatal breastfeeding education positively influences this, and also initiation and duration of any breastfeeding (particularly in settings with low breastfeeding rates) in a systematic review on structured versus non-structured breastfeeding programmes in acute and primary settings (Beake et al., 2012).

Further supporting the finding that breastfeeding education improves initiation, descriptive studies and individual randomised controlled trials generally find breastfeeding is initiated more often in women who attend antenatal classes (Artieta-Pinedo et al., 2013; Forster \& McLachlan, 2007; James, 2004; Kronborg, Maimburg, \& Vaeth, 2012; Lu et al., 2003). Andaya, Bonuck, Barnett, and Lischewski-Goel's (2012) study indicates significant improvement in confidence and knowledge, and women breastfeeding longer after antenatal training. Su et al., (2007) found that women receiving antenatal education alone are more likely to be breastfeeding at six weeks, three months and six months than those receiving 'routine care', although postnatal support was demonstrated to be marginally more effective than antenatal education. Conversely, Lavender et al (2005) measured expectations and realities of breastfeeding, and found a different outcome. In this study women were allocated to either routine antenatal education or an additional single educational group session supervised by a lactation specialist. Whilst there was breastfeeding in both groups the authors concluded that the intervention failed to promote the uptake of breastfeeding compared to routine antenatal education (Lavender et al., 2005a). Promotion of exclusive breastfeeding with low income mainly Hispanic women in the United States also showed a non-significant increase between intervention and control group but almost all intended to breastfeed at the outset (Sandy, Anisfeld, \& Ramirez, 2009).

Therefore it can be concluded that whilst some studies support the premise that antenatal breastfeeding education is effective in improving initiation, duration and exclusivity of breastfeeding, the evidence isn't yet strong enough to be irrefutable. One of the confounding issues is how we measure effectiveness. 
Are initiation or duration or exclusivity rates the best measure?. I have identified other difficulties in establishing the effectiveness and will now introduce these in the following section, but address them in more detail in my discussion. As well as measurement of rates, the intention to breastfeed notably impacts on the effectiveness of interventions to promote breastfeeding, as does the age of the woman. Furthermore, the issue of what constitutes routine or standard care in the literature isn't always clearly defined and alongside this, the timing, format and delivery of antenatal breastfeeding education can have a bearing on the effectiveness of this intervention. Lastly the type of postnatal education and postnatal support is identified as a complexity because it also can influence the duration of breastfeeding.

\section{Intention and initiation}

Definitions of some breastfeeding terms frequently used in the literature are included in this introduction about the complexities of the effectiveness of antenatal breastfeeding education identified in this review. Intention is selfexplanatory; that a woman intends, in the antenatal period or at birth, to breastfeed her child. This raises the question of whether women in my study had a high level of intention to breastfeed in the first instance because they were motivated enough to seek and voluntarily access antenatal education. This is in comparison to those groups where intention is low but where women are exposed to opportunistic or tailored antenatal breastfeeding education interventions. Intention is one of the questions asked in my survey for demographic and background information, and part of the eligibility criteria; the impact of which will be addressed in the discussion.

There is some variation in the literature regarding the definition of initiation, with the United States Preventative Services Taskforce studies defining it as any breastfeeding at discharge or up to 2 weeks after delivery. Using the definition of initiation from the EXCEL (Early Experiences and Counselling for Effective Lactation) programme from Guam, (USA), initiation refers to "baby ever to the breast" (Pobocik et al., 2000) and has been used in this research because I wanted to capture women who had attempted any breastfeeding. The complexity in using this definition is that there is evidence that antenatal 
interventions have less effect where there is already high intention and initiation (Forster et al., 2004; Guise et al., 2003; Mattar et al., 2007). Therefore it was of interest to see whether the education intervention had an influence on these factors in this population of adolescents, but also whether there was a correlation between intention and initiation as other studies of adolescents have found (Greenwood \& Littlejohn, 2002; Lavender et al., 2005a; Wambach \& Cole, 2000).

\section{Age}

Age is another complexity when measuring the effectiveness of antenatal breastfeeding education, as described in the introduction. This research has focused on young women. The literature acknowledges that adolescents are a hard to reach group in terms of 'breastfeeding promotion' and that they are less likely to attend antenatal education compared to older mothers (Alexander, O'Riordan, \& Furman, 2010; Dwyer, 2009; Greenwood \& Littlejohn, 2002; Uzun, Orhon, Baskan, \& Ulukol, 2013; Wambach et al., 2011)

However antenatal breastfeeding education specifically for adolescents in the United States and United Kingdom has shown that as well as significant differences between the intervention and control group in terms of breastfeeding initiation, adolescents gain network support from other breastfeeding adolescents which can positively influence whether they meet their breastfeeding goals (Lavender et al., 2005b; Volpe, 2002).

Another group of authors undertook a longitudinal study with thirty five young Australian women (aged 15-24 years) completing questionnaires after participating in an antenatal class specifically for young women (Greenwood \& Littlejohn, 2002). This study is relevant to my research firstly because of the age of the group studied, and it also includes breastfeeding duration, with the setting closely resembling some antenatal education settings in New Zealand. Despite being a small study, $(n=42)$, it usefully contributes to the opinion that antenatal education has a positive effect on breastfeeding outcomes for young women. Many studies reviewed do allude to postnatal, or peer support postnatally, suggesting education and support is best delivered across the continuum, much 
like the findings from studies on older mothers (Hannula, Kaunonen, \& Tarkka, 2008). This makes it difficult to compare with other studies which have antenatal support only as there is evidence to suggest that ongoing postnatal support can positively influence continuation of breastfeeding particularly for adolescents if it is delivered in a non-judgemental, caring, individualized, accessible way (Dykes, Moran, Burt, \& Edwards, 2003a; Hall \& Hauck, 2007; Lavender et al., 2005a; Nicoletti, 2006; Spear, 2006; Volpe \& Bear, 2000).

Another study recognised this positive effect, for example a breastfeeding and support programme set up on the Pacific Island of Guam - EXCEL (early experiences and counselling for effective lactation) (Pobocik et al., 2000). Because of the setting this study may not be generalisable to other populations, however it has relevance for a New Zealand population as was aimed at adolescents, had a reasonable sample $(n=407)$ and demonstrated a culturally sensitive intervention based on social learning theory. As previously identified, there are no studies specifically looking at young women or adolescents in New Zealand, identifying a gap in the literature, with most studies arising in other developed countries.

\section{Type of antenatal education}

Another complexity is around the descriptions of 'routine care' in the literature on antenatal breastfeeding education. Routine care ranges from: the prenatal care provider being electronically prompted to discuss breastfeeding and individual sessions with a lactation consultant (Andaya et al., 2012), to breastfeeding promotion information within an antenatal programme (Beake et al., 2012). An aspect of findings from three studies is the reference to, and comparison of, results from studies with routine care (Lavender et al., 2005a; Lumbiganon et al., 2012; Su et al., 2007). However as described above, there is huge variance in what constitutes routine care which makes it difficult to define and to compare studies. One interesting finding was the issue of routine care when hospitals or communities participate in the Baby Friendly Hospital Initiative and Baby Friendly Community Initiative. It could be argued that routine care for the control groups in any study should be of a higher standard compared to those where the World Health Organisation (WHO) code isn't 
enforced. This impacts on the validity of studies using routine care (Dyson et al., 2005).

Forster and McLachlan (2007) found that breastfeeding outcomes were significantly improved when women delivered in Baby Friendly accredited hospitals or hospitals where a number of the ten steps had been implemented, as did the Bartington, Griffiths, Tate, and Dezateux (2006) study undertaken in the United Kingdom. This improvement was however only for initiation as there was no difference at one month for women who delivered in units with neither accreditation nor certification. Grguric et al (2012) looked at the awareness of breastfeeding recommendations and found women who knew of the WHO recommendations, were $26 \%$ more likely to initiate and $34 \%$ less likely to have stopped breastfeeding (Grguric, Wen, Kylberg, Ashmore, \& Macenroe, 2012).

The hospitals providing contracts for antenatal education providers in my study are both Baby Friendly accredited, meaning the content of breastfeeding education is assessed to ensure there is adherence to the WHO code and New Zealand Breastfeeding Authority standards. This breastfeeding education intervention in this study is known as standard or routine care for women attending antenatal education at BirthEd. Therefore another complexity associated with measuring the effectiveness, was targeted programmes for breastfeeding education as opposed to the standard or routine antenatal education. A randomised controlled trial of knowledge sharing practice with empowerment strategies (KSPES) in Thailand showed rates of exclusive breastfeeding in the study group were significantly higher when compared with those in the control groups through to six months (Kupratakul, Taneepanichskul, Voramongkol, \& Phupong, 2010). The empowerment strategies used in Kupratakul et al's (2010) study may be similar to strategies to enhance selfefficacy which have been shown to improve breastfeeding outcomes (Blyth et al., 2004). Noel-Weiss conducted a randomised controlled trial of a prenatal breastfeeding workshop to specifically enhance confidence and measured the success of breastfeeding by participants in the intervention group compared to control at four and eight weeks. Attendees of the workshop had more exclusive breastfeeding (58 vs $70 \%$ ) and less weaning (22 vs $15 \%$ ) compared with the control group (Noel-Weiss et al., 2006a). Whilst this evidence reveals a positive relationship between attendance at antenatal education and either 
breastfeeding initiation and/or duration, it could be argued the outcome will be more positive when the programme is targeted.

\section{Timing, format and delivery of antenatal breastfeeding education}

The variables of timing, format and delivery of antenatal breastfeeding education also appear to impact on its effectiveness. Firstly timing may impact on women who are undecided about their plan to breastfeed as there is a strong correlation between knowledge of recommended infant feeding, intention and initiation. Low intention may be remedied by the timing of antenatal education with some researchers suggesting breastfeeding promotion and emphasis of health benefits should be started early in pregnancy (Jiang et al., 2012; van Rossem et al., 2009). With regard to adolescents, Wambach (2004) suggests they also need education on decision making early on. This study found two main themes when looking at how adolescents make their decision to breastfeed. Adolescents were found to commonly be ambivalent and uncertain which may reflect their developmental stage, though social and family influences impacted on their decision making (Wambach \& Koehn, 2004).

Like timing, format and delivery of education are also seen as influential in the success of breastfeeding promotion. Whether the education sessions are individual or in a group format does not appear to predict success in the systematic review by Beake et al. (2012) who, found structured programmes compared with standard care positively influenced the initiation and duration of exclusive breastfeeding and any breastfeeding, particularly in settings with low breastfeeding rates.

The length of the course, whether it is to an individual or in a group, is an important variable in the success, with longer courses being more successful (Dyson et al., 2005; New Zealand Breastfeeding Authority, 2012; Renfrew et al., 2005). A prospective cohort study of six hundred and fourteen first time mothers in Northern Spain found that the risk of cessation of breastfeeding in the first month was twice as high amongst those attending one to four antenatal classes compared to those attending five or more (Artieta-Pinedo et al., 2013). 
Contrary to this were findings from $\mathrm{Li}$, Fein, Chen, and Grummer-Strawn (2008) and Mattar et al. (2007) who described 'one' encounter of antenatal education and counselling in two Asian countries, and found one off interventions effective in increasing knowledge, attitudes and breastfeeding practice.

The future of antenatal breastfeeding education may of course sit with electronic based (e-based) interventions. Pate (2009) in her research found a breastfeeding promotion programme delivered via the internet increased breastfeeding self-efficacy and may be an alternative to time-consuming and expensive provider based breastfeeding education and support. Likewise, Huang et al. (2007) found a web based programme could increase knowledge and attitude and improve breastfeeding rates. This requires further examination and poses the question with regard to the importance of the role of antenatal education and support as opposed to it just being for knowledge sharing.

The timing of interventions is an aspect relevant to the effectiveness of breastfeeding success with adolescents just as it is with adult mothers. Targeting non pregnant adolescents with breastfeeding education before pregnancies were initiated was one of the recommendations by the authors (Mossman, Heaman, Dennis, \& Morris, 2008). Studies from four developed countries have been found describing non-pregnant adolescent female and adolescent male, attitudes and knowledge of breastfeeding, as well as their intentions (Giles, Connor, McClenahan, \& Mallet, 2010; Goulet, Lampron, Marcil, \& Ross, 2003; Greene, Stewart-Knox, \& Wright, 2003; Juliff, Downie, \& Rapley, 2007; Marrone, Vogeltanz-Holm, \& Holm, 2008; Martens, 2001). These studies were reviewed to get a sense of how adolescents viewed breastfeeding when not having to make the decision to breastfeed at that time, and may help us understand why adolescents choose either breast- or bottle-feeding when they become mothers during their adolescent years.

The important findings from the studies support the idea that breastfeeding is a socially learned behaviour and social decision, and that if adolescents are not exposed to breastfeeding role models, attitudes towards breastfeeding can be more negative and impact on feeding decisions (Giles et al., 2007; Greene et al., 2003). Other influences on feeding decisions included whether adolescents knew that they had been breastfed themselves. If so, they often held more 
positive attitudes towards breastfeeding (Giles et al., 2010; Greene et al., 2003) and the influence of others such as the mother's mother, peer and partner were a significant influence over infant feeding decisions too (Feldman-Winter \& Shaikh, 2007; Fraser, 2008; Greene et al., 2003; Juliff et al., 2007; Nelson, 2009; Nelson \& Sethi, 2005; Park, Meier, \& Song, 2003; Volpe \& Bear, 2000; Wambach \& Cole, 2000).

Juliff et al. (2007) suggest the fathers of the baby should be involved in education and decision making. This is supported by Alexander et al. (2010) who compared teens and non-teens, breastfeeding intentions and attitudes. While they didn't find that attitude improved with age, the influence of the father was significant. What did improve with age however were attitudes towards the advantages of breastfeeding (Goulet et al., 2003; Marrone et al., 2008).Furthermore, Marrone (2008) found increased knowledge about breastfeeding influenced these positive attitudes, which in turn influenced intention to breastfeed. Attitudes towards breastfeeding in public may impact on the attitude that breastfeeding in front of others could cause embarrassment and appears to be a significant influence in breastfeeding success (Dykes et al., 2003a; Dyson, Green, Renfrew, McMillan, \& Woolridge, 2010; Giles et al., 2010; Greene et al., 2003; Wambach \& Cole, 2000; Wambach \& Cohen, 2009). These findings above are linked to the intention to breastfeed and reveal that the social and family influences are a significant part of the decision to breastfeed.

\section{Postnatal Support}

Whilst my review focuses on the antenatal period from early pregnancy through to birth, many papers reviewed address the postnatal period and this becomes another confounding variable for my research. There is some evidence that the effectiveness of antenatal breastfeeding education is enhanced by postnatal support. In one study Hannula et al. (2008) found interventions using various methods of education and support are more effective than support using one method only; and expanding from pregnancy to the intrapartum period and throughout the postnatal period was more effective than shorter interventions. This is a common theme with substantial evidence. Interventions across the continuum were more successful than those in the postnatal period only 
(Andaya et al., 2012; Chung et al., 2008; de Oliveira, Camacho, \& Tedstone, 2001; Kronborg et al., 2012). These findings are supported by the National Institute for Health and Clinical Excellence (NICE) guidelines (Renfrew et al., 2005) and the National Breastfeeding Advisory Committee of New Zealand (2007). My research has measured duration of breastfeeding by surveying women on three occasions postnatally and questioning the types of support they have received following the birth of their babies. While the focus has been on antenatal education, the impact of postnatal support cannot be ignored as demonstrated in the literature and forms part of the discussion of my research findings.

Another significant factor in the postnatal period is support from lay-persons or peers. When this lay support is associated with antenatal breastfeeding education, it is more effective than usual care (Chung et al., 2008; Kaunonen, Hannula, \& Tarkka, 2012), significantly improves initiation rates and impacts on duration (Chapman, Damio, Young, \& Perez-Escamilla, 2004) and can be as effective as traditional breastfeeding education (Rempel \& Rempel, 2011). Interestingly, (Jolly et al., 2012a) find peer support in the antenatal and postnatal period does not seem to be effective in the United Kingdom setting, supporting a previous study by some of the same authors, which found that although peer support may increase breastfeeding continuation in low or middle income countries, (especially exclusive breastfeeding), in high income countries (or countries where breastfeeding support is part of routine postnatal healthcare), it has less effect (Jolly et al 2012a). Because of this I asked the question in my survey about who gave the participants support and will discuss this lay support compared to health professional support and the New Zealand maternity setting further in the discussion.

\section{Modifiable factors}

A key aspect in the literature was the notion that some factors influencing breastfeeding are modifiable and some are not. This became a significant point for my research in that while factors such as maternal age (Callen \& Pinelli, 2004) education level (van Rossem et al., 2009) and socioeconomic status (Lu et al., 2003) influence breastfeeding, these are non-modifiable and, whilst well 
researched, can be difficult to address. There is some thought that it is the modifiable factors that we should be targeting in breastfeeding education (Leger-Leblanc 2008) and modifying simultaneously (Meedya, Fahy, \& Kable, 2010). Such modifiable factors include knowledge, attitudes and intention. With regard to knowledge and attitudes, commitment has been found to be a factor of breastfeeding success. Nesbitt et al. (2012) found that adolescent mothers who commit to breastfeeding have a longer duration of breastfeeding compared to mothers who decided to only try. Avery, Zimmermann, Underwood, and Magnus (2009) find a commitment to breastfeeding is needed to overcome a lack of knowledge. However Feldman-Winter found the reverse, in that it is education that helps make the commitment to breastfeeding. (Feldman-Winter \& Shaikh, 2007).

A second attitude is the confidence 'to try' which has been also linked to breastfeeding success (Dennis, 2003; Dennis et al., 2011). Thirdly is the attitude of self-efficacy and the suggestion that breastfeeding competence in adolescents is closely linked to this confidence in the ability to breastfeed (Dennis, 2003; Mossman et al., 2008; Nicoletti, 2006). Furthermore there is evidence that these modifiable variables, if addressed, may have a positive influence on the duration of breastfeeding (Dennis, 1999; Meedya et al., 2010; Stuebe \& Bonuck, 2011). With this in mind, and looking at previous research on breastfeeding self-efficacy, this shaped the design of my study in order to test my hypothesis.

\section{Breastfeeding Self-efficacy}

Dennis theorised breastfeeding self-efficacy in 1999, basing it on Bandura's self-efficacy concept from social cognitive theory (Bandura, 1977). Breastfeeding self-efficacy is defined as "the confidence a woman has in her ability to breastfeed her baby" (Noel-Weiss et al., 2006a, p. 617). Bandura offers an explanation of human behaviour, using the concepts of self-efficacy, outcome expectations and incentives. "Self-efficacy expectations are focused on people's belief on their own capacity to carry out particular behaviours"(Polit \& Beck, 2008, p. 149) 
Four factors that influence people's cognitive appraisal of self-efficacy were identified by Bandura. Dennis relates these four factors to breastfeeding. These include;

1. Their own performance accomplishments, for example, mothers who have previous breastfeeding experience or successful initial attempts will have higher breastfeeding self-efficacy than mothers who have not.

2. Verbal persuasion, for example mothers who receive positive evaluations and encouragement by a credible significant other (professionals, family, and peers) will have higher breastfeeding self-efficacy than mothers who do not

3. Vicarious experience - for example, mothers who have observed successful breastfeeding will have higher breastfeeding self-efficacy than mothers who have not and

4. Physiologic and affective cues (such as anxiety and pain) can affect a mother's breastfeeding self-efficacy (Dennis, 1999)

The literature reviewed suggests that breastfeeding self-efficacy is a significant modifiable variable influencing breastfeeding, and that this confidence antenatally and postnatally is positively associated with, and predictive of, breastfeeding duration in both adult and adolescent mothers (Blyth, 2002; Dennis, 2002b, 2003; Dennis \& Faux, 1999; Dennis et al., 2011; Lavender et al., 2005a; Noel-Weiss, Rupp, Cragg, Bassett, \& Woodend, 2006b; Pollard \& Guill, 2011). A tool was developed and used to measure this in many of these studies and will be presented in the next section.

\section{The Breastfeeding Self Efficacy Scale}

Given the correlation with self-efficacy and positive breastfeeding outcomes Dennis and Faux (1999) developed an instrument based on self-efficacy theory to measure maternal breastfeeding confidence. It is called the Breastfeeding Self-Efficacy Scale (BSES). Following reliability testing, this tool was adapted and a 14 item Short Form (BSES-sf) was developed (Dennis, 2003). Testing indicated it was an excellent measure of breastfeeding self-efficacy, could help to identify mothers at high risk of discontinuing breastfeeding, and it could guide 
antenatal programme development to enhance breastfeeding self-efficacy. This tool has been adapted and used in many countries, in many languages and has included adolescents (Alus Tokat, Okumus, \& Dennis, 2010; Blyth et al., 2004; Dai \& Dennis, 2003; Dennis, 2003; Dennis et al., 2011; Gregory, Penrose, Morrison, Dennis, \& MacArthur, 2008; McCarter-Spaulding \& Gore, 2009; Molina Torres, Davila Torres, Parrilla Rodriguez, \& Dennis, 2003; Nichols, Schutte, Brown, Dennis, \& Price, 2009; Noel-Weiss et al., 2006b; Oliver-Roig et al., 2012; Oria, Ximenes, de Almeida, Glick, \& Dennis, 2009; Zubaran et al., 2010)

Because breastfeeding self-efficacy is a modifiable variable, the breastfeeding self-efficacy scale short form (BSES-sf) can guide health professionals to provide individualised interventions, such as confidence building strategies, aimed at these breastfeeding mothers (Creedy et al., 2003; Dennis, 2003; Kingston, Dennis, \& Sword, 2007)

With regard to self-efficacy and adolescent mothers, Mossman et al (2008) applied the BSES-sf and a Breastfeeding attitude questionnaire (BAQ) to a convenience sample of 100 pregnant adolescent women contemplating breastfeeding. The results showed that significantly more mothers with higher prenatal attitude scores initiated breastfeeding, and that those with a higher attitude score and self-confidence score were more likely to continue breastfeeding until four weeks postpartum. The results support the self-efficacy theory and confirmed the findings of studies using BSES-sf with adult mothers in many countries (Alus Tokat et al., 2010; Awano, 2010; Blyth et al., 2004; Dai \& Dennis, 2003; Dennis, 2003; Eksioglu \& Ceber, 2011; McQueen, Dennis, Stremler, \& Norman, 2011; Nichols et al., 2009; Noel-Weiss et al., 2006b; Pollard \& Guill, 2011).

More recently, a pivotal study by Dennis et al (2011) was the first to psychometrically test the BSES-sf among adolescents. They also found using the scale resulted in findings aligning to those found with adult mothers, making the scale a reliable tool. An aim of this study was to test the generalisability of this finding by repeating the study in other adolescent populations has been a prompt for my research. Of much interest is the identification of self-efficacy as 
a modifiable factor and the curiosity to see if this is in fact generalisable and does improves breastfeeding rates.

The discovery of this modifiable factor from the literature had exciting implications for my research and was influential in shaping the design. By using an existing validated tool to repeat elements of the research on adolescents in New Zealand, I was able to try and discover whether antenatal breastfeeding education increased adolescent breastfeeding self-efficacy and improved breastfeeding rates in this group vulnerable to not breastfeeding their infants.

\section{Informing the research design}

The literature on the effectiveness of antenatal breastfeeding education for adolescents is drawn from the international scene because there was no New Zealand research addressing this specifically. The identification of the concept of breastfeeding self-efficacy as a modifiable factor influencing breastfeeding hugely shaped the design of this research. The use of the BFSE-sf scale was an integral part of meeting the aims of the research and of demonstrating the effect of the intervention on breastfeeding self-efficacy. Other important factors which are thought to impact on breastfeeding success also needed to be examined. These included timing, format and delivery of this education and socio-demographic factors such as support, were also collected to give context to the study. Detail of the research design is provided more fully in the following chapter. 


\section{Chapter 3}

\section{Research Design}

The literature suggests that breastfeeding self-efficacy is an important modifiable variable which can be enhanced through antenatal education and that high self-efficacy is predictive of initiation and longer duration of breastfeeding (Alus Tokat et al., 2010; Baghurst et al., 2007; Creedy et al., 2003; Dennis, 2003; Dennis et al., 2011; Kingston et al., 2007; McQueen et al., 2011; Wilhelm, Rodehorst, Stepans, Hertzog, \& Berens, 2008). My research seeks to discover whether this is also true for New Zealand women under 25 years old. Self-efficacy in young mothers is of great interest due to the vulnerability of these mothers and their babies in terms of breastfeeding initiation and continuation. This chapter outlines the research approach used to test this theory. It also describes the theoretical approach and the methods used.

\section{Research approach}

This research is based on the theoretical approach of Dennis (1999). According to this theory, breastfeeding self-efficacy relates to a mother's confidence in her ability to breastfeed her infant. Dennis proposes that breastfeeding self-efficacy predicts whether a mother chooses to breastfeed or not, how much effort she will expend, whether she will have self-enhancing or self-defeating thought patterns about breastfeeding, and how she will emotionally respond to breastfeeding difficulties. The breastfeeding self-efficacy scale - short form (BSES-sf) developed by Dennis has been used extensively to measure this. Of particular relevance is the study by Dennis et al. (2011) of Canadian adolescents, which established a link between breastfeeding self-efficacy and duration. My research aims to replicate, with some local modifications, parts of 
her research. It seeks to evaluate the impact of antenatal education on breastfeeding self-efficacy in a group of New Zealand young women.

The research takes a quantitative approach, using a formal, objective, systematic process to gather data which is utilized to test the hypothesis. This methodology was chosen because the research interest itself leads to a quantitative intervention study; it is founded in a hypothesis that can only be tested via measurement. Consequently quantitative research is more easily generalised to a larger population. In order to measure this, Dennis's Breastfeeding self-efficacy scale - short form (BFSE-sf scale), a validated tool, has been used.

\section{Aims and objectives of study}

The aim of this research was to ascertain whether antenatal education, within a structured antenatal education course for young women, improves breastfeeding self-efficacy and whether this, in turn, impacts positively on breastfeeding. The research hypothesis is that antenatal breastfeeding education undertaken in a New Zealand setting will increase young women's breastfeeding self-efficacy and will improve breastfeeding rates in this age group. This was examined by:

1. Applying breastfeeding self-efficacy testing at three time points: before and after breastfeeding education in an antenatal class, and postnatally.

2. Testing the validity of the Breastfeeding Self Efficacy Scale - sf (BSESsf) on young New Zealand mothers.

3. Analysing the data to clearly establish the relationship between breastfeeding self-efficacy, antenatal education and breastfeeding outcome

4. Determining whether there is a difference in self-efficacy and outcomes between 15-19 year olds and 20-25 year olds

5. Examining the impact of other variables on breastfeeding success such as support, whether the participants were breastfed themselves, timing of the first breastfeed. 


\section{Design specifics}

\section{Setting}

This research was undertaken in the context of antenatal education carried out by BirthEd. The company BirthEd is contracted by the local health authority to provide antenatal and parenting education to women in two of their health districts. This educational programme was of particular relevance to this study because, on average, $33 \%$ of women accessing classes are under 25 years old and the company provides targeted classes specifically for this age group and their significant support. (BirthEd, 2012; Dwyer, 2009). Permission from BirthEd management and the stakeholders to approach their clients under 25 years old was obtained. The settings for my research were three "youth friendly" venues where the youth antenatal education classes are conducted by BirthEd employees. Two were Youth Health Services, where youth can access health, social, work transition and peer mentor services. The third venue was a teen parenting school which provides 'second-chance' education for students who are unable to complete their formal education at local colleges.

\section{Participant selection}

Participants in the study were young women who were enrolled in youth antenatal education classes undertaken by BirthEd between August 2011 and April 2012. During this time there were six classes scheduled with up to 10 women in each which meant a possible sample of 60 young women.

In order to be eligible for the study women needed to be under thirty week's gestation at the beginning of the study and had to be considering breastfeeding. Women who had made a decision to bottle-feed and/or to adopt their baby out were excluded at the beginning of the study, mainly because they would be unlikely to attend the breastfeeding class. If the mother's baby was born at under thirty seven weeks gestation, admitted to the Special Care Baby Unit or Neonatal Unit or born with congenital abnormalities, no further data was collected. Their antenatal data would have been included however, to meet one 
of the objectives around measuring self-efficacy prior to and following the intervention.

\section{Preparation of educators, participant recruitment and administration of questionnaires}

In order to inform and prepare the educators about this piece of research, a two hour training workshop for BirthEd educators and a Lactation Consultant was run in May 2011. Apart from presenting the study, the participants of the workshop, BirthEd educators, were also asked for input into the questionnaire design. The workshop was also undertaken to ensure consistency of the antenatal education. All educators were to follow the teaching guidelines of the BirthEd teaching manual. I facilitated this training workshop.

All participants recruited to the study were under 25 years of age at the start of the nine week course (six antenatal and three postnatal sessions). I approached the classes as a group in either week two or three of the course, which was well prior to the breastfeeding education session (usually at week six or seven). The study was outlined to the women, including the eligibility and exclusion criteria, and an information sheet was given. There was an opportunity for possible participants to ask questions at this point. Eligible women in those classes, willing to participate were then enrolled in the study. There were forty one participants in all. The data for the two age groups of 15-19 and 20-25 was separated later. The first questionnaire was administered at week two or three and the second immediately after the breastfeeding class at week six or seven. The first postnatal questionnaire was administered at around one to two weeks after the birth by a phone call. The second and third postnatal questionnaires were planned for six weeks and three months consecutively, also by phone.

\section{The education session}

The education session on breastfeeding was held on either session six or seven of the course. This session included information on the advantages of breastfeeding to mother and baby, whānau and society. Also basic anatomy and physiology of milk production, the importance of skin to skin contact at birth, 
teaching about baby's feeding cues, correct positioning of baby at the breast to get a correct latch and basic trouble shooting, were all included. Various approaches were used to communicate the information. These included interactive games using 24 hour clocks to highlight possible time spent breastfeeding, scenario based problem solving activities, visual aids to outline and prompt discussion on advantages of breastfeeding and use of dolls and breast models. A DVD "Follow me Mum" by Rebecca Glover was shown and participants were free to take pamphlets on correct positioning and a pack from La Leche League with their hand-outs and meeting times. Other places to get postnatal support were discussed. This session is considered routine for BirthEd classes and is aligned with the World Health Organisation 10 Steps and Baby Friendly Hospital Initiative requirements

\section{Questionnaire design}

A questionnaire was chosen as the best method to address the objectives of this research. This was for reasons of practicality as a large amount of information could be collected over a short time period. The information could then be coded and quantified in order to measure change and test the hypothesis.

The basis of the questionnaires were the Breastfeeding Self-Efficacy Scale (short form) (BSES-sf) tool. This was developed by Dennis (2002) and consists of 14 questions using a Likert scale which related to confidence in breastfeeding (Appendix 3). These questions are presented positively in order to facilitate response. An example of a question is 'I think I can always breastfeed my baby without using formula'. When the scale was administered postnatally the questions were changed from 'I think I can...' to 'I can...'The ratings were summed into a total score ranging from 14 to a maximum of 70 with a higher score demonstrating a higher level of maternal breastfeeding self-efficacy (Dennis, 2003; Polit \& Beck, 2008). Permission was sought and granted from the author Dennis to use the tool (Appendix 4.1). No changes were made to the tool. There were five episodes of data gathering via questionnaire and there was some variation in what data was collected when (Table 2). 
Table 2: Timing and contents of questionnaires

\begin{tabular}{|l|l|}
\hline \multicolumn{1}{|c|}{ Questionnaire timing } & \multicolumn{1}{c|}{ Questionnaire contents } \\
\hline $\begin{array}{l}\text { Before the antenatal } \\
\text { class (AN1) }\end{array}$ & $\begin{array}{l}\text { BSES-sf, demographics, education, income, } \\
\text { smoking, decision-making, breastfeeding } \\
\text { exposure, partner supportive of breastfeeding, } \\
\text { Mother breastfed or not, }\end{array}$ \\
\hline $\begin{array}{l}\text { Immediately after the } \\
\text { class (AN2) }\end{array}$ & BSES-sf only \\
\hline $\begin{array}{l}\text { 1-2 weeks postnatal } \\
\text { (PN1) }\end{array}$ & $\begin{array}{l}\text { BSES-sf, breastfeeding status, birth outcome, first } \\
\text { breast feed, carer, support }\end{array}$ \\
\hline $\begin{array}{l}6 \text { weeks post birth } \\
\text { (PN3) }\end{array}$ & $\begin{array}{l}\text { breastfeeding status, duration of breastfeeding or } \\
\text { reasons for cessation }\end{array}$ \\
\hline $\begin{array}{l}\text { 3 months after the birth } \\
\text { (PN4) }\end{array}$ & $\begin{array}{l}\text { breastfeeding status, duration of breastfeeding or } \\
\text { reasons for cessation }\end{array}$ \\
\hline
\end{tabular}

Alongside the tool, four of the five questionnaires also asked for further detail, both demographic and social. These questions were based on the findings of the review of the literature, in particular addressing the concept of modifiable and non-modifiable variables. The antenatal questionnaire (AN1) included demographic variables such as age, marital status, ethnicity, education, income, smoking, intention to breast feed, and exposure to breastfeeding.

These did not need to be repeated in the second antenatal questionnaire (AN2) which was administered directly after the education session. A voucher was given following completion of this questionnaire, for a 'Babes in Arms' movie session at a central local movie theatre. This was to compensate for any inconvenience caused and to encourage ongoing participation in the study. It also supported ongoing breastfeeding as the "Babes in Arms' sessions are breastfeeding friendly. At this time, permission to follow up postnatally was gained verbally. As described above, first names, estimated due date, best contacts and times were obtained.

In the first postnatal questionnaire ( PN1), administered within 2 weeks of the birth, questions included type of feeding, caregiver, gestation, birth outcome, first breast feed, and support both professional and social. The second and third 
postnatal questionnaires (PN2 and PN3) included only questions on infant feeding and reasons for not breastfeeding if appropriate (Appendix 3).

These questionnaires were pre-tested on five adolescents, and viewed by BirthEd educators, including a Māori educator, and a youth worker, for appropriateness. Based on feedback, modifications were made to some questions for ease of reading and to not cause offence to participants. Other adaptations were also made to address breastfeeding issues salient to young mothers in New Zealand and phrased in language appropriate to them. Examples of adaptation include changing the definitions of breastfeeding to the New Zealand Ministry of Health's definitions, maternity carers to fit with the New Zealand maternity system definition and income brackets reflective of New Zealand household incomes.

\section{Data Analysis}

Responses were recorded by participants directly on the questionnaires at the time of administration in the case of AN1 and AN2 questionnaires. PN1, PN2 and PN3 questionnaires were undertaken over the telephone and were entered directly onto blank survey forms. This data was coded, entered into an Excel spreadsheet, and transferred to Statistical Packages for the Social Sciences (SPPS) for Windows Version 20.

Data analysis was not commenced until the data set was complete which was three months following the last course. The data file was then modified to create new variables such as the total of the Breastfeeding Self-efficacy scale scores (BSES), and the difference in scores between the three time points. This was a key finding of interest in order to meet the objectives of the study to see whether there was a change in this score pre and post-test. Secondly, the reliability of the BSES-sf was estimated using a Cronbach's Alpha coefficient.

Other variables were created by collapsing continuous variables such as age into two groups of less than 20 years and between 20 and 25 years. Categorical data were regrouped. For example, ethnicity into three groups: New Zealand European, Māori and Pacifika and other, income into two groups and level of education into four. This was due to the small numbers in some categories. 
Next univariate analysis was performed to inspect frequency distributions and content of each variable. This allowed recoding of missing values and the examination of outliers. These variables were investigated to determine if there was an impact of these variables on the breastfeeding self-efficacy scores and duration of breastfeeding. Values of $p<0.05$ were considered statistically significant. Statistical input from the statistician at Victoria University of Wellington was obtained.

To look at whether there were any significance differences between self-efficacy scores in the three time periods, I performed a paired samples t-test. I created a new variable to determine the difference in scores, in particular for AN2-AN1 as there had been a significant change in this score following the intervention. In order to ascertain whether this significance had an impact on breastfeeding duration, I undertook an independent samples t- test looking at breastfeeding success. The success was determined by collapsing the variable into two categories: those exclusively or fully breastfeeding and secondly those partially or not breastfeeding. This was defined by the definitions from the New Zealand Ministry of Health (Appendix 3). Collapsing was performed to categorise the degree of breastfeeding.

Given that there are many variables that impact on breastfeeding success, as outlined in the literature, these data were also collected. These data were age, level of education and income, whether the woman's mother had breastfed, and support. Chi squared tests were performed to ascertain association with breastfeeding success. Had there been statistical significance between any of these variables and BSES or breastfeeding success, it may have been possible to conduct a multiple regression in order to ascertain the impact of each of these variables. In actuality there was either no significance found and/or the sample sizes were too small to undertake these tests so a multiple regression was not possible. The validity of the BSES was tested at three time points by estimating the Cronbach's alpha coefficient. At the postnatal time point, (PN1) there was an original intention to look at the impact of antenatal education on self-efficacy after the birth however too many confounding variables were identified at this stage to make any assumptions valid. It became clear that a much larger sample size would be required to undertake further statistical 
testing. However it was still possible to undertake a Cronbach's alpha coefficient in the postnatal period.

\section{Reliability and validity}

The reliability of the BSES-sf had been previously evaluated using the following criteria: (a) Cronbach's alpha coefficient; (b) corrected item-total correlation; and (c) alpha estimate when an item was dropped from the scale. Poorly functioning items were defined as: (a) items that when deleted increased the alpha coefficient by more than 0.10 or (b) items that had a corrected item-total correlation less than 0.30 (Dennis, 2003). This criteria was used in previous BSES psychometric investigations and ensured comparability of results. Factor analysis was completed and a one-way analysis of variance was used to examine differences between two groups for categorical data; t-tests and correlations were conducted for data at the interval level of measurement (Creedy et al., 2003; Dennis, 2003; Dennis et al., 2011).

Because the BSES - sf had been psychometrically tested on adolescents previously, the tool was able to measure what I was setting out to measure with Breastfeeding Self-efficacy, by producing a score out of a possible total of between 14 and 70. (Dennis et al., 2011)

The results should be generalizable to similar samples, for instance adolescents attending antenatal classes. However there may be limitations if the BSES -sf was applied to pregnant adolescent women in another setting, in that women attending classes may be found to be more motivated and have higher selfefficacy in the first instance. This will form part of the discussion of the results from this study.

\section{Ethical considerations}

\section{Informed consent}

To ensure potential participants were well informed when they joined the study, care was taken about how the study was presented. The information sheet in 
particular invited the women to ask questions (Appendix 2). The contact numbers were highlighted should they have questions or concerns regarding the study. No consent form was signed as consent was assumed by participation in the first questionnaire (AN1). At the bottom of each questionnaire there was a prompt to ask participants if they were happy to be further contacted and their verbal consent was recorded.

Participants were informed that they were free to withdraw from the research at any time. The issue of consent for those under 16 (if any) was addressed by involving a family member in consent to participate if appropriate. Dennis (2011) in the psychometric testing of the breastfeeding self-efficacy scale in adolescents, assumed that participants attending antenatal care on their own, could consent to pregnancy care and treatment and therefore participation in the study. In the event, no participants under 16 were recruited.

\section{Confidentiality}

Individuals were assigned a number to identify which class they were recruited from. I also needed to identify them by first name to allow a more personal approach for the third part of the questionnaire where individuals would be contacted by phone. Given these women would have just had a baby and the time-consuming nature of caring for a baby, negotiation of convenient times to call took place at the time of completing the second antenatal questionnaire and were recorded. For this to happen there needed to be partial identification in first name so whilst anonymity wasn't achieved, confidentiality was assured. Completed questionnaires recorded only first names and a number pertaining to the class and participant for example EV1 01. (Evolve Class one, participant one). The estimated due date of their baby was also recorded to ensure telephone questionnaires were administered in a timely manner. This linked to a master sheet recording dates of administration of the questionnaires. Once entered into the database their names were removed. Both the questionnaires and master sheet were kept in a locked filing cabinet to which no one else had access. 


\section{Treaty of Waitangi and Māori Participants}

In 2011, 15.4\% of all BirthEd clients identified as Māori (BirthEd Dec 2011, personal communication). Therefore the possibility of Māori adolescents enrolling in BirthEd courses in the study period was reasonably high. The principles of the Treaty of Waitangi: Participation, Partnership and Protection were acknowledged and upheld. The following statements from the Health Research Council set this out for this context.

"All health research conducted in Aotearoa New Zealand is of relevance to Māori" (Health Research Council, 2010, p. 2) and therefore Māori women should have the same opportunity as non-Māori women to participate in studies. This was addressed as this study was set up to ensure Māori women were able to fully participate. Interviewers who were culturally aware and sympathetic were appointed; although for the telephone surveying ethnicity was not apparent to the interviewer at the time of administration over the phone as this was not written on the blank questionnaire and had only been determined in AN1. At the meeting with educators, feedback from a recent Māori Breastfeeding Hui was given and support of Māori breastfeeding was informally discussed. One of the BirthEd educators who identifies as Māori, was present at this meeting. The questionnaire was also shown to the Māori breastfeeding coordinators at both District Health Boards and permission was sought to have their names and phone numbers on the information sheet should Māori participants require additional information or support from them with regard to the study. It was agreed with the co-ordinators that the findings from this research may be of interest to the Māori population, health professionals and researchers. Therefore copies of findings will be available and will be forwarded to the Māori Health Development groups at Hutt Valley and Capital and Coast District Health Boards.

\section{Protection from harm}

There was potential for psychological harm to participants in the study if women indicated that they had no intention to breastfeed and felt criticised for their decision. There is anecdotal evidence to suggest this criticism may make a 
woman feel guilty or inferior in some way. While recognising the risk was not much different than for standard class participants, care was taken to give participants a chance to ask for support or to complain about the study. The information sheet made it clear participation was voluntary and could end any time which reduced the impact of exclusion. The relative risk of causing psychological harm was considered balancing the very small risk of this (especially given sensitive handling) with the benefits of breastfeeding education.

To gain ethical approval the study had to ensure the maintenance of confidentiality and privacy and a process of informed consent, cultural safety and minimisation of harm as outlined above. Ethical approval was provided by the Central Regional Ethics Committee of the Health Research Council (Appendix 1).

\section{Challenges during the study}

Overall there were only a few challenges during the study and I was able to make small changes to overcome these; in most cases without affecting the rigour of the work. For example, one woman who attended the breastfeeding session didn't hand in her second questionnaire. I was able to trace her and post out a questionnaire with a stamped envelope addressed to the BirthEd mailbox but she did not return it resulting in the need to withdraw her from the study. From that time on I was more careful about following up and recording returned questionnaires.

I learnt with the telephone surveying, that often the women wouldn't answer their cell phones if they did not recognise the number or if it came up as a private number. I would then text them first to warn them of my call or ask for a good time to call them. Fourteen women needed more than two attempts to reach them. Consequently some of the questionnaires were administered when their babies were older than one to two weeks old, or they had birthed before their estimated date of delivery. In these cases I tried to call them for the PN 2 and 3 surveys as proposed, when their babies were six weeks and twelve weeks old, meaning the intervals between calls were sometimes more or less 
than anticipated. This still gives an indication of breastfeeding status around these postpartum points of six and twelve weeks.

One participant had a stillbirth. She had completed both AN1 and AN2 questionnaires. Fortunately any harm was averted, as because of the connection with BirthEd, I had heard about this prior to calling the woman concerned. On behalf of the company I was able to send condolences and hoped this served to let the woman know that she was withdrawn from the study. This was not addressed in my considerations of ethics but a plan was then put in place for educators/administrators of BirthEd to inform me of any other adverse outcomes that came to their attention. Lead maternity carers were not formally made aware of their clients' participating in the research but in hindsight this may have been a mechanism to prevent this ethical dilemma. The recommendation for future studies of this nature would be to ensure there is a mechanism in place to notify the researcher of such an event.

The question of literacy was not addressed with regard to the self-administered questionnaires and BSES-sf. When open ended questions are used there is the potential to have questions unanswered. Most questions were multi-choice, Likert scale or short answer, but still relied on the fact that the woman was literate. The advantage of using a researcher to ask questions as in the postnatal questionnaires, is that they can elicit the information with careful questioning without prompting.

\section{Summary}

This study examined the impact of antenatal education on the breastfeeding self-efficacy of young women by using a validated tool before and after an antenatal breastfeeding session and again in the first two weeks after the birth. In acknowledging the complexity of impacts on successful breastfeeding, a range of relevant demographic, birth outcome, professional support and social support data was collected. The study looked at breastfeeding outcomes soon after the birth and at six weeks and three months. The next chapter presents these findings. 


\section{Chapter 4}

\section{Results}

This chapter summarises the results from a study of antenatal breastfeeding education and self-efficacy in young women. It addresses the hypothesis that "antenatal education on breastfeeding increases young women's breastfeeding self-efficacy and improves breastfeeding rates"

These findings answer the following questions:

1. Did the antenatal class improve breastfeeding self-efficacy (BSE) in young women and adolescents?

2. When BSE is measured prior to or after an antenatal class, or in the postnatal period, is it related to success of breastfeeding at six or twelve weeks postpartum?

Furthermore, the results served to meet the secondary objectives of this study which were to determine whether there is a difference between breastfeeding self-efficacy and outcomes between 15-19 year olds and 20-25 year olds and to examine the changes in self-efficacy in relation to variables influencing the young mothers' breastfeeding experience, such as breastfeeding support, hospital and birthing experience.

The results in this chapter are divided into four sections. Firstly the demographic characteristics of the participants are presented, giving details of their age, ethnicity, marital status, educational achievements and household income. The second section outlines the reliability testing of the BSE tool. Next the impact of the intervention on Breastfeeding Self-efficacy scores is described and then the relationship of these scores on breastfeeding duration is presented. Finally the relationship between the demographic characteristics and both breastfeeding self-efficacy scores and breastfeeding rates are given. 


\section{The Study Population}

There were eight BirthEd classes (six originally scheduled and two added) in the time frame for this study. Sixty two women made enquiries and were enrolled in the classes with a total of forty six attending the first antenatal education session. Forty one women (89\%) entered the study with one participant being withdrawn after the second time point as she suffered an intrauterine death of her baby at thirty nine weeks gestation. Demographic data was therefore included for forty women. From these forty women, five were lost to the study in the antenatal period. One participated in the first antenatal questionnaire (AN1) and then didn't meet criteria for eligibility as she had no intention to breastfeed. Two completed the AN1 questionnaire but did not attend the breastfeeding class. Two others were lost to the study as they did not complete the second questionnaire (AN2) despite attending the breastfeeding education class. Two women were not contactable for the telephone interviews following their births and two, when contacted postnatally, had ceased breastfeeding within the first week. Their data however was included to examine the difference in breastfeeding self-efficacy before and following the intervention. (Figure 1) 


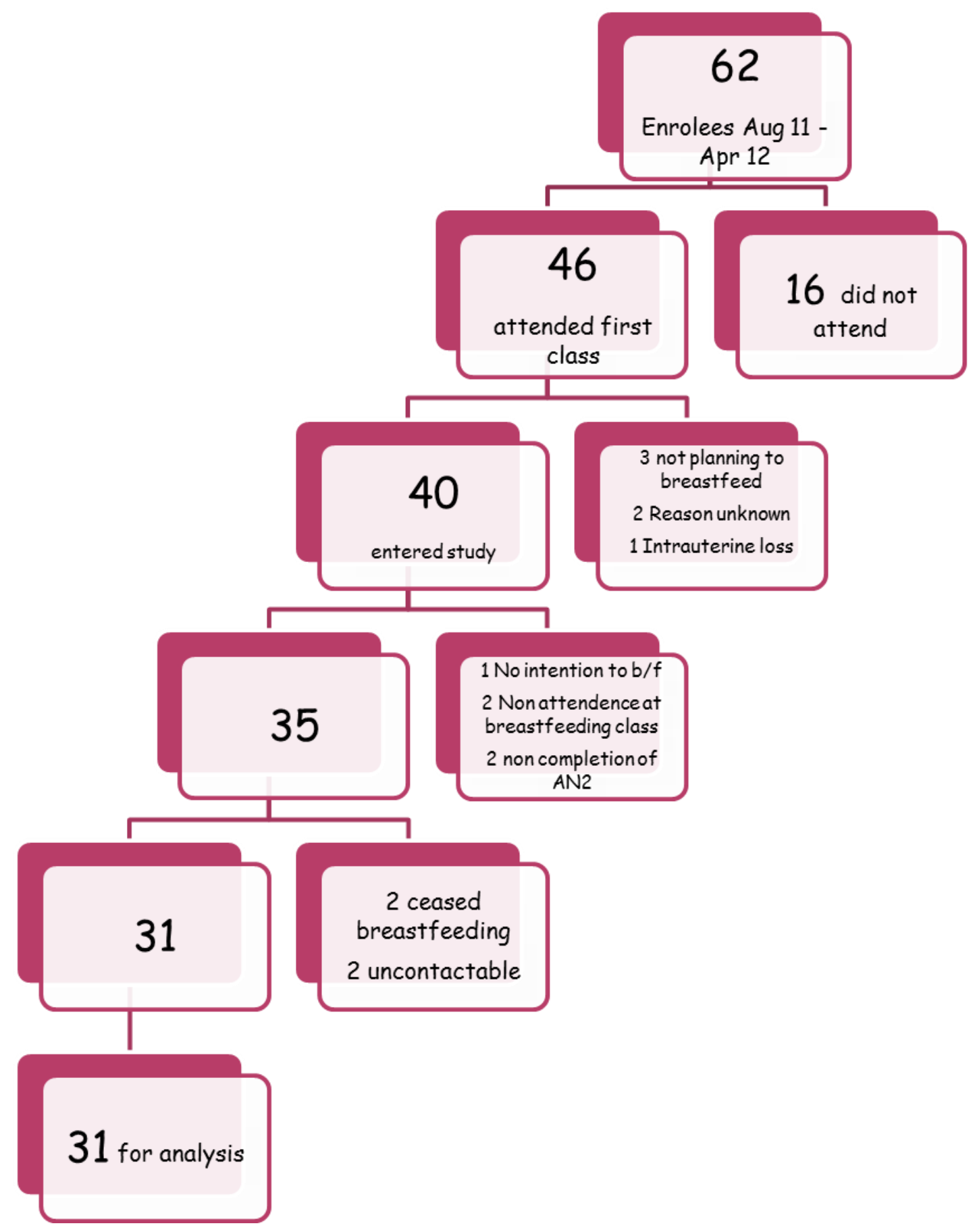

Figure 1 Participant Recruitment 


\section{Demographic Characteristics}

Participants were asked socio-demographic questions in order to give a profile of the study population. The age of participants ranged from 16-25 years with a mean of 20.25 years. Twenty two (55\%) participants were under 20 years of age. Although the study primarily looked at adolescents, the upper age limit is in keeping with the eligible population for enrolment within BirthEd youth classes, which is 25 years old. Data on age was split to repeat analysis on those aged less than 20 years and those aged between 20 and 25 years old.

The majority of the young women (62.5\%) identified as NZ European and eight $(20 \%)$ identified as Māori. The remaining six (15\%) were in the group of Pacifika and women of other ethnicities. Thirty three $(82.5 \%)$ participants were married or living in a de-facto relationship with the father of their baby. Six (17\%) gave their status as single, either having never been married, separated or divorced, with one participant not responding. Household income was requested with a response rate of $93 \%$. Results were collapsed into two categories, those whose households earned under $\$ 35,000$ and those who earned over $\$ 35,000$. Fifty two percent of women in this study specified a household income of $\$ 35,000$ or less. This is comparable with the national rates where $67.2 \%$ of youth aged less than 24 years have an annual income of $\$ 21,268$ or under. (Statistics New Zealand, 2013). Twenty eight (70\%) participants had attended (or were attending) secondary school, with twenty one (52\%) identifying they had achieved National Certificate of Educational Attainment (NCEA) level one or higher. Eleven women (27.5\%) had had some tertiary education with two (5\%) having a tertiary qualification (Table 3 ). 
Table 3: Participant age, ethnicity, marital status, education level and household income.

\begin{tabular}{|c|c|c|c|c|}
\hline Variable & $\begin{array}{c}15-20 \\
\text { years } \\
=n\end{array}$ & $\begin{array}{l}\text { 21-25 } \\
\text { Years } \\
=n\end{array}$ & $\begin{array}{l}\text { Total } \\
=n\end{array}$ & $\%$ \\
\hline Age & 22 & 18 & 40 & 100 \\
\hline \multicolumn{5}{|l|}{ Ethnicity } \\
\hline New Zealand European & 16 & 10 & 25 & 62.5 \\
\hline New Zealand Māori & 4 & 4 & 8 & 20 \\
\hline Pacifika and other & 2 & 4 & 6 & 15 \\
\hline Missing & & & 1 & 2.5 \\
\hline Total & 22 & 18 & 40 & 100 \\
\hline \multicolumn{5}{|l|}{ Marital Status } \\
\hline Married/Defacto & 16 & 17 & 33 & 82.5 \\
\hline $\begin{array}{l}\text { Single/never } \\
\text { married/divorced }\end{array}$ & 5 & 1 & 6 & 15 \\
\hline Missing & 1 & & 1 & 2.5 \\
\hline Total & 22 & 18 & 40 & 100 \\
\hline \multicolumn{5}{|l|}{ Education } \\
\hline Secondary school & 1 & 6 & 7 & 17 \\
\hline $\begin{array}{l}\text { Secondary school with } \\
\text { NCEA level } 1 \text { or higher }\end{array}$ & 16 & 5 & 21 & 53 \\
\hline Some tertiary education & 3 & 6 & 9 & 22.5 \\
\hline $\begin{array}{l}\text { Completed tertiary } \\
\text { education }\end{array}$ & & 2 & 2 & 5 \\
\hline Missing & 1 & & 1 & 2.5 \\
\hline Total & 22 & 18 & 40 & 100 \\
\hline \multicolumn{5}{|l|}{ Household Income } \\
\hline$<35,000$ & 14 & 7 & 21 & 52.5 \\
\hline$>35,000$ & 6 & 10 & 16 & 40 \\
\hline Missing & 3 & & 3 & 7.5 \\
\hline Total & 23 & 17 & 40 & 100 \\
\hline
\end{tabular}




\section{Other Characteristics of this sample}

Twenty three $(57.5 \%)$ of young women in this sample made the decision to breastfeed after finding they were pregnant. Thirty women had a vaginal delivery $(75 \%)$, four $(10 \%)$ had a caesarean section and there was an unknown birth outcome for six (15\%). All women were primiparous.

\section{Breastfeeding rates}

One of the criteria for participating in the study was that the women had an intention to breastfeed. Those making a decision antenatally to formula feed and the woman with the intrauterine loss were excluded from participating in the study. However, nine of the forty remaining women, either did not initiate breastfeeding or whether they did or not was unknown. Using the definition of "baby ever to the breast" thirty one women (77.5\%) did initiate breastfeeding.

Table 4: Breastfeeding rates at 6 and 12 weeks for under and over 20 year olds.

\begin{tabular}{|l|c|c|c|}
\hline $\begin{array}{l}\text { Type and duration } \\
\text { of breastfeeding }\end{array}$ & $\begin{array}{c}\mathbf{1 5 - 1 9 y r} \text { olds } \\
\mathbf{n}(\%)\end{array}$ & $\begin{array}{c}\mathbf{2 0 - 2 5 y r} \text { old } \\
\mathbf{n}(\%)\end{array}$ & TOTAL \\
\hline Excl/Fully 6 weeks & 14 & 13 & 27 \\
\hline Partial/Not 6 weeks & 6 & 3 & 9 \\
\hline Missing & 3 & 1 & 4 \\
\hline TOTAL & $23(57.5)$ & $17(42.5)$ & 40 \\
\hline Excl/Fully 12 weeks & 8 & 11 & 19 \\
\hline Partial/Not 12 weeks & 12 & 5 & 17 \\
\hline Missing & 3 & 1 & 4 \\
\hline TOTAL & $23(57.5)$ & $17(42.5)$ & 40 \\
\hline
\end{tabular}




\section{Reliability of the Breastfeeding Self-efficacy Scale}

Reliability analysis on the BSES was performed and shows in this study that the Cronbach's alpha coefficient was 0.932 . 0.941 and 0.955 respectively for all three times the scales were used (AN1, AN2, PN1), indicating high internal consistency (Tavakol \& Dennick, 2011). This finding is in keeping with other studies (Appendix 5) and Dennis et al (2011) where consistency of the scale was comparable between adolescents and adult populations.

\section{Impact of breastfeeding education on Breastfeeding Self- Efficacy scores.}

Antenatal breastfeeding education improved breastfeeding self-efficacy in this group of women. There was an increase in the mean score from 44.09 to 55.69. This was statistically significant (Table 5).

Table 5: Breastfeeding self-efficacy scores before and after antenatal breastfeeding education for women of 15-19 and 20-25 years

\begin{tabular}{|l|l|l|c|}
\hline BSES-sf Mean & $\begin{array}{l}\text { BSE before } \\
\text { education } \\
\text { mean(sd) }\end{array}$ & $\begin{array}{l}\text { BSE after } \\
\text { education mean } \\
(\mathrm{sd})\end{array}$ & $\begin{array}{c}\text { Significance } \\
\mathrm{P}<.001\end{array}$ \\
\hline Overall $\mathrm{n}=36$ & $44.09(10.74)$ & $55.69(9.22)$ & $\mathrm{P}<.001 \mathrm{t}=-9.415$ \\
\hline $15-19$ years $\mathrm{n}=19$ & $44.21(11.083)$ & $55.68(10.520)$ & $\mathrm{P}<.001 \mathrm{t}=-6.940$ \\
\hline 20-25 years $\mathrm{n}=17$ & $42.94(11.128)$ & $53.35(12.206)$ & $\mathrm{P}<.001 \mathrm{t}=-4.660$ \\
\hline
\end{tabular}

\section{Baseline BSES-sf scores}

The breastfeeding self-efficacy scores collected as a baseline prior to the breastfeeding education were examined in light of the demographic characteristics (Table 6); age, education, income and support, in order to explore whether these variables could impact on self-efficacy scores. The mean AN1 total was not statistically significantly different between 15-19 year olds and $20-25$ year olds. ( $(38)=-0.050, p=.960)$. 
Those on incomes under NZ\$35,000 actually had higher mean BSES- than those reporting household income to be greater than $N Z \$ 35,000$. These results are not statistically significant in this sample, (t $(37)=-1.792) \mathrm{p}=.082$ ) because of an issue with power (for example $n=21$ and $n=16$ for incomes over and below $\mathrm{NZ} \$ 35,000$ respectively). The BSES mean score was higher in those having completed a tertiary qualification, but no statistical significance could be drawn again due to not enough power to detect this.

Women who identified more than two sources of breastfeeding support had a higher mean antenatal BSE score (47.00 vs 40.33) $(p=.092)$ (Table 8). Support is discussed more fully in the following chapter.

Table 6: Baseline BSE scores taken before antenatal breastfeeding class for age, education, income and ethnicity

\begin{tabular}{|c|c|c|c|}
\hline VARIABLE & Number & $\begin{array}{c}\text { AN 1 } \\
\text { BSES-sf } \\
\text { Mean }\end{array}$ & $\begin{array}{c}\text { Standard } \\
\text { Deviation }\end{array}$ \\
Age & & & \\
15-19 years & 22 & 42.59 & 12.424 \\
$20-25$ years & 18 & 42.78 & 10.828 \\
TOTAL & 40 & 42.68 & 11.586 \\
Level of Education & & & \\
Secondary school & 7 & 39.57 & 11.660 \\
NCEA level 1 or higher & 21 & 44.00 & 12.665 \\
Some tertiary education & 9 & 41.11 & 11.439 \\
Completed tertiary education & 2 & 47.00 & \\
Household Income & & & \\
$<\$ 35,000$ & 21 & 46.29 & 12.426 \\
>\$35,000 & 16 & 39.62 & 9.164 \\
& & & \\
Ethnicity & & & 8.701 \\
NZ Māori & 25 & 43.56 & 11.709 \\
NZ European & 6 & 37.67 & 8.756 \\
\hline Pacifika women and other & & & \\
\hline
\end{tabular}




\section{Change in breastfeeding self-efficacy and its relationship to breastfeeding success}

In order to address the question of whether a change in BSE, was related to breastfeeding success, a two-step process was undertaken. Firstly the results of the differences in scores between AN2-AN1 were calculated and tested for normal distribution. Secondly, an independent samples t-test was conducted to examine whether the increase in breastfeeding self-efficacy scores was associated with breastfeeding success. Success in this study is defined as exclusive or full breastfeeding. Those who were partially or not breastfeeding were regarded as not successfully breastfeeding.

The PN1-AN2 difference was not normally distributed so a Wilcoxon Signed Ranks Test was used to test for the difference in Breastfeeding efficacy between time points (Table 7). This showed significant differences between AN2-AN1 $(p<.001)$, meaning an improvement in breastfeeding self-efficacy after the intervention, but for PN1-AN2 the results show only a trend towards statistical significance with the PN1 score being higher than the AN2 score(p value $=.092$ )

Therefore in this study there was no statistically significant association between the improvement in scores on the BSES-sf after the antenatal class, and breastfeeding success. This result is to be expected because there was no comparison group and women who participated at the PN1 time interval were all breastfeeding to some degree. Those not breastfeeding or uncontactable were withdrawn from the study $(n=9)$. This may reflect perseverance which is one of the features of self-efficacy theory and this will be discussed further in chapter five. 
Table 7: Change in BSES and relationship to breastfeeding at 6 and 12 weeks

\begin{tabular}{|l|c|c|c|c|c|c|}
\hline $\begin{array}{l}\text { CHANGE IN } \\
\text { BSES score }\end{array}$ & \multicolumn{2}{|c|}{$\begin{array}{c}\text { Exclusive/Fully } \\
\text { Breastfeeding }\end{array}$} & \multicolumn{2}{c|}{$\begin{array}{c}\text { Partial/Not } \\
\text { breastfeeding }\end{array}$} & W (z) & P-value \\
\hline & $\begin{array}{c}6 \text { wks } \\
\text { Mean }+ \\
(\mathrm{SD})\end{array}$ & $\begin{array}{c}12 \mathrm{wks} \\
\text { Mean }+ \\
(\mathrm{SD})\end{array}$ & $\begin{array}{c}6 \text { wks } \\
\text { Mean }+ \\
(\mathrm{SD})\end{array}$ & $\begin{array}{c}12 \mathrm{wks} \\
\text { Mean }+ \\
(\mathrm{SD})\end{array}$ & $\begin{array}{c}\text { Wilcoxon } \\
\text { Signed Ranks } \\
\text { test }\end{array}$ & $\begin{array}{c}\text { Asymp.Sig } \\
(2 \text { tailed })\end{array}$ \\
\hline AN2-AN1 & $\begin{array}{c}12.18 \\
(8.443)\end{array}$ & $\begin{array}{c}12.82 \\
(6.462)\end{array}$ & $\begin{array}{c}10.61 \\
(7.245)\end{array}$ & $\begin{array}{c}10.71 \\
(8.348)\end{array}$ & -5.090 & .000 \\
\hline PN1-AN2 & 8.60 & 9.89 & 2.85 & 4.05 & -1.683 & .092 \\
& $(9.723)$ & $(9.293)$ & $(19.857)$ & $(17.300)$ & & \\
\hline
\end{tabular}

\section{Factors influencing the duration of breastfeeding}

Other variables were also examined as potential influences on the duration of breastfeeding. Although data such as; type of carer, interventions, timing of first breastfeed, use of formula in hospital and birth weight were collected, the size of the groups, particularly when further split into under 15-19 year olds and 2025 year olds, were too small to conduct any statistical tests. These would have been seeking to find any correlation with these variables, breastfeeding selfefficacy scores and duration. Therefore the most useful information is frequencies and the mean BSES for each of the variables, as presented in Table 8. Perceived degree of support, as mentioned previously, is an interesting variable as there appears to be a difference in mean baseline scores antenatally of those identifying over two or under two supports for breastfeeding. This however could not be proven statistically. Analysis of actual support was beyond the scope of this study but would most likely influence the confidence to breastfeed or continue breastfeeding. For example, the majority of women at $(n=36)$ reported that their partners were supportive or very supportive of their decision to breastfeed. And nineteen (61\%) women indicated they had breastfeeding support postnatally from two or over two sources. Table 8 , also shows there is little difference in mean breastfeeding self-efficacy scores between under 15-19 year and 20- 25 year olds for most of the variables. 
Table 8: Mean breastfeeding self-efficacy scores for women under and over 20 years for variables potentially influencing breastfeeding duration.

\begin{tabular}{|c|c|c|c|c|}
\hline & $\begin{array}{l}\text { Under } 20 \\
\text { years }\end{array}$ & $\begin{array}{l}\text { Mean AN } 1 \\
\text { BSES (SD) }\end{array}$ & $\begin{array}{c}\text { Over } 20 \\
\text { years }\end{array}$ & $\begin{array}{l}\text { Mean AN1 } \\
\text { BSES (SD) }\end{array}$ \\
\hline \multicolumn{5}{|c|}{ When decided to breastfeed } \\
\hline Before pregnancy & 7 & $\begin{array}{c}43.00 \\
(4.243)\end{array}$ & 7 & $\begin{array}{c}44.86 \\
(7.267)\end{array}$ \\
\hline After pregnancy & 13 & $\begin{array}{c}43.23 \\
(15.849)\end{array}$ & 10 & $\begin{array}{c}40.90 \\
(13.304)\end{array}$ \\
\hline \multicolumn{5}{|c|}{ Did own mother breastfeed? } \\
\hline Yes & 17 & $\begin{array}{c}44.71 \\
(11.134)\end{array}$ & 14 & $\begin{array}{l}45.64 \\
(9.756)\end{array}$ \\
\hline No & 5 & $\begin{array}{c}35.40 \\
(15.192)\end{array}$ & 4 & $\begin{array}{l}32.75 \\
(8.921)\end{array}$ \\
\hline \multicolumn{5}{|c|}{ Partners feelings about breastfeeding decision } \\
\hline Not supportive & 1 & 44.00 & 0 & \\
\hline Somewhat & 1 & 42.00 & 0 & \\
\hline No Opinion & 2 & $\begin{array}{c}24.00 \\
(11.314)\end{array}$ & 0 & \\
\hline Supportive & 6 & $\begin{array}{c}44.00 \\
(12.394)\end{array}$ & 2 & $\begin{array}{l}39.50 \\
(7.778) \\
\end{array}$ \\
\hline Very Supportive & 12 & $\begin{array}{c}42.59 \\
(12.424)\end{array}$ & 16 & $\begin{array}{c}43.19 \\
(11.280)\end{array}$ \\
\hline \multicolumn{5}{|c|}{ Type of Birth } \\
\hline Caesarean & 1 & 44.00 & 3 & $\begin{array}{c}43.00 \\
(14.731)\end{array}$ \\
\hline Vaginal & 17 & $\begin{array}{c}43.71 \\
(11.537)\end{array}$ & 13 & $\begin{array}{c}42.31 \\
(11.108)\end{array}$ \\
\hline Unknown & 4 & & 2 & \\
\hline \multicolumn{5}{|c|}{ First Breastfeed } \\
\hline Under 1 hour & 9 & $\begin{array}{c}41.67 \\
(11.358)\end{array}$ & 11 & $\begin{array}{l}41.82 \\
(9.569)\end{array}$ \\
\hline $1-2 \mathrm{hrs}$ & 3 & $\begin{array}{c}42.00 \\
(11.586)\end{array}$ & 3 & $\begin{array}{c}38.67 \\
(19.348)\end{array}$ \\
\hline$>2 \mathrm{hrs}$ & 5 & $\begin{array}{c}50.80 \\
(12.872)\end{array}$ & 2 & $\begin{array}{l}51.50 \\
(6.364)\end{array}$ \\
\hline \multicolumn{5}{|c|}{ Formula Received In hospital } \\
\hline Yes & 1 & 60.00 & 4 & $\begin{array}{l}45.75 \\
(9.032)\end{array}$ \\
\hline No & 15 & $\begin{array}{c}42.93 \\
(10.905)\end{array}$ & 12 & $\begin{array}{c}41.33 \\
(12.108)\end{array}$ \\
\hline \multicolumn{5}{|c|}{ Degree of Support Antenatally } \\
\hline$\geq 2$ identified supporters & 11 & $\begin{array}{c}47.82 \\
(10.925)\end{array}$ & 8 & $\begin{array}{c}45.88 \\
(10.616)\end{array}$ \\
\hline$\leq 1$ identified supporters & 6 & $\begin{array}{l}38.17 \\
(9.261)\end{array}$ & 6 & $\begin{array}{c}42.50 \\
(11.309)\end{array}$ \\
\hline $\begin{array}{l}\text { Degree of support } \\
\text { Postnatally }\end{array}$ & & $\begin{array}{l}\text { Mean PN1 } \\
\text { BSES }\end{array}$ & & $\begin{array}{l}\text { Mean PN1 } \\
\text { BSES }\end{array}$ \\
\hline$\geq 2$ identified supporters & 11 & $\begin{array}{l}63.18 \\
(6.226)\end{array}$ & 8 & $\begin{array}{c}62.50 \\
(12.282)\end{array}$ \\
\hline$\leq 1$ identified supporters & 6 & $\begin{array}{c}54,50 \\
(13.278)\end{array}$ & 6 & $\begin{array}{c}56.60 \\
(17.315)\end{array}$ \\
\hline
\end{tabular}




\section{Reasons for cessation of breastfeeding}

Although this study used a quantitative methodology, an open ended question was included for the last two questionnaires (PN 2 and 3) to give some context to the results. This was around the reasons for discontinuing breastfeeding. The main reasons for discontinuing breastfeeding were: physical complaints, perceived/actual decreased milk supply, issues with the baby for example tongue tie, and social effects such as baby being minded by someone other than the breastfeeding mother. Table 9 gives examples of participant's responses to question 4 "Please describe your reasons for stopping"PN2/3 (Appendix 3). Verbatim comments were analysed for content. Four themes emerged, Physical complaints, decreased supply, issues with baby and social.

Table 9: Examples of reasons for cessation of breastfeeding as cited in PN 2 and 3 questionnaires.

\section{PHYSICAL COMPLAINTS}

I had Raynaud's, better now the weather is warmer" but I am mixed feeding" (Age 24)

"Had mastitis" (Age 20)

\section{DECREASED SUPPLY}

"He would be on for 1-2 hrs then still looking for more, I was expressing and not getting very much. He's more settled with formula".... (Age 21)

\section{ISSUES WITH BABY}

"I am partially feeding, baby likes to comfort feed and still goes to breast before each feed but I stopped because of his weight gain."(Age 24 yrs)

"Baby had a tongue tie, I was seen by the lactation consultant at the hospital, but I stopped breastfeeding when I got home" (Age 21 yrs)

'Knew it was best for baby, got mastitis at 1 week and was on antibiotics, baby got reflux, but l expressed for one month" (age 19 years)

\section{SOCIAL}

"Baby is having 3 bottles a day now. Tried at 2 months at night to go to movies but then carried on breastfeeding" (age 17)

"Going back to work tomorrow for a shift and will be away 8 - 10 hrs. Have expressed but mum will bring her in for a feed" (age 23) 


\section{Summary}

Results from this study show a significant relationship between antenatal breastfeeding education and adolescent breastfeeding self-efficacy. There were a high proportion of young mothers initiating breastfeeding (77\%). Although the breastfeeding self-efficacy scores of those continuing to breastfeed were high, this is most likely due to them persevering with breastfeeding despite challenges and is open to influence from many other sources such as degree of support they perceived and received. It cannot be proven it was due to their breastfeeding self-efficacy scores or the education solely and further research with comparison groups is warranted to make this link with breastfeeding selfefficacy. These findings are discussed in Chapter 5. 


\section{Chapter 5}

\section{Discussion}

Young mothers, both in New Zealand and globally, attend antenatal education less frequently, and are less likely to breastfeed compared to their older adult counterparts (Dwyer, 2009; UNICEF, 2007). The concern is that this vulnerable group of women and their babies are missing out on the important benefits of breastfeeding. Previous studies have shown breastfeeding antenatal education to be an important modifiable influence on breastfeeding self-efficacy, which in turn can positively affect initiation rates and duration of breastfeeding (Blyth, 2002; Dennis, 2003; Dennis et al., 2011).

This research was undertaken with the objective of ascertaining whether the findings from previous studies looking at this problem were generalizable to a New Zealand population, specifically young mothers.

The hypothesis of this study was that antenatal education about breastfeeding would increase breastfeeding self-efficacy and improve breastfeeding rates in an urban New Zealand population of young women. A quantitative pre-post test design was used to test the hypothesis by:

- Applying breastfeeding self-efficacy testing at three time points: before and after breastfeeding education in an antenatal class, and postnatally.

- Testing the reliability and validity of the Breastfeeding Self Efficacy Scale (BSES)for this population.

- Analysing the data to make clear the relationship between breastfeeding self-efficacy, antenatal education and improved breastfeeding rates.

- Determining whether there is a difference in self-efficacy and outcomes between 15-19 year olds and 20-25 year olds. 
The results of this study were mixed. Whilst the literature suggested that antenatal breastfeeding education improves breastfeeding self-efficacy and that this leads to improved rates and duration of breastfeeding, this was only partly verified in this study. This study found that the self-efficacy tool was a valid measure to use in this population and that antenatal breastfeeding education improved breastfeeding self-efficacy. However, it found no association between this improved breastfeeding self-efficacy and breastfeeding success. Other factors thought to contribute to breastfeeding self-efficacy were explored but no conclusions on these influences could be confirmed. There was no significant difference between 15-19 year olds and 20-25 year olds in terms of breastfeeding self-efficacy.

This discussion examines these findings giving possible explanations as to why this might be so. It examines the implication that the findings provide some guidance for practice and recommendations for future research.

\section{Breastfeeding self-efficacy and breastfeeding success.}

A fundamental aspect of this study is the theoretical framework of breastfeeding self-efficacy and the tool that was used to examine this. This section revisits this framework and outlines how it fitted this study.

Breastfeeding self-efficacy was a term coined by Dennis in 1999, and is defined as "the confidence a woman has in her ability to breastfeed her baby" (NoelWeiss et al., 2006b pg 617). It is derived from Bandura's social cognitive theory and the concept of self-efficacy generally, but in this case applied specifically to breastfeeding. Dennis (1999) found mothers with high levels of breastfeeding self-efficacy more likely to begin to breastfeed and to persist through challenges; seeking resources to help if the challenges are beyond their ability resolve. There are four sources of self-efficacy: performance accomplishments, vicarious experiences, social and verbal persuasion and somatic experiences (Bandura, 1977). This relationship between breastfeeding and antenatal education, and how many of the sources of breastfeeding self-efficacy were applied in this study setting, can be identified as follows. Increased knowledge 
(from the class content) is strongly correlated with breastfeeding confidence (Chezem, Friesen, \& Boettcher, 2003). Other sources of self-efficacy are in the form of verbal persuasion and encouragement, for example from the educator and fellow attendees and vicarious experience, perhaps through people coming to sessions to share their experiences or the use of videos to illustrate such skills as correct latching.

Dennis (1999) applies these ideas to breastfeeding and her self-efficacy framework fits well with this study in the context of antenatal education and midwifery in New Zealand, where an underlying philosophy is to empower women to care for their babies and be informed of the benefits of breastfeeding. Another way this framework fits with this particular study is the pragmatic view that increased breastfeeding self-efficacy leads to a positive change in health behaviour, such as the uptake and success of breastfeeding.

The tool developed by Dennis (1999) to measure self-efficacy caters to this pragmatist approach by eliciting levels of confidence on specific aspects of managing breastfeeding. This has been reflected in this study by the increase in self-efficacy following the intervention. This intervention is interactive and practical and includes many of the sources of self-efficacy in the breastfeeding session.

The use of the validated Breastfeeding Self-Efficacy scale -short form (BSES sf) as a tool to measure self-efficacy was one of the central aspects of this study. The tool has been psychometrically tested a number of times, including its use with adolescents in Canada. The results of Dennis's (2011) study suggested antenatal education may be a particularly important source of modifying breastfeeding self-efficacy in a group of adolescent mothers, and furthermore that this would be predictive of breastfeeding initiation, duration and exclusivity. This is congruent with other studies which find the tool to be reliable and consistent in the prediction of breastfeeding outcomes (Creedy et al., 2003; Dennis, 2003; Dennis et al., 2011).

Importantly, testing of the tool in this research on New Zealand urban young mothers, demonstrated high internal consistency over the three times the scale 
was used, with the Cronbach's alpha coefficient being over the recommended 0.7 (Pallant, 2011).

Forty participants completed the breastfeeding self-efficacy scale prior to and following an antenatal breastfeeding education session, giving the opportunity to compare scores measuring breastfeeding self-efficacy. The outcome of this measuring is that it showed a significant increase in the mean scores after the intervention, confirming antenatal education as a source of modifying breastfeeding self-efficacy.

The utilisation of the information gained is important. Identifying women with low self-efficacy scores who may have no intention to breastfeed, or who may be at risk of not initiating breastfeeding or discontinuing, allows practitioners and educators to focus their efforts on improving self-efficacy in this group and hopefully influence breastfeeding outcomes. More specifically, from a practical perspective, use of this tool prior to breastfeeding sessions could guide educators in session preparation. Depending on the scores for individual questions, aspects of breastfeeding such as comfort of feeding in front of others, for example "I think I can always comfortably breastfeed with my family members present" (Question 8 on the tool), could be addressed if identified as an issue. Other common reasons for cessation of breastfeeding are perceived insufficient milk and questions 3 and 13 focus on this. "I think I can always breastfeed my baby without using formula as a supplement "and Question 13 "I think I can always manage to keep up with my baby's breastfeeding demands". This could assist in targeting those specific issues and also those identified with low breastfeeding self-efficacy in general, possibly impacting on their initiation and continuation rates. More widely these strategies would appeal to stakeholders such as the District Health Boards and Ministry of Health who strive to improve breastfeeding rates for the obvious health reasons and cost benefits to the health dollar. This health message can influence the first breastfeeding decision point, which is intention.

\section{Intention to breastfeed}

There are many influences on the intention of young women to breastfeed. According to Wambach (2000) the decision by adolescent mothers to 
breastfeed is almost always made during pregnancy as opposed to adult mothers who are more likely decide before. Although Alexander et al, (2010) didn't find any correlation of intention with age, a higher proportion of women in the current study made their decision during pregnancy $(n=13$ under 20 years old and $n=10$ over 20 years old), compared to prior to pregnancy ( $n=7$ under 20 years and $n=7$ over 20 years). All however intended to breastfeed due to recruitment criteria (three excluded because of an intention not to breastfeed) and this intention could account for the high self-efficacy score after the intervention, though there was wide variation in the mean baseline scores (SD 9.22) to suggest that intention is possibly independent of self-efficacy antenatally. Clarifying the link between engagement in antenatal education and intention would offer insight into where to concentrate strategies to enhance breastfeeding. It may be that the target group for improving self-efficacy are those not intending to breastfeed. And indeed not attending antenatal education.

Other factors influencing intention may be; whether women were breastfed themselves, (Horta, Victora, Gigante, Santos, \& Barros, 2007), whether they had been exposed to seeing breastfeeding, (vicarious influence), (Hoddinott, Kroll, Raja, \& Lee, 2010), and partner's feelings and support of breastfeeding. (Mannion, Hobbs, McDonald, \& Tough, 2013), (Social and verbal influence). Whilst participants were asked questions pertaining to some of these variables, for example: Question 13 AN1/2, "Did your mother breastfeed any of her children?" (page 86) the numbers were too small to show any correlation or statistical significance with breastfeeding self-efficacy and further exploration was outside the scope of the study. However it is worthwhile briefly discussing the influence of these variables on initiation and cessation of breastfeeding, particularly regarding the influence of support. (page 69)

It could be argued that women in the current study group who intended to breastfeed were more likely to engage in antenatal education because they are more self-efficacious, and vice versa. The improvement in mean self-efficacy scores after the breastfeeding education intervention may be related to initiation of breastfeeding but had no significant influence on breastfeeding duration. The indication that antenatal breastfeeding education modifies self-efficacy may help educators and midwives to focus on those with low self-efficacy to improve 
intention (and initiation) and address specific challenges. Having comparison groups of young women 1) not intending to breastfeeding and 2) not attending antenatal breastfeeding education would have been useful and is a recommendation for future studies in groups of young women.

\section{Initiation of breastfeeding}

Whilst other studies have been able to demonstrate that self-efficacy predicts initiation of breastfeeding in adolescents (Dennis et al., 2011; Mossman et al., 2008), this wasn't shown in this study. Actual initiation rates were $77 \%$. This is comparable with national figures for all age groups (New Zealand Breastfeeding Authority, 2012), though as stated previously (pg 4), we are unable to compare with national figures for young women.

To link the improvement in mean self-efficacy scores with the prediction of initiation was more difficult in this study, with one reason being the recruitment criteria used. Firstly these young women may have been more motivated or self-efficious, because they were voluntarily attending antenatal classes. Secondly only women intending to breastfeed were eligible. Had this study included all women attending the breastfeeding education classes including those not intending to breastfeed, important information may have been gained. This might have included whether the intervention enhanced their self-efficacy and therefore make it more likely that they initiated breastfeeding. It is probably reasonable to assume based on other studies that where there is an intention, there are higher rates of initiation (Dyson et al., 2010; Sipsma et al., 2013; Stuebe \& Bonuck, 2011; Wambach \& Koehn, 2004). Initiation is the second decision point with the third being continuation or cessation of breastfeeding.

\section{Continuation of breastfeeding}

With regard to the decision of continuation of breastfeeding in this study, no significant link was found between self-efficacy scores antenatally or postnatally with those who ceased breastfeeding. Those who had mean scores which decreased from the second antenatal scoring (after the intervention) to postnatally (at one to two weeks postpartum), were the participants who 
identified challenges or had discontinued in the early postpartum timeframe. Those who had not initiated or whose initiation was unknown at one to two weeks $(23 \%)$ were not scored. Again a comparison with those who did not attend antenatal education would measure how much self-efficacy does impact on breastfeeding outcomes.

\section{Other influences on self-efficacy}

Although antenatal education is an important source of modifying self-efficacy, the role of other factors influencing the breastfeeding decision points of intention, initiation and continuation, need to be considered. Questions were asked to explore how these may also influence self-efficacy scoring. This section will focus particularly on support that could be provided to young women, relating to these breastfeeding decision points.

Breastfeeding initiation and continuation in this group of young women is complex and multi-factorial. The literature cites such issues influencing initiation. Examples of these are: influence and support of the partner (Alexander et al., 2010; Dennis, 2002b; Hoddinott et al., 2010; Mossman et al., 2008), support from adolescents own mothers (Dennis, 2002b; Grassley \& Eschiti, 2008; Hannon, Willis, Bishop-Townsend, Martinez, \& Scrimshaw, 2000; Mossman et al., 2008; Wambach \& Cole, 2000), support from professionals (Dykes et al., 2003a; Lu et al., 2003) and knowledge , or lack of, the benefits of breastfeeding, (Fairbrother \& Stanger-Ross, 2010; Spear, 2006; Swanson, Power, Kaur, Carter, \& Shepherd, 2006; Wambach \& Cohen, 2009). For continuation of breastfeeding, age is a factor, with older adolescents less likely to discontinue than younger ones (Renfrew et al., 2005; Wambach \& Cole, 2000). Specific reasons for cessation include the embarrassment of feeding in public (Dyson et al., 2010; Mossman et al., 2008; Nelson, 2009; Wambach \& Cole, 2000), and perceived supply problems (Avery et al., 2009; Otsuka, Dennis, Tatsuoka, \& Jimba, 2008), and a lack of appropriate support extending into the postnatal period. In this study different facets of support for women between ages of 15-19 and 20-25 years, will be addressed in the following section. 


\section{Support}

As support of breastfeeding occurs both antenatally and postnatally, it was of interest to try and establish; 1) a link between these variables and the antenatal self-efficacy scores and 2) a correlation between these variables and postnatal self-efficacy scores.

The number of participants were too small to draw any conclusions of statistical significance for either the antenatal or postnatal period. However, previous studies have shown a link with higher self-efficacy scores, support, and both initiation and continuation in this age group. Based on the theory of self-efficacy, those scoring more highly are more likely to persevere in the face of challenges. However, the question of what type of support, when it is given and the effect on sustaining self-efficacy needs to be addressed.

Two groups of support people potentially exert influence on self-efficacy scores and were of interest in this study. These were firstly, lay support people who were generally identified as partners and family or peers and secondly, other dedicated breastfeeding supporters such as Mum4Mum, La Leche League, Lactation consultants and Midwives.

I asked questions in my survey about who gave participants support postnatally and found that it was a mixture of lay and dedicated breastfeeding and professional support. This was re- categorised as degree of support with those identifying 2 or more ( $n=19 / 31$ ) compared to those identifying equal to or less than 1 source of support $(n=12 / 31)$ (Table 8$)$. Whilst there was no statistically significant difference in the self-efficacy scores of women perceiving they had more support compared to those perceiving they had one or less source of support, the results indicate they could be significant had the sample size been bigger. There is evidence that antenatal support into the postnatal period is important to sustain breastfeeding (Hannula et al., 2008; Spear, 2006). However when surveying at six and twelve weeks, the women in this study's breastfeeding status and reasons for ceasing breastfeeding was ascertained, but ongoing support wasn't questioned. Although outside the scope of the objectives for this research, more data on support would have been useful as this is likely to have had an impact on their breastfeeding self-efficacy at one 
week postpartum and continuation of breastfeeding rates. In the New Zealand maternity system, Lead Maternity Carers were one consistent source of support for this group until the six week postpartum point. Whether the participant perceived them as such or not is an opportunity to explore with further research, though the role with regard to breastfeeding is very clear under our legislation. (New Zealand Crown, 2007) as will be explained.

\section{Role of the Lead Maternity Carer}

The Lead Maternity Carer (LMC) is obliged under Section 88 of the Primary Maternity Services Notices 2007 to impart breastfeeding information. Knowledge regarding breastfeeding gained from a woman's LMC prior to antenatal education, potentially effects self-efficacy scores as it would be classed as 'verbal persuasion', a source of breastfeeding self-efficacy information as described by Dennis (2002a). In the survey a question was asked on prior preparation for breastfeeding (Question 12, pg 86) and some women $(n=10)$ clearly identified their midwife LMC's as sources of information in this time period.

The impact of in-hospital midwife input was gauged in this study with participants being asked to rate between 1 to 5 with $1=$ not supportive, $2=$ somewhat supportive, $3=$ no opinion, $4=$ supportive and $5=$ very supportive (Question 9 PN1). The results showed their perception of support was rated as either supportive or very supportive. These midwives were not the participants Lead Maternity Carer (LMC), but core staff, who in the absence of the LMC, follow the previously determined plan of care regarding breastfeeding whilst the woman is an inpatient.

Postnatally in New Zealand, the LMC is in contact with the woman for four to six weeks and is a main source of support of breastfeeding. Twenty eight out of thirty two respondents $(87.5 \%)$ identified her LMC as a source of breastfeeding support in the postnatal period. A large survey in the United Kingdom showed breastfeeding was sustained when consistent advice, practical support and active encouragement was given from midwives (Rempel \& Moore, 2012). 
Lead Maternity Carers need to be made aware of the finding that antenatal breastfeeding education is an important source of modifying breastfeeding selfefficacy, and that self-efficacy should not be underestimated for its potential to impact on breastfeeding initiation rates. As well as a partnership with women, including fulfilment of their obligation under section 88 and the WHO code, appropriate referral to other sources of antenatal education can enhance this self- efficacy further. Equally there needs to be consideration of how findings of poor breastfeeding self-efficacy of individual women can be communicated between parties if it is to be used as a tool to predict initiation and attrition. Postnatally, LMC's are in a prime position to help women sustain breastfeeding by enhancing self-efficacy through verbal persuasion. The findings from this research will be disseminated to the stakeholders such as the District Health Boards, and published to convey the impact of antenatal breastfeeding education on self-efficacy and how this in turn may effect breastfeeding outcomes.

\section{Lay support}

Questions on perceived support were asked of participants with regard to numbers of friends and family who had breastfed. This wasn't quantified initially but asked as an open question. Subsequently this information was recategorised into degree of support. Most identified some potential supporters of breastfeeding with partners and family featuring. Part of the reason for asking this question was to determine the link of the concept of vicarious experience as a source of self-efficacy. Women who have been exposed to breastfeeding modelling by peers are thought to have more success (or higher self-efficacy) (Hoddinott et al., 2010). All of the participants in this study were primiparous, and are different to multiparous women in that, women who have birthed before can base their feeding on past experience. Their source of self-efficacy comes from performance accomplishment with success reflected in the self-efficacy scores. Park et al. (2003) suggests older adolescents may therefore be more successful breastfeeding [and have higher self-efficacy] due to the opportunity to be exposed to breastfeeding, however the reverse may be true if they are having subsequent babies and didn't breastfeed successfully the first time. An interesting finding is that the age of the young person in this study had no 
bearing on the results of the BSES-sf scores as all ages improved following the intervention. This means the relevancy of age group may not be so imperative though the premise would be that younger women would have lower scores. As stated, in this sample all women were primiparous and so were more likely to rely on vicarious experience as a resource for self-efficacy.

Question 15 (AN1/2) was about their partner's level of support. Participants were asked to rate their perception of their partners feeling about their decision to breastfeed on a likertscale. They were asked to rate between 1 to 5 with $1=$ not supportive, 2 = somewhat supportive, $3=$ no opinion, $4=$ supportive and $5=$ very supportive. Ninety percent $(n=36)$ said their partner was supportive or very supportive. Whilst the number of responses were too small to draw any statistical conclusions between the relationship to this antenatal support and self-efficacy, what was of interest was the link with this and the high initiation of breastfeeding. There may be a mistaken presumption that the high level of support antenatally continued into the postnatal period and boosted the selfefficacy scores at this time. Whilst the mean breastfeeding self-efficacy score was significantly different for this postnatal question on perceived support, this couldn't be related solely to lay support as there are many sources of support. This perceived support would be useful to explore in future research given there is strong evidence that antenatal education and postnatal support in combination improve breastfeeding outcomes (Hannula et al., 2008; Jolly et al., 2012a). Therefore, although the focus of this study was on antenatal education, postnatal support cannot be ignored as a variable affecting the postnatal selfefficacy scores.

\section{Peer support}

With regard to peer support postnatally, Jolly et al, (2012b) found peer support in the antenatal and postnatal period does not seem to be effective in the United Kingdom setting. This supports a previous study by some of the same authors, which found that although peer support may increase breastfeeding continuation in low or middle income countries, (especially exclusive breastfeeding), in high income countries (or countries where breastfeeding support is part of routine postnatal healthcare, as in the New Zealand maternity 
care system), it has less effect (Jolly et al., 2012b). However, it seems there is a place for lay and peer support alongside professional support in New Zealand as evidenced by the Breastfeeding Peer Counsellor Programme which is a La Leche League initiative that builds on community's capacity to provide costeffective breastfeeding peer support. They believe, "A woman who has successfully breastfed is a valuable asset to her community, and often highly motivated to help and support other mothers"(La Leche League, 2008). The effectiveness needs further investigation to see if Jolly and colleagues findings can be translated to this setting.

\section{Appropriate support for Māori women}

In the New Zealand literature regarding breastfeeding for Māori, there is a strong sentiment that whānau is very important for sharing information on breastfeeding (Fox 1997; Ellison-Loschmann,1997). This leads to the questions of the place of peer support for breastfeeding, and the method of delivery of antenatal education, particularly with Māori having a culture based on oral tradition. This is therefore a challenge for providers of antenatal breastfeeding education to include family/peers in an antenatal education programme and to provide culturally specific education sessions. This is corroborated by Renfrew et al. and the NICE guidelines (2005), which suggest cultural specific education sessions increase the duration of breastfeeding. Consideration of cultural factors are relevant because of the lower breastfeeding rates by this group of New Zealanders and a tendency to impose Pakeha (New Zealanders of European descent) frameworks on Māori, who may access antenatal and postnatal education more readily if it was more culturally appropriate, led by peers and not necessarily health professionals. Findings from the New Zealand literature (Fox, 1997; Ellison-Loschmann, 1997) support this idea.

\section{Postnatal support}

\section{Grandmothers}

In this study, Grandmothers of the baby (young women's own mothers), were identified as important sources of support to the young breastfeeding mother. 
Wambach \& Cohen (2009) reinforce this and suggest grandmothers may have the most influence in the decision to breastfeed or not, and there is a positive correlation with this intention to breastfeed by young mothers when they have been breastfed themselves (Grassley \& Eschiti, 2008). Vicarious experience is a source of self-efficacy and whether this was experience of seeing younger siblings of the young women being breastfed or not, isn't always clear in the literature but is a reasonable suggestion given the age of the young women in my study and the possibility of having young siblings. On the other hand one study found that grandmothers can be detrimental to the process, particularly in the early postnatal period, and if they have not breastfed themselves (Grassley, Spencer, \& Law, 2012). They may undermine a young women's confidence and pamphlets such as one produced by one of the District Health Boards is specifically written to counter this. "To the Grandmother of the breastfed baby" gives useful facts and tips to enhance breastfeeding. One example of this in the pamphlet is the statement that comments such as " 'your milk is too thin' are not helpful" used to illustrate how comments can undermine confidence. (Capital and Coast District Health Board, 2014).

One New Zealand Māori midwife who felt "there is a whānau (family) concept about sharing baby and relating to breastfeeding sometimes the older generation can think they are doing a good thing in taking the baby from the mother not realising the impact of this separation on many levels such as bonding, establishing breastfeeding" [and self-efficacy] (Personal Communication 2011). In this study one young woman identified she was back to school and her grandmother was caring for baby. However she was still breastfeeding partially which is of note. The question of whether grandmothers should be included in antenatal breastfeeding education is worth further exploration or maybe we should be empowering young women, through antenatal education, to educate their families. Perhaps the Grassley et al, (2012) study involving a "Grandmothers tea" to assess knowledge and attitude of this influential source of breastfeeding support, could be repeated in our New Zealand setting as those Grandmothers receiving information about breastfeeding showed significantly higher post-test knowledge which could promote breastfeeding. 


\section{Dedicated support}

Some dedicated breastfeeding support was identified in this study as helpful, but only in the postnatal period, presumably as problems arose. Six women surveyed had contact with a Lactation Consultant and it would be of interest to examine the individual self-efficacy scores postnatally of the women seeking this support. If, for example, their perception was that they had poor supply or indeed had painful latch problems, it may follow that their self-efficacy scores would reflect this. On the other hand, perhaps high self-efficacy in the first instance does correlate with perseverance. A feature of the theory of selfefficacy is the confidence to perform a task and the amount of effort a woman is prepared to expend to master the task. Women with high breastfeeding selfefficacy are more likely to persevere and seek support (Dennis, 1999; Blyth et al, 2002)

In summary of this section, support is an important influence on breastfeeding outcomes for young women. It makes sense that support also influences breastfeeding self-efficacy in this group. One of the features of self-efficacy is perseverance, so it follows that women with higher self-efficacy scores are more likely to seek support for challenges with breastfeeding. The literature suggests that this support needs to be across the whole spectrum of breastfeeding decision points from intention, to initiation, to the decision to continue or not. It should also be appropriate and reflect the culture of young women. Support antenatally is going to influence intention and initiation of breastfeeding. New Zealand is fortunate to have breastfeeding support as part of routine postnatal healthcare. More investigation into postnatal support of young women in this postnatal time period, would close this knowledge gap on the role of support and the link to self-efficacy, in order to sustain breastfeeding.

\section{The quality and type of antenatal education}

A second influence on the results from this study discussed here, is regarding routine versus targeted antenatal education. Whilst antenatal education has been shown to positively modify breastfeeding self-efficacy (Dennis et al., 2011; Noel-Weiss et al., 2006b), not all antenatal education is the same. Also if this 
education is aligned with an institution that is baby friendly hospital accredited, it may influence breastfeeding initiation and even self-efficacy (Basire et al., 1997; Torres de Lacerda, Lucena de Vasconcelos, Nascimento de Alencar, Osório, \& Pontes, 2013). Education varied in format and delivery and some programmes were regarded routine whilst others used interventions to enhance self-efficacy and were based on adult learning theory and Bandura's proposed sources of enhancing self-efficacy, as described in chapter one (Noel-Weiss et al., 2006b).

In this study, the education intervention was deemed 'routine', however the BirthEd courses take adolescent learning into account and use strategies which are consistent with suggestions to improve breastfeeding self-efficacy. (Glover, 2009). They are also aligned with districts in which hospitals have Baby Friendly Hospital accreditation. Strategies are used such as enhancing knowledge of breast milk production and supply (verbal persuasion), acknowledging existing knowledge and experience (performance accomplishment), the use of DVD's, life size dolls, knitted breasts to teach positioning and attachment in a comfortable atmosphere (vicarious learning). Although a prescriptive course outline is used, it needs to be acknowledged that there are inevitable variations between educators. Despite this, the results show routine antenatal education was effective in increasing breastfeeding selfefficacy. However antenatal education designed to specifically enhance young women's confidence in their ability to breastfeeding would potentially see further improvement of self-efficacy scores and would provide evidence as to whether it is necessary to modify routine antenatal breastfeeding education.

\section{Age}

Interestingly, there was no significant difference between the before intervention scores for the women in both groups (15-19 and 20-25 years) and the after intervention score for either group (Table 5). Despite having an adolescent focus, the reason this variable was collapsed was, firstly, because there is a wide variance of age of adolescents in the literature and secondly, because of the convenience of not having to exclude some women from the BirthEd antenatal classes who may have been up to 25 years old. Traditionally adolescence spans the time from being a child to becoming an adult, usually 
ten years. It can be further divided into early adolescence, 10-14 years and late adolescence, 15-19 years. One could argue that there is potential for huge difference in the physical and psychological development between a 15 year old and 25 year old. Other differences may be reflected in the demographic data collected between these two groups, for instance education attainment and household income, whether they have a steady partner or not . This wasn't investigated in detail as the objective was whether there was a difference in breastfeeding self-efficacy or not. However future research should aim to recruit more women into each group because of the different needs of adolescents and young women, and to explore whether there is a difference in the variables impacting on breastfeeding due to age.

\section{Other influences on breastfeeding success}

\section{Modifiable and non-modifiable influences}

The remaining demographic influences identified (but not exhaustive due to the complexities of breastfeeding), are either modifiable such as smoking, or less modifiable such as education level, household income and non-modifiable such as age and ethnicity. Again while these variables may have an impact on selfefficacy and breastfeeding outcomes, the small numbers of women in this study makes examining these variables too difficult and a larger population should be sampled for it to be generalizable to other populations.

\section{Duration of breastfeeding}

When looking at breastfeeding success, the variables were collapsed, due to sample sizes, to those who were breastfeeding exclusively or fully and those who were partial or not breastfeeding. By definition partial is "the infant has taken some breast milk and some infant formula or other solid food in the past 48 hours" Ministry of Health, 2002 pg 10) (Appendix 3). Partially breastfeeding could be further graded as there is a considerable difference between a baby receiving one artificial feed per day compared to a baby receiving one breastfeed only a day. Poon, (2011) suggests more detailed questions on 
breastfeeding status is warranted in a questionnaire and should be considered in a future study of breastfeeding self-efficacy in young women.

\section{Reporting Breastfeeding}

The notion of the Hawthorne effect with regard to reporting breastfeeding amounts is a consideration. This effect describes a circumstance where someone may change their behaviour or response due to being observed or researched. As an illustration of this, my results showed that there was an interesting response to the question about smoking with only $10 \%$ of participants declaring any smoking. Of these two reported smoking socially, one reported smoking less than 10 a day and one smoked 10-25 cigarettes a day. This appears to be unusually low for the socio-economic status and age group of women in the study and could be attributed to the Hawthorne effect as smoking is widely understood to be harmful in pregnancy. However, participants were asked to answer the question regarding breastfeeding status honestly (PN2/3) and assured of confidentiality. I believe there was less likelihood of false reporting of breastfeeding because the telephone interviewing and reassurance of confidentiality meant there was little reason to give a different answer though it needs to be considered as a possibility. Like the praise given to pregnant women for every cigarette reduced, perhaps consideration for praising young women for any breastfeeding achieved whether it is partial or fully or exclusive. There are huge implications in how we define and collect statistics on these rates, which is raised here, but beyond the scope of this study.

\section{Limitation of this study}

There were limitations to this study discovered during the research process. These are around the sample, with the number recruited unable to provide the power to detect significance of some variables on breastfeeding self-efficacy. The ability to focus on adolescents was limited by the gap in the literature and perplexity of definitions for young women. A control group would have served 
to eliminate and isolate variables and examine their effect on breastfeeding selfefficacy. Finally, the wording for some instructions to answer questions may have been unclear leading to instrument bias, for example Question 11 (PN1). Recommendations for future research will be presented in the following sections.

\section{Conclusion}

Results from this study are the first to present an insight to breastfeeding selfefficacy in young New Zealand mothers. They have shown that breastfeeding self-efficacy increased following a routine antenatal breastfeeding education intervention with a group of young pregnant women.

No statistically significant difference was found for breastfeeding duration at six and twelve weeks, compared to national breastfeeding rates, therefore some participants fell short of meeting recommendations by the World Health Organisation and the Ministry of Health in New Zealand for optimal breastfeeding duration. However, it could be argued partial breastfeeding is superior to no breastfeeding at all.

The reasons for continuing breastfeeding, or not, are multi-factorial, however support in the antenatal and postnatal period appears to be an important factor in determining breastfeeding self-efficacy and duration, and warrants further exploration. What this research has revealed is that it may be young New Zealand women are well supported with breastfeeding postnatally due to our maternity system, compared to some other developed countries. The question, therefore, is whether self-efficacy enhancing interventions are going to further increase breastfeeding rates in the New Zealand context, or are there other modifiable variables related to outcomes? If antenatal breastfeeding education influences self-efficacy, potentially impacting on intention and initiation, then further intervention in the form of education to enhance self-efficacy, in the postnatal period, would serve to strengthen the evidence that this is still an important modifiable influence on duration and does increase the rate of 
breastfeeding in this group of mothers. The final section outlines future research directions and the significance of this research.

\section{Significance and recommendations}

Preparing women antenatally to be successful at breastfeeding can have a major impact on the health of society in general. The most significant outcome of this research is the potential for an improvement to our breastfeeding initiation in groups of young women through enhancing breastfeeding selfefficacy. Improving breastfeeding self-efficacy, using Dennis's model as a framework, can be achieved in many settings wherever antenatal breastfeeding education is imparted. This may be both one on one or in group settings. An understanding of the sources of self-efficacy, for example performance accomplishments, vicarious experiences, social and verbal persuasion, and somatic experiences, will improve the ability of midwives and educators to enhance breastfeeding self-efficacy, and give women tools to meet challenges, persevere with breastfeeding and ultimately improve outcomes on many levels. However, in order for this to happen, there needs to be professional education on what breastfeeding self-efficacy is. This study has shown that use of the tool developed by Dennis, known as the Breastfeeding self-efficacy scale (shortform), is a valid measure for Breastfeeding self-efficacy in this population of young women and therefore results of this research should be communicated to midwives and educators in order to guide and focus their efforts on improving breastfeeding self-efficacy.

There are five main recommendations from this research. Firstly the intervention should be repeated and breastfeeding self-efficacy measured in a larger group. Secondly, it would be advantageous to also factor in comparison groups. For example, focusing on those intending to breastfeed and those not intending to, in order to see if an antenatal breastfeeding education intervention changes the intention to breastfeed. Thirdly, comparing a group who didn't attend the intervention with those who did, to examine any differences in selfefficacy and breastfeeding outcomes. Fourthly, a recommendation to examine more closely the relationship between support and breastfeeding self-efficacy, incorporating support around all of the breastfeeding decision points: intention, 
initiation and continuation. Finally, further research in New Zealand is warranted, regarding the impact of Lead Maternity Carers as a source of support and influence on breastfeeding in young women.

By adding to the evidence that antenatal breastfeeding education is a valid source of modifying self-efficacy, midwives and educators will be more inclined to embed this in their practice. These people are important sources of enhancing self-efficacy because they are in prime positions to do so, particularly with first time and young mothers.

The following quote from Mahatma Ghandi was taken from Glover and Leach (2009) slideshow on breastfeeding self-efficacy and perfectly sums up what we can be striving towards to promote, protect and support breastfeeding.

"If I have the belief that I can do it, I shall surely acquire the capacity to do it even if I may not have it at the beginning"

Mahatma Gandhi 


\section{Appendices}




\title{
1.Ethical Approval
}

\author{
Health \\ and \\ Disability \\ Ethics \\ Committees
}

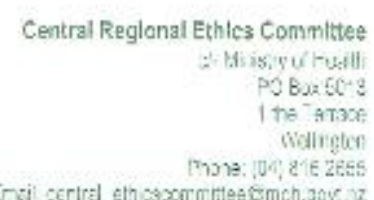

1 July 2011

Ms Nicky Jackson

15 Cashmere Avenue

Khandallah

Weillgnton

Dear Ms Jackson

Ethics ref:

Sludy tille:

CEN/11/EXP/040 (please quote in all correspondence)

Breastieading self efficacy in adolescent mothers prlor to and

following attencance at an antenatal breastfeecting class

This expedited study was glven ethical approval by the Chairperson of the Central Ethics Cunmilles un 18 June 2011.

This approval is valic until 30 Aprll 2012. provided that Annual Progress Reports are submitted (see below).

\section{Access to ACC}

For the purposes of section 32 of the Accident Compensation Act 2001, the Committee is satisfied that this study is not being conducted principally for the henefit of the manufacturer or distr butor of the medicine or item in respect of which the trial is being carried out. Participants Injurad as a result of treatment recaived in this trial will therefore be eligible to be considered for compensation in respect of those iriuries under the ACC scheme.

\section{Amendments and Protocol Deviations}

All s gnificant amendments to this proposal must recaive prior approval from the Committee. Significant amendmerts include (but are not limited to) changes to:

- the researcher responsible for the conduct of the stucy at a study site

- the addition of an exira study site

- the design or curation of the study

- the method of recruitment

- information sheeis and informed consent procedures.

Significant deviations from the approved protocol must be reported to the Committee as soon as possible.

\section{Annual Progress Reports and Final Reports}

The first Annual Progress Reoort for this study is due to the Committee by 01 July 2012. The Annual Report Form that should be used is available at www.ethicscommittees. health.govt.nz. Please note that if you do not provide a progress report by this date, ethical approval may be withdrawn. 
A Final Report is also required at the conclusion of the study. The Final Report Form is also available at www.ethicscummiltees. health.govt.nz.

\section{Requirements for the Reporting of Serious Adverse Events (SAEs)}

SAEs occurring in this study must be individually reported to the Committee within 7-15 days only where they.

- are unoxpected because they are not outlined in the investigatcr's brochure, and

- are not defined study end-points (e.g. death or hospitalisation), and

- occur in patients located in New Zealand, and

- if the study involves blinding, result in a cecision to break the study code.

There is no requirement for the incividual reporting to ethics committees of SAEs that do not meet all of these criteria. However, if your study is overseen by a data monitoring committee, copies of its letters of recommendation to the Principal Invastigator should be forwarded to the Committee as soon as possible.

Please see www ethicscommittees health govt.nz for more information on the reporting of SAEs, and to download the SAE Report Form.

We wish you all the best with your study.

Yours sincerely

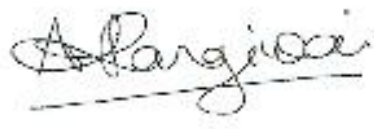

AWHINA RANGIWAI

ADMINISTRATOR

Central Ethics Committee 


\section{Information sheet}

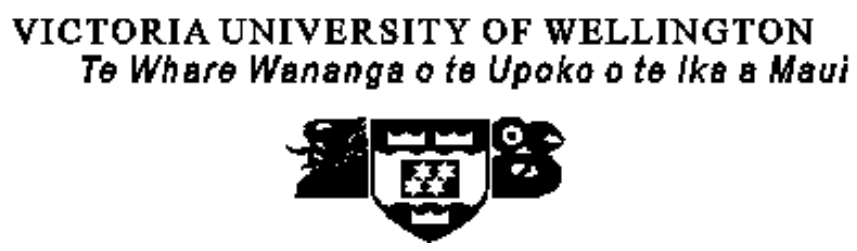

\section{Information about breastfeeding study}

This is a survey to look at the impact of antenatal education on breastfeeding and how it helps young mothers.

It has been modelled on a survey done in Canada on young women to see if their confidence in breastfeeding changes after attending antenatal breastfeeding classes.

If you choose to participate in the study you will be required to:

1. Answer a questionnaire in class in the next couple of weeks. (10 mins)

2. Come to the breastfeeding class on and answer a questionnaire following the class. (10 mins).

(For your trouble you will receive a movie voucher).

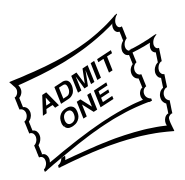

3. Be telephoned 1-2 weeks after baby is born and asked some questions about your birth and how the feeding is going. (10 mins)

4. Be telephoned when your baby is about 6 weeks old to ask how things are going feeding your baby. (3 mins).

5. Be telephoned when your baby is about 12 weeks old to ask how things are going with feeding your baby. (3 mins)

If you have further questions or comments about the study, you can contact: Me Nicky Jackson on 0274504343 or my supervisor Dr Joan Skinner on 4636654 or Diane Kotua (Maori Breastfeeding Co-ordinator Hutt Hospital on 5709542 or Maria Hakaraia for Capital and Coast District Health Board on3855999 
This study has approval from the Central Region Ethics Committee. Ref no: CEN/11/EXP/040

You are free to withdraw from the study at any time.

Thank you for your time.

Nicky Jackson 


\section{Questionnaires}

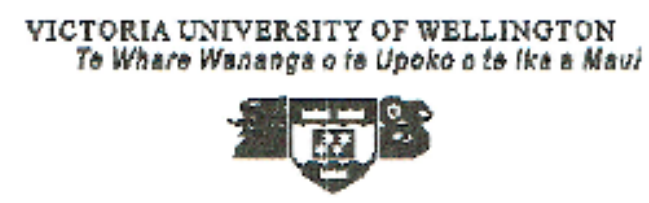

\section{Antenatal Questionnaire (AN1/2)}

Thank you for agreeing to take part in this questionnaire. These first 14 questions will help the researcher learn about the participants in the study.

Please answer by FILLING IN THE BLANK or CIRCLING the number beside your choice:

1. How old will you be when your baby is born? years old

2. What is your marital status? married/living together with baby/s father single/never married/separated/divorced. 1

3. What is your ethnicity? You may circle more than one.

$\begin{array}{lll}\text { NZ Maori } & \text { Samoan } & \text { Latin Amer/Hispanic } \\ \text { Tokelouon } & \text { Other Pacific Is } & \text { African } \\ \text { Fijian } & \text { SE Asian } & \text { Middle Eastern } \\ \text { Niuean } & \text { Indian } & \text { Other European } \\ \text { Tongan } & \text { Chinese } & \text { NZ European } \\ \text { Cook Is Maori } & \text { Other Asian } & \text { Other please specify }\end{array}$

4. What level of education have you completed?

Secondary school .................. 1

Secondary school with NCEA Level 1 or higher.........?

Some univer sity or other tertiary education..... 3

Completed university diploma/degree or post graduate degree.

4

5. How much money does your household earn per year?

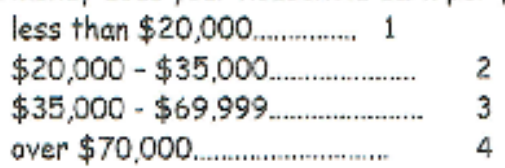

6. What is your amoking status?

non-smoker ...................... 1
social smoker (under 10 per week).............
less than 10 per day......................
10-25 per day ........... 4
more than 25 per day ........ 5


7. Are you going to attend the breastfeeding class at week 6 of this course?

8. Are you planning to breastfeed your baby?

9 If so how much will you bresstfeed?

10 How do you feel about the thought of breastfeeding your baby? (please circle)

$$
\text { Good/Bad Happy/Sad Pleasant/Unhappy }
$$

11 When clid you make your decision to breastfeed?

$$
\text { before getting pregnant after getting pregnant }
$$

12 What other preparation have you done for breastfeeding?

13 Did your mother breastfeed any of her children?

$$
\text { yES NO }
$$

14 How many of your friends or other family members have breastfed?

15 How does your partner feel about your decision to breastfeed? (circle one)

\begin{tabular}{l|l|l|l|l|}
\hline $\begin{array}{l}\text { not } \\
\text { supportive }\end{array}$ & Somewhat supportive & no opinion & supportive & $\begin{array}{l}\text { Very } \\
\text { supportive }\end{array}$ \\
\hline
\end{tabular}

For each of the following statements, please choose the answer that best describes how confident you are about breastfeeding your new baby. Please mark your answer by circling the number that is closest to how you feel. There is no right or wrong answer.

$$
\begin{aligned}
& 1=\text { not at all confident } \\
& 2=\text { not very confident } \\
& 3=\text { sometimes confident } \\
& 4=\text { confident } \\
& 5=\text { very confident }
\end{aligned}
$$




\begin{tabular}{|c|c|c|c|c|c|c|}
\hline \multirow[b]{2}{*}{1} & \multirow[b]{2}{*}{ I think I can always determine that my baby is getting enough milk } & \multicolumn{2}{|c|}{$\begin{array}{l}\text { at All } \\
\text { afident }\end{array}$} & \multicolumn{3}{|c|}{$\begin{array}{l}\text { Very } \\
\text { confident }\end{array}$} \\
\hline & & 1 & 2 & 3 & 4 & 5 \\
\hline 2 & $\begin{array}{l}\text { I think I can always successfully cope with breestfeeding like I have } \\
\text { with other challenging tasks }\end{array}$ & 1 & 2 & 3 & 4 & 5 \\
\hline 3 & $\begin{array}{l}\text { I think I can alwoys breostfeed my baby without using formula os a } \\
\text { supplement }\end{array}$ & 1 & 2 & 3 & 4 & 5 \\
\hline 4 & $\begin{array}{l}\text { I think I can always ensure that ny baby is properly latched on for } \\
\text { the whole feeding }\end{array}$ & 1 & 2 & 3 & 4 & 5 \\
\hline 5 & $\begin{array}{l}\text { I think I con always manoge the breastfeeding situation to my } \\
\text { sutisfaction }\end{array}$ & 1 & 2 & 3 & 4 & 5 \\
\hline 6. & I think I con alwoys manage to breastfeed even if my baby is crying & 1 & 2 & 3 & 4 & 5 \\
\hline 7 & I think I can alwoys keep wanting to breast feed & 1 & 2 & 3 & 4 & 5 \\
\hline 8 & $\begin{array}{l}\text { I think I can always comfortably breostfeed with my family } \\
\text { members present }\end{array}$ & 1 & 2 & 3 & 4 & 5 \\
\hline 9 & I think I con alwoys be satisfied with my breastfeeding experience & 1 & 2 & 3 & 4 & 5 \\
\hline 10 & $\begin{array}{l}\text { I think I cen always deal with the foct that breastfeeding con be } \\
\text { time consuming }\end{array}$ & 1 & 2 & 3 & 4 & 5 \\
\hline 11 & $\begin{array}{l}\text { I think I can always finish feeding my boby on one breast before } \\
\text { switching to the other breast }\end{array}$ & 1 & 2 & 3 & 4 & 5 \\
\hline 12 & $\begin{array}{l}\text { I think I can always continue to breastfeed my baby for every } \\
\text { feeding }\end{array}$ & 1 & 2 & 3 & 4 & 5 \\
\hline 13 & $\begin{array}{l}\text { I think I can clways manage to keep up with my baby's } \\
\text { breastfeeding demonds }\end{array}$ & 1 & 2 & 3 & 4 & 5 \\
\hline 14 & I think I con alwoys tell when my baby is finished breastfeeding & 1 & 2 & 3 & 4 & 5 \\
\hline
\end{tabular}

Finally

After attending the brecstfeeding class and when baby is 1.2 weeks old we will be caking you to complete another short questionncire.

Do you agree to this?

YES NO

Thank You 


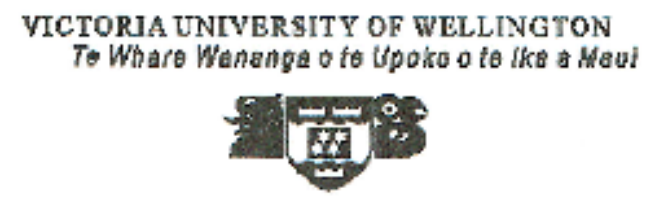

\section{Postnatal Questionnaire (PN1)}

After Baby (1-2 weeks)

These first 15 questions will help the researcher learn about the participants in the study.

Please answer by FILLING IN THE BLANK or CIRCLING the number:

1. Who was your LMC for your pregnancy and the birth of your baby?

Independent (LMC) Midwife...................
Hospital Midwife..................
Private Obstetrician.......................
Hospital Obstetrician ......................... 4

2. How many weeks pregnant were you when your baby was born?

3. What was your baby's weight at birth? (grams.)

4. What was the type of birth? (circle)

$$
\begin{aligned}
& \text { caesarean } \\
& \text { vaginal }
\end{aligned}
$$

5. Describe any interventions in the labour/birth (eg. forceps, ventouse (suction cap), epidural, induction)

6. When did you breastfeed your boby for the first time? (number of hours after birth) 
7. Did your baby receive formula in hospital? YES

8. If YES how much?

9. While in the hospital, how much help, from the midwives, did you need with breastfeeding? (circle one)

\begin{tabular}{|c|c|c|c|c|}
\hline $\begin{array}{l}\text { none at } \\
\text { all }\end{array}$ & & & & very much \\
\hline 1 & 2 & 3 & 4 & 5 \\
\hline
\end{tabular}

10. Since leaving the hospital, which professional services have you used for breostfeeding help? (eg. hospital clinic, midwife visits, private lactation consultant, La Leche Leogue, Mum4Mum)

11. If you answered \#9, please describe how helpful these services were for you. (circle one) Indicate scole for each helper.

\begin{tabular}{|l|l|l|l|l|}
\hline $\begin{array}{l}\text { Who: } \\
\text { not at } \\
\text { all }\end{array}$ & & & & very much \\
\hline 1 & 2 & 3 & 4 & 5 \\
\hline
\end{tabular}

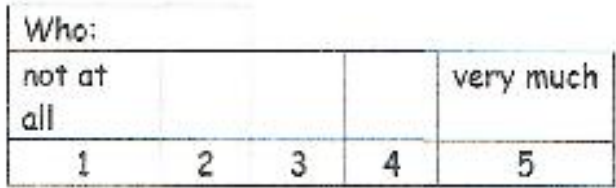

\begin{tabular}{|c|c|c|c|c|}
\hline Who: & & & & \\
\hline $\begin{array}{l}\text { not at } \\
\text { all }\end{array}$ & & & & very much \\
\hline 1 & 2 & 3 & 4 & 5 \\
\hline
\end{tabular}

12. Among friends and family, who provides ongoing breastfeeding support for you? 
13. How much does your baby cry? (circle one)

\begin{tabular}{|c|c|c|c|c|}
\hline $\begin{array}{l}\text { not at } \\
\text { all }\end{array}$ & & & very much \\
\hline 1 & 2 & 3 & 4 & 5 \\
\hline
\end{tabular}

14. How helpful have friends and family been since coming home with the baby? (circle one)

\begin{tabular}{|c|c|c|c|c|}
\hline $\begin{array}{l}\text { not at } \\
\text { all }\end{array}$ & & & & very much \\
\hline 1 & 2 & 3 & 4 & 5 \\
\hline
\end{tabular}

15. Breastfeeding my baby makes me feel (please circle) 
For each of the fol owing statements, please chcose the answer that best describes how conf dent you are with breastfeeding your new baby. Please mark your answer by circling the number that is closest to how you feel. There is no right or wrong answer.

$1=$ not at all confident

2 = not very confident

$3=$ sonet mes confident

$4=$ confident

$5=$ very confident

Not at Al

Confident

Vary confident

\begin{tabular}{|c|c|c|c|c|c|c|}
\hline 1 & I can always determ ne that my baby is getting enough milk & 1 & 2 & 3 & 4 & 5 \\
\hline 2 & $\begin{array}{l}\text { I can always successfully cope with breastfeeding like I hove with other } \\
\text { challenging tasks }\end{array}$ & 1 & 2 & 3 & 4 & 5 \\
\hline 3 & I oon always breastfeed my boby without using formula as a supplement & 1 & 2 & 3 & 4 & 5 \\
\hline 4 & $\begin{array}{l}\text { I can always ensure that my baby is properly latched on for the whole } \\
\text { feeding }\end{array}$ & 1 & 2 & 3 & 4 & 5 \\
\hline 5 & I can clways manage the breastfeeding situation to my satisfaction & 1 & 2 & 3 & 4 & 5 \\
\hline 6 & I can always manage to breostfeed even if my baby is crying & 1 & 2 & 3 & 4 & 5 \\
\hline 7 & I can always keep wanting to breastfeed & 1 & 2 & 3 & 4 & 5 \\
\hline 8 & I can always camfortobly brenstfees with ny family members present & 1 & 2 & 3 & 4 & 5 \\
\hline 9 & I can alwoys be satisfied with my breastfeeding experience & 1 & 2 & 3 & 4 & 5 \\
\hline 10 & I can always deal with the fact that breastfeeding can be time consuming & 1 & 2 & 3 & 4 & 5 \\
\hline 11 & $\begin{array}{l}\text { I can always finish feeding my baby on one breast before switching to the } \\
\text { other breast }\end{array}$ & 1 & 2 & 3 & 4 & 5 \\
\hline 12 & I can always continue to breast feed my baby for every feeding & 1 & 2 & 3 & 4 & 5 \\
\hline 13 & I can olways monage to keep up with my babys breastfeeding demands & 1 & 2 & 3 & 4 & 5 \\
\hline 14 & I can always tell when my boby is finished breostfeeding & 1 & 2 & 3 & 4 & 5 \\
\hline
\end{tabular}




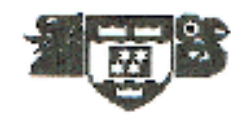

\section{Telephone Questionnaire for Duration Rates and Infant Feeding Categories (PN2/3) \\ 6 weeks and 12 weeks Postpartum}

Thank you for being honest in answering these 4 questions. Your name will not be associated with the summary of findings.

1. Is your baby being breastfed any amount as of today?

Yes... 1 (Go to question 2)

No. 2 (Go to question 3)

2. If yes, how much is your baby breastfeeding? (using MOH definitions as below)

Exclusive.................. 1
Fully ................ 2
Partial........................ 3
1 Nat at allificially) 4

3. If no, how old was your baby (in days) when you stopped breastfeeding?

4. Please describe your reason for stopping

Do you agree to being contacted again in 6 weeks? YES NO
Is this still the best contact and time? .......................... YES NO
If NO, what is the best contact and time? .............................
Thank You




\section{Definitions for Infant Feeding}

To ensure consistency in reporting duration rates, definitions for breastfeeding will be:

Breastfeeding definitions adopted by the New Zealend Ministry of Health in 1999.

Exclusive: the infant has never, to the mothers knowledge, hod any water, formula or other liquid or solid food.

Only breost milk, from the breast or expressed, and prescribed medicines (as per Medicine Act 1988) have been given from birth.

Futly: the infant has taken breost milk only, and no other liquids or solids except a minimal amount of water or prescribed medicines, in the post 48 hours

Portiol: the infant hos taken some breast milk and some infant for'mula or other solid food in the post 48 hours

Antificial: the infant hos hod no breast milk but has had alternative liquid such as infont formula, with or without solid focd, in the post 48 hours. (Ministry of Health, 2002 p10) 


\section{Correspondence}

\subsection{Cindy Lee Dennis}

Russgll Holmea and Nicky Jackson

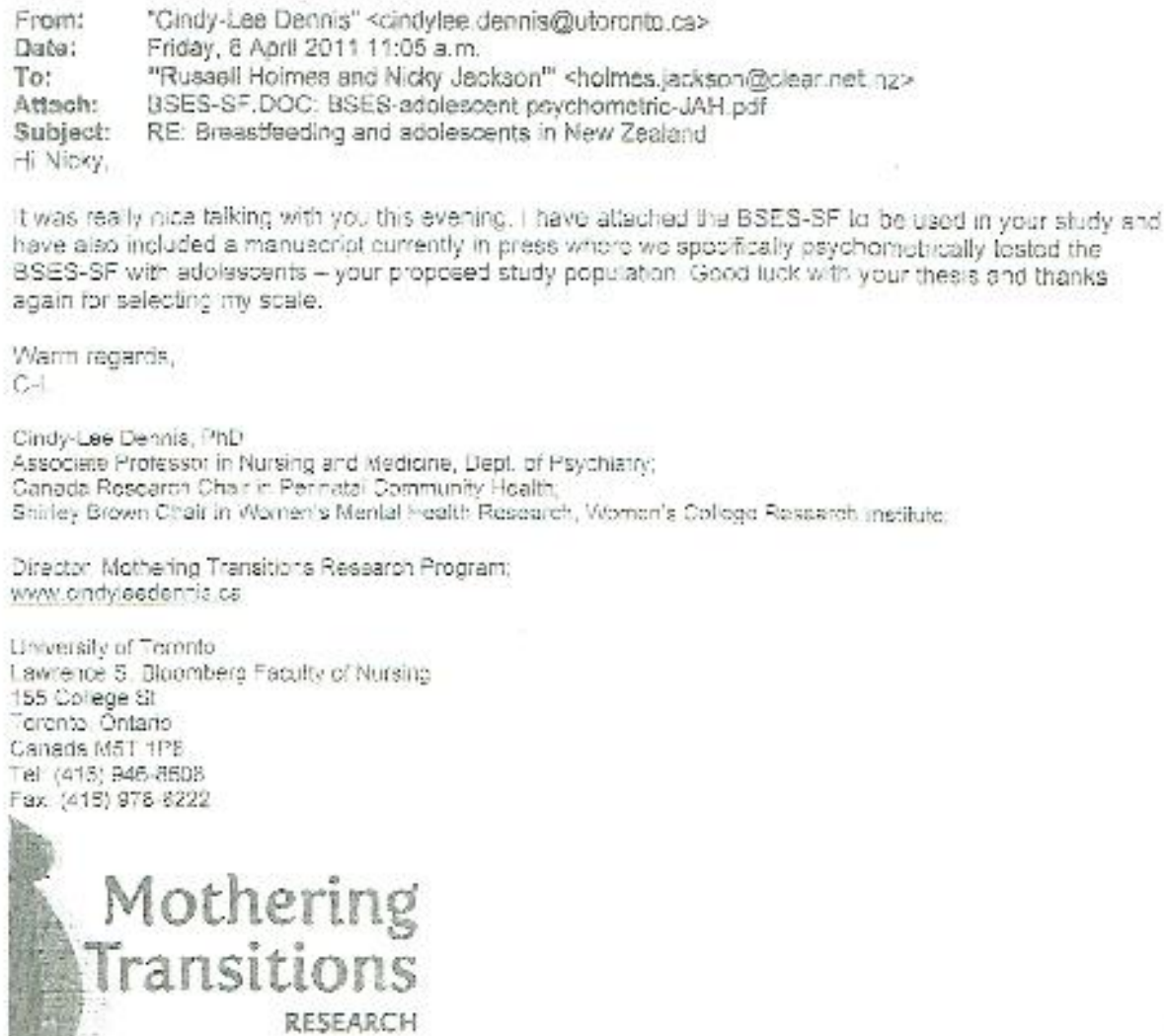

From: Russeli Holmes and Nicky Jackson Imillotholmes.jactsangaciar.nat,nz? Sent: April 7, $20116: 25 \mathrm{AM}$

To: cinchiee.dennis Gitutoronto.ce

Subjscti: Breastreecing and odolegoorts in New Zcaiand

Good Morring M/s Dennis

I am a Masters Stucent at Victoria University in Welington New Zealand. I am just about to commence work on my thesis and am looking at researching breastfeeding outcomes of adolescent worren attenting antenatal breastfeeding education classes.

I have looked of course at your work and that of Marion Mossmans and Joy Noe Weiss's and atso an Australian study by Greenwood and Littiejohn. (among many ofthers) I am intenoing to call you when I can co-ordinate the time zones as I am interested in whether it is possible to obtain permission to use the BSES SF. I would like to sec if this could be used as a tool for Midwives to target appropriate breastfeeding education antenatally and improve the autcomes of breastfeeding abolescents. My research woild be a comvenience sample of adolescents enrolled in antersatal classes which include breastfeeding education. I would like to 


\section{Breasteeding Self-IC Mitcycy Segle-Short Form}

The Breastfooding Self-Efticacy Scale - Short Form (BSES-SF) is under the copy right of Dr. Cindy-Tec Dennis (2003). Permission to use the BSES-SF must be obtained in writing or via email prior to use. There is no charge for this use. However, the cequester must agree to forward a copy of all research to the developer following any investigation.

Enail or mail all correspondence to:

Dr. Cindy-Lee Dennis

University of Toronto

Lawrence S. Bloomberg Faculty of Nursing

155 College Siruet

Tomonto, Ontario, Canada

MST IP8

Chindyles durnis:antorontaces 


\subsection{Joy Noel Weiss(Noel-Weiss, 2005)}

Nicky Jackson

\begin{tabular}{|c|c|}
\hline Fram: & Jry the Weiss [notwersogrogers.om] \\
\hline Sent: & Thurscsy, April 28, $20103: 20 \mathrm{PM}$ \\
\hline To: & Nicky Jacksan' \\
\hline Subjact: & RE: RCT publiahed is JOGNN 2006 \\
\hline
\end{tabular}

Dear Hoky

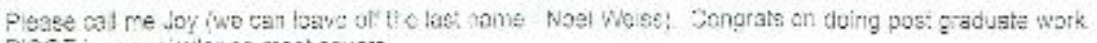
Fico- in very thimilar on most ocu

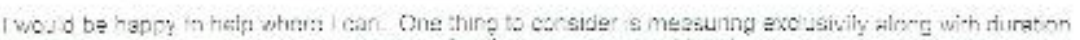

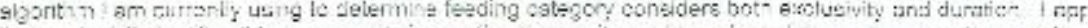

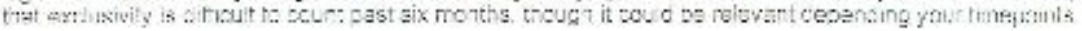

\section{reeding cstegoriss}

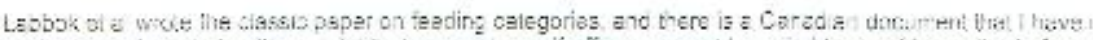

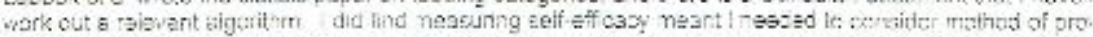

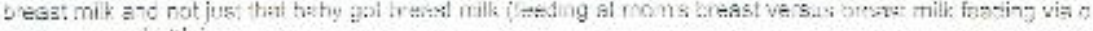
neane - asp. bottlei

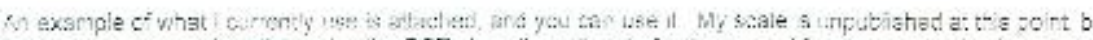

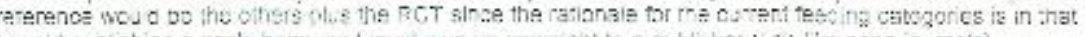

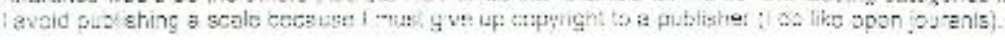

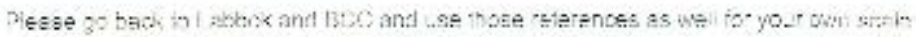

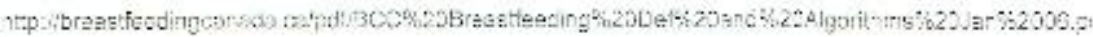

Other qurstionesireg

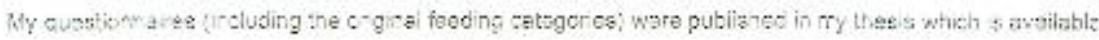

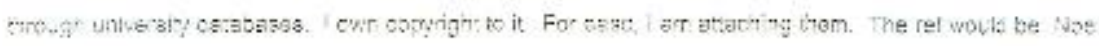

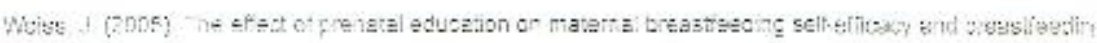

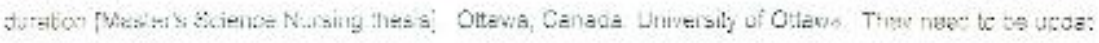

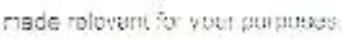

Selit-arfececy seate

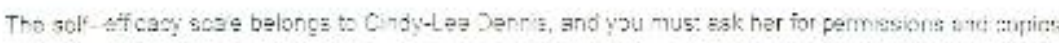

Plesse es me know it t cen nelp others se

s. 


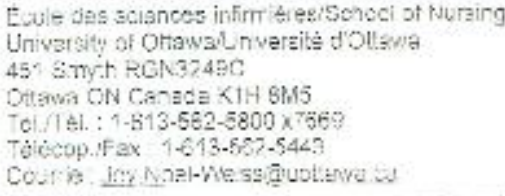

From: Nicky Jackson [mailto:nickyjudooneckear,net,nz]

Sent: Wodrcetay, April 28, 2010 B:52 PM

To: noclwasserogers.com

Subject: RCT pabished in MOGN 2006

\section{Cear Mis Woiss}

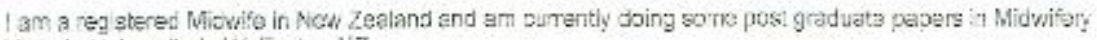
Vizeris univereity in Wollinglon NZ

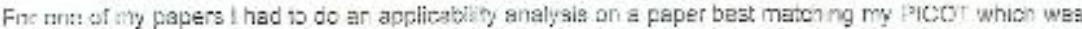

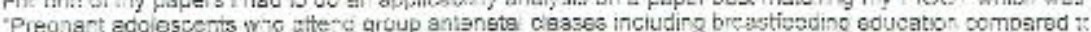

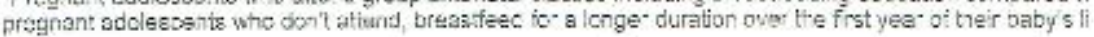

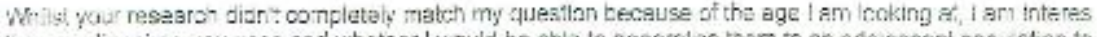

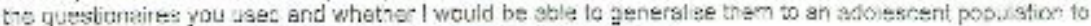
roscarch the offecte of antensta aducation arourd breasfeeding

$i$ am therstcre wondeng if it would te possible to have a bok st them sec the seif efficamy smoring

Kind Regards

Nicky Jackson 


\section{Summary BSES-sf included studies with Cronbachs Alpha Coefficient}

\section{CRONBACH'S ALPHA CO-EFFICIENT RESULTS FOR BREASTFEEDING SELF EFFICACY SCALE - short form}

\begin{tabular}{|c|c|c|c|c|c|c|c|c|}
\hline Author/Year & Country & Sample & Timing & $\begin{array}{l}\text { Mean BSES } \\
\text {-sf } \\
\text { (std } \\
\text { deviation) }\end{array}$ & $\begin{array}{l}\text { Mean } \\
\text { Age }\end{array}$ & $\begin{array}{l}\text { Cronbach's } \\
\text { Alpha }\end{array}$ & Signif. & Comment \\
\hline $\begin{array}{l}\text { Dennis } \\
2003\end{array}$ & Canada & $\begin{array}{l}104 \\
585 \\
\text { breastfeeding } \\
\text { mothers } \\
459 \\
389\end{array}$ & $\begin{array}{l}\text { Antenatal } \\
1 \text { week } \\
4 \text { weeks } \\
8 \text { weeks }\end{array}$ & $\begin{array}{l}55.88(10.85) \\
56.39(10.48) \text { bf } \\
42.58(13.35) \text { af } \\
57.66(9.89) \text { bf } \\
46.13(11.38) \text { af } \\
58.88(8.89) \text { bf } \\
45.94(11.46) \text { af }\end{array}$ & 29 & .94 & $\begin{array}{l}P=<.001 \\
P=<.001\end{array}$ & $\begin{array}{l}\text { Scores at } 1 \text { week } \\
\text { significantly related } \\
\text { to infant feeding } \\
\text { method at } 4 \text { wks } \\
\text { and } 8 \text { wks }\end{array}$ \\
\hline $\begin{array}{l}\text { Wutke and Dennis } \\
2006\end{array}$ & Poland & $\begin{array}{l}105 \\
\text { breastfeeding } \\
\text { mothers }\end{array}$ & $\begin{array}{l}\text { In } \\
\text { hospital } \\
8 \text { weeks } \\
16 \text { weeks }\end{array}$ & $\begin{array}{l}55.5(8.4) \\
56.7(8.1) \mathrm{bf} \\
50.7(7.9) \text { af } \\
57.9(7.3) \mathrm{bf} \\
50.6(8.5) \text { af }\end{array}$ & 28 & .89 & $\begin{array}{l}P=<.003 \\
P=<.003\end{array}$ & $\begin{array}{l}\text { At } 8 \text { and } 16 \text { weeks } \\
\text { postpartum a sig } \\
\text { difference in } \\
\text { scores between } \\
\text { those } \\
\text { breastfeeding and } \\
\text { those formula } \\
\text { feeding }\end{array}$ \\
\hline $\begin{array}{l}\text { O'Brien } \\
2007\end{array}$ & $\begin{array}{l}\text { Australia } \\
\text { Rural }\end{array}$ & 342 & $\begin{array}{l}\text { Varied } \\
0-14 \\
\text { days }\end{array}$ & $47.88(12.24)$ & 30 & .95 & & \\
\hline $\begin{array}{l}\text { Gregory et al } \\
2008\end{array}$ & $\begin{array}{l}\text { UK } \\
\text { ( } 36.3 \% \text { SE } \\
\text { Asian) }\end{array}$ & 165 & $\begin{array}{l}\text { In } \\
\text { hospital } \\
4 \text { weeks }\end{array}$ & $\begin{array}{l}46.46(12.75) \\
49.4(12.9) \text { bf } \\
44.7(9.5) \text { partial } \\
42.4(11.7) \text { af }\end{array}$ & $\begin{array}{l}21-29 \\
40.6 \% \\
30-39 \\
52.1 \% \\
\end{array}$ & .90 & $P=<.001$ & $\begin{array}{l}\text { Scores signif } \\
\text { associated with } \\
\text { infant feeding } \\
\text { method at } 4 \text { wks. }\end{array}$ \\
\hline $\begin{array}{l}\text { Otsuka et al } \\
2008\end{array}$ & Japan & $\begin{array}{l}262 \\
180\end{array}$ & $\begin{array}{l}\text { In } \\
\text { hospital } \\
4 \text { weeks }\end{array}$ & $44.7(11.9)$ & 31.5 & .95 & $P=<.001$ & $\begin{array}{l}\text { Mothers } \\
\text { perception of } \\
\text { insuffient milk at } 4 \\
\text { wks postpartum } \\
\text { were significantly } \\
\text { related to } \\
\text { breastfeeding self- } \\
\text { efficacy in hospital } \\
\text { in the immediate } \\
\text { postpartum period }\end{array}$ \\
\hline $\begin{array}{l}\text { Semenic et al } \\
2008\end{array}$ & Canada & $\begin{array}{l}189 \\
156\end{array}$ & $\begin{array}{l}24-72 \mathrm{hrs} \\
6 \text { weeks } \\
4 \text { months }\end{array}$ & $\begin{array}{l}48.0(9.4) \\
51.9(11.7) \\
56.9(10)\end{array}$ & 30.1 & $?$ & & All primapara \\
\hline Tokat et al & Turkey & $\begin{array}{l}140 \mathrm{AN} \\
150 \mathrm{PN}\end{array}$ & $\begin{array}{l}\text { Antenatal } \\
12 \text { weeks } \\
\text { In } \\
\text { hospital } \\
12 \text { weeks }\end{array}$ & $\begin{array}{l}58.52(8.80) \\
57.23(6.8) \text { bf } \\
54.7(6.7) \text { af } \\
60.09(8.2) \\
58.64(7.05) \text { bf } \\
53.46(7.22) \text { af } \\
\end{array}$ & $\begin{array}{l}25.9 \\
24.4\end{array}$ & $\begin{array}{l}.87 \mathrm{AN} \\
.86 \mathrm{PN}\end{array}$ & $\begin{array}{l}P=<.04 \\
P=<.000\end{array}$ & $\begin{array}{l}\text { Significant } \\
\text { difference in AN } \\
\text { and PN scores } \\
\text { between bf and af } \\
\text { mothers }\end{array}$ \\
\hline $\begin{array}{l}\text { McCarter } \\
\text { Sapulding and } \\
\text { Gore } \\
2009\end{array}$ & $\begin{array}{l}\text { USA } \\
\text { (African } \\
\text { descent) }\end{array}$ & 125 & 1 week & $51.86(12.05)$ & 30.4 & .94 & & $\begin{array}{l}\text { Results } \\
\text { significantly } \\
\text { predicted } \\
\text { breastfeeding } \\
\text { at } 4 \text { and } 24 \\
\text { weeks }\end{array}$ \\
\hline $\begin{array}{l}\text { Kingston et al } \\
2007\end{array}$ & Canada & 63 & $\begin{array}{l}4 \\
\text { weeks }\end{array}$ & & & & $\mathrm{P}=<.003$ & $\begin{array}{l}\text { At } 4 \text { weeks } \\
\text { postpartum, } \\
\text { significant } \\
\text { difference in } \\
\text { scores between } \\
\text { those bf and } \\
\text { those af }\end{array}$ \\
\hline
\end{tabular}




\section{References}

Adolescence (n.d). In Oxford English online dictionary . Retrieved from http://dictionary.oed.com 15 September 2012

Alexander, A., O'Riordan, M. A., \& Furman, L. (2010). Do breastfeeding intentions of pregnant inner-city teens and adult women differ? Breastfeed Med, 5(6), 289-296. doi: 10.1089/bfm.2009.0083

Alus Tokat, M., Okumus, H., \& Dennis, C. L. (2010). Translation and psychometric assessment of the Breast-feeding Self-Efficacy Scale-Short Form among pregnant and postnatal women in Turkey. Midwifery, 26(1), 101-108. doi: 10.1016/j.midw.2008.04.002

Andaya, E., Bonuck, K., Barnett, J., \& Lischewski-Goel, J. (2012). Perceptions of primary care-based breastfeeding promotion interventions: qualitative analysis of randomized controlled trial participant interviews. Breastfeed Med, 7(6), 417-422. doi: 10.1089/bfm.2011.0151

Artieta-Pinedo, I., Paz-Pascual, C., Grandes, G., Bacigalupe, A., Payo, J., \& Montoya, I. (2013). Antenatal education and breastfeeding in a cohort of primiparas. J Adv Nurs, 69(7), 1607-1617. doi: 10.1111/jan.12022

Avery, A., Zimmermann, K., Underwood, P. W., \& Magnus, J. H. (2009). Confident commitment is a key factor for sustained breastfeeding. Birth, 36(2), 141-148. doi: 10.1111/j.1523-536X.2009.00312.x

Awano, M. S., K. (2010). Development and evaluation of a self care program on breastfeeding in Japan: A quasi-experimental study. International Breastfeeding Journal, 5(9).

Baghurst, P., Pincombe, J., Peat, B., Henderson, A., Reddin, E., \& Antoniou, G. (2007). Breastfeeding self-efficacy and other determinants of the duration of breastfeeding in a cohort of first-time mothers in Adelaide, Australia. Midwifery, 23(4), 382-391. doi: 10.1016/j.midw.2006.05.004

Bandura, A. (1977). Self-efficacy: Toward a unifying theory of behavioral change. Psychological Review, 84(2), 191-215. doi: 10.1037/0033295X.84.2.191

Bartington, S., Griffiths, L. J., Tate, A. R., \& Dezateux, C. (2006). Are breastfeeding rates higher among mothers delivering in Baby Friendly accredited maternity units in the UK? International Journal of Epidemiology, 35(5), 1178-1186. doi: 10.1093/ije/dyl155

Basire, K., Pullon, S., \& McLeod, D. (1997). Baby feeding: the thoughts behind the statistics. NZ Med J, 110(1044), 184-187. 
Beake, S., Pellowe, C., Dykes, F., Schmied, V., \& Bick, D. (2012). A systematic review of structured compared with non-structured breastfeeding programmes to support the initiation and duration of exclusive and any breastfeeding in acute and primary health care settings. Maternal \& child nutrition, 8(2), 141-161. doi: 10.1111/j.1740-8709.2011.00381.x

BirthEd. (2012). Performance Monitoring Report December 2012. Wellington. Retrieved from www.birthEd.co.nz

Blyth, R. C., D. K. Dennis, C. L. Moyle, W. Pratt, J. De Vries, S. M. (2002). Effect of maternal confidence on breastfeeding duration: an application of breastfeeding self-efficacy theory. Birth, 29(4), 278-284.

Blyth, R. J., Creedy, D. K., Dennis, C. L., Moyle, W., Pratt, J., De Vries, S. M., \& Healy, G. N. (2004). Breastfeeding duration in an Australian population: The influence of modifiable antenatal factors. Journal of Human Lactation, 20(1), 30-38. doi: 10.1177/0890334403261109

Butler, S., Williams, M., Tukuitonga, C., \& Paterson, J. (2004). Factors associated with not breastfeeding exclusively among mothers of a cohort of Pacific infants in New Zealand. N Z Med J, 117(1195), U908.

Callen, J., \& Pinelli, J. (2004). Incidence and duration of breastfeeding for term infants in Canada, United States, Europe, and Australia: a literature review. Birth, 31(4), 285-292. doi: 10.1111/j.0730-7659.2004.00321.x

Capital and Coast District Health Board. (2014). To the grandmother of the breastfed baby. Wellington.

Centers for Disease Control and Prevention. (2008). Breastfeeding practices: Results from the national immunization survey.Retrieved from http://cdc.gov/breastfeeding/.

Central Cancer Network. (2010). Cancer Control Indicators. Wellington.

Chapman, D. J., Damio, G., Young, S., \& Perez-Escamilla, R. (2004). Effectiveness of breastfeeding peer counseling in a low-income, predominantly Latina population: a randomized controlled trial. Arch Pediatr Adolesc Med, 158(9), 897-902. doi: 10.1001/archpedi.158.9.897

Chezem, J., Friesen, C., \& Boettcher, J. (2003). Breastfeeding knowledge, breastfeeding confidence, and infant feeding plans: effects on actual feeding practices. Journal of obstetric, gynecologic, and neonatal nursing : JOGNN / NAACOG, 32(1), 40-47.

Chung, M., Raman, G., Trikalinos, T., Lau, J., \& Ip, S. (2008). Interventions in primary care to promote breastfeeding: an evidence review for the U.S. Preventive Services Task Force. Ann Intern Med, 149(8), 565-582. 
Craig, E., Adam, J., Oben, G., Reddington, A., Wicken, A., \& Simpson, J. (2011). The Health Status of Children and Young People in the Hutt Valley and Capital and Coast District Health Boards.Wellington: NZ Child and Youth Epidemiology Service.

Creedy, D. K., Dennis, C. L., Blyth, R., Moyle, W., Pratt, J., \& De Vries, S. M. (2003). Psychometric characteristics of the breastfeeding self-efficacy scale: data from an Australian sample. Research in nursing \& health, 26(2), 143-152. doi: 10.1002/nur.10073

Dai, X., \& Dennis, C. L. (2003). Translation and validation of the Breastfeeding Self-Efficacy Scale into Chinese. J Midwifery Womens Health, 48(5), 350-356.

de Oliveira, M. I., Camacho, L. A., \& Tedstone, A. E. (2001). Extending breastfeeding duration through primary care: a systematic review of prenatal and postnatal interventions. Journal of human lactation : official journal of International Lactation Consultant Association, 17(4), 326-343.

Dennis, C. L. (1999). Theoretical underpinnings of breastfeeding confidence: a self-efficacy framework. Journal of human lactation : official journal of International Lactation Consultant Association, 15(3), 195-201.

Dennis, C. L. (2002a). Breastfeeding initiation and duration: a 1990-2000 literature review. Journal of obstetric, gynecologic, and neonatal nursing : JOGNN / NAACOG, 31(1), 12-32.

Dennis, C. L. (2002b). Breastfeeding peer support: maternal and volunteer perceptions from a randomized controlled trial. Birth, 29(3), 169-176.

Dennis, C. L. (2003). The breastfeeding self-efficacy scale: psychometric assessment of the short form. Journal of obstetric, gynecologic, and neonatal nursing : JOGNN / NAACOG, 32(6), 734-744.

Dennis, C. L., \& Faux, S. (1999). Development and psychometric testing of the Breastfeeding Self-Efficacy Scale. Research in nursing \& health, 22(5), 399-409.

Dennis, C. L., Heaman, M., \& Mossman, M. (2011). Psychometric testing of the breastfeeding self-efficacy scale-short form among adolescents. The Journal of adolescent health : official publication of the Society for Adolescent Medicine, 49(3), 265-271. doi:

10.1016/j.jadohealth.2010.12.015

Dwyer, S., Dr,. (2009). Childbirth Education, antenatal education and transitions of maternity care in new zealand.Wellington: Families Commission Research Fund. 
Dykes, F., Moran, V. H., Burt, S., \& Edwards, J. (2003). Adolescent Mothers and Breastfeeding: Experiences and Support Needs-An Exploratory Study. Journal of Human Lactation, 19(4), 391-401. doi: $10.1177 / 0890334403257562$

Dyson, L., Green, J. M., Renfrew, M. J., McMillan, B., \& Woolridge, M. (2010). Factors influencing the infant feeding decision for socioeconomically deprived pregnant teenagers: The moral dimension. Birth: Issues in Perinatal Care, 37(2), 141-149. doi: 10.1046/j.1523-536X.2002.00202.X

Dyson, L., McCormick, F., \& Renfrew, M. (2005). Interventions for promoting the initiation of breastfeeding. Cochrane Database of Systematic Reviews(2). doi: 10.1002/14651858.CD001688.pub2]

Eksioglu, A. B., \& Ceber, E. (2011). Translation and validation of the Breastfeeding Self-efficacy Scale into Turkish. Midwifery, 27(6), e246-253. doi: 10.1016/j.midw.2010.10.009

Ellison-Loschmann, L. (1997). Maori Women's Experiences of Breastfeeding: A Thesis Submitted to Victoria University of Wellington in Partial Fulfillment of the Requirements for the Degree of Master of Arts (Applied) in Midwifery: Victoria University of Wellington.

Essex, C., Smale, P., \& Geddis, D. (1995). Breastfeeding rates in New Zealand in the first 6 months and the reasons for stopping. $N Z$ Med J, 108(1007), 355-357.

Fairbank, L., O'Meara, S., Renfrew, M., Wooldridge, M., Sowden, A., \& ListerSharp, D. (2000). A systematic review to evaluate the effectiveness of interventions to promote the initiation of breastfeeding. Health Technology Assessment Programme, 4(25).

Fairbrother, N., \& Stanger-Ross, I. (2010). Reproductive-aged women's knowledge and attitudes regarding infant-feeding practices: an experimental evaluation. Journal of human lactation : official journal of International Lactation Consultant Association, 26(2), 157-167. doi: $10.1177 / 0890334409352853$

Feldman-Winter, L., \& Shaikh, U. (2007). Optimizing Breastfeeding Promotion and Support in Adolescent Mothers. Journal of Human Lactation, 23(4), 362-367.

Ford, R. P., Mitchell, E. A., Scragg, R., Stewart, A. W., Taylor, B. J., \& Allen, E. M. (1994). Factors adversely associated with breastfeeding in New Zealand. J Paediatr Child Health, 30(6), 483-489.

Forster, D., McLachlan, H., Lumley, J., Beanland, C., Waldenstrom, U., \& Amir, L. (2004). Two mid-pregnancy interventions to increase the initiation and duration of breastfeeding: a randomized controlled trial. Birth, 31(3), 176182. doi: 10.1111/j.0730-7659.2004.00302.x 
Forster, D. A., \& McLachlan, H. L. (2007). Breastfeeding initiation and birth setting practices: a review of the literature. Midwifery Womens Health, 52(3), 273-280. doi: 10.1016/j.jmwh.2006.12.016

Fox, R. A. (1997). The Antenatal Education Needs of Maori Women (in the Tainui Region) and Implications for Midwifery Practice. (Unpublished Masters Thesis), Victoria University of Wellington, Wellington.

Fraser, S. (2008). The role of support in the lives of adolescent mothers. (Unpublished Masters Thesis), Massey, Auckland.

Giles, M., Connor, S., McClenahan, C., \& Mallet, J. (2010). Attitudes to breastfeeding among adolescents. Human Nutrition and Dietetics, 23(3), 285-289.

Giles, M., Connor, S., McClenahan, C., Mallett, J., Stewart-Knox, B., \& Wright, M. (2007). Measuring young people's attitudes to breastfeeding using the Theory of Planned Behaviour. Journal of Public Health, 29(1), 17-26. doi: 10.1093/pubmed/fdl083

Glover, M., Manaena-Biddle, H., \& Waldon, J. (2007). Influences that affect Maori women breastfeeding. Breastfeeding review : professional publication of the Nursing Mothers' Association of Australia, 15(2), 5-14.

Glover, R., \& Leach, S. (Writers). (2009). Building Breastfeeding Self-efficacy.

Goulet, C., Lampron, A., Marcil, I., \& Ross, L. (2003). Attitudes and subjective norms of male and female adolescents toward breastfeeding. Journal of Human Lactation, 19(4), 402-410.

Grassley, J., \& Eschiti, V. (2008). Grandmother breastfeeding support: what do mothers need and want? Birth, 35(4), 329-335. doi: 10.1111/j.1523536X.2008.00260.x

Grassley, J. S., Spencer, B. S., \& Law, B. (2012). A grandmothers' tea: evaluation of a breastfeeding support intervention. J Perinat Educ, 21(2), 80-89. doi: 10.1891/1058-1243.21.2.80

Greene, J., Stewart-Knox, B., \& Wright, M. (2003). Feeding preferences and attitudes to breastfeeding and its promotion among teenagers in Northern Ireland. Journal of human lactation : official journal of International Lactation Consultant Association, 19(1), 57-65.

Greenwood, K., \& Littlejohn, P. (2002). Breastfeeding intentions and outcomes of adolescent mothers in the Starting Out program. Breastfeeding review : professional publication of the Nursing Mothers' Association of Australia, 10(3), 19-23.

Gregory, A., Penrose, K., Morrison, C., Dennis, C. L., \& MacArthur, C. (2008). Psychometric properties of the Breastfeeding Self-Efficacy Scale-Short Form in an ethnically diverse U.K. sample. Public Health Nurs, 25(3), 278-284. doi: 10.1111/j.1525-1446.2008.00705.x 
Grguric, J., Wen, R. A., Kylberg, E., Ashmore, S., \& Macenroe, T. (2012). International perspectives on the Baby-Friendly Initiative. Journal of human lactation : official journal of International Lactation Consultant Association, 28(3), 281-284. doi: 10.1177/0890334412447929

Guise, J. M., Palda, V., Westhoff, C., Chan, B. K., Helfand, M., \& Lieu, T. A. (2003). The effectiveness of primary care-based interventions to promote breastfeeding: systematic evidence review and meta-analysis for the US Preventive Services Task Force. Ann Fam Med, 1(2), 70-78.

Hall, W. A., \& Hauck, Y. (2007). Getting it right: Australian primiparas' views about breastfeeding: A quasi-experimental study. Int J Nurs Stud, 44(5), 786-795. doi: 10.1016/j.jijnurstu.2006.02.006

Hannon, P. R., Willis, S. K., Bishop-Townsend, V., Martinez, I. M., \& Scrimshaw, S. C. (2000). African-American and Latina adolescent mothers' infant feeding decisions and breastfeeding practices: a qualitative study. The Journal of adolescent health : official publication of the Society for Adolescent Medicine, 26(6), 399-407.

Hannula, L., Kaunonen, M., \& Tarkka, M. T. (2008). A systematic review of professional support interventions for breastfeeding. J Clin Nurs, 17(9), 1132-1143. doi: 10.1111/j.1365-2702.2007.02239.x

Health Research Council. (2010). Heath Research Council Guidelines on Ethics in Health Research Version 2 Retrieved 19 May 2011, from hrc.govt.nz/assets/pdfs/publications/ethics/20July/2010.pdf

Hoddinott, P., Kroll, T., Raja, A., \& Lee, A. J. (2010). Seeing other women breastfeed: how vicarious experience relates to breastfeeding intention and behaviour. Maternal \& child nutrition, 6(2), 134-146. doi: 10.1111/j.1740-8709.2009.00189.x

Horta, B. L., Victora, C. G., Gigante, D. P., Santos, J., \& Barros, F. C. (2007). Breastfeeding duration in two generations. Rev Saude Publica, 41(1), 1318.

Huang, M. Z., Kuo, S., Avery, M. D., Chen, W., Lin, K., \& Gau, M. (2007). Evaluating effects of a prenatal web-based breastfeeding education programme in Taiwan. J Clin Nurs, 16(8), 1571-1579. doi: 10.1111/j.1365-2702.2006.01843.x

Jackson, C. (2005). The Baby Friendly Hospital Initiative: Implementing the Process in New Zealand. (Unpublished master's thesis), Victoria University, Wellington.

James, J. P. (2004). An analysis of the breastfeeding practices of a group of mothers living in Victoria, Australia. Breastfeeding review : professional publication of the Nursing Mothers' Association of Australia, 12(2), 19-27. 
Jiang, H., Li, M., Yang, D., Wen, L. M., Hunter, C., He, G., \& Qian, X. (2012). Awareness, intention, and needs regarding breastfeeding: findings from first-time mothers in Shanghai, China. Breastfeed Med, 7(6), 526-534. doi: 10.1089/bfm.2011.0124

Johnson, R., \& Denny, S. (2007). The Health and Wellbeing of Secondary School Students attending Teen Parenting Units.Auckland: University of Auckland Retrieved from www.youth2000.ac.nz.

Jolly, K., Ingram, L., Freemantle, N., Khan, K., Chambers, J., Hamburger, R., . . . Macarthur, C. (2012a). Effect of a peer support service on breastfeeding continuation in the UK: a randomised controlled trial. Midwifery, 28(6), 740-745. doi: 10.1016/j.midw.2011.08.005

Jolly, K., Ingram, L., Khan, K. S., Deeks, J. J., Freemantle, N., \& MacArthur, C. (2012b). Systematic review of peer support for breastfeeding continuation: metaregression analysis of the effect of setting, intensity, and timing. BMJ, 344, d8287. doi: 10.1136/bmj.d8287

Juliff, D., Downie, J., \& Rapley, P. (2007). Knowledge and attitudes of secondary school students to breastfeeding. Neonatal, Paediatric \& Child Health Nursing, 10(3), 13-18.

Kaunonen, M., Hannula, L., \& Tarkka, M. T. (2012). A systematic review of peer support interventions for breastfeeding. J Clin Nurs, 21(13-14), 19431954. doi: 10.1111/j.1365-2702.2012.04071.x

Kingston, D., Dennis, C. L., \& Sword, W. (2007). Exploring breast-feeding selfefficacy. J Perinat Neonatal Nurs, 21(3), 207-215. doi: 10.1097/01.JPN.0000285810.13527.a7

Kronborg, H., Maimburg, R. D., \& Vaeth, M. (2012). Antenatal training to improve breastfeeding: a randomised trial. Midwifery, 28(6), 784-790. doi: 10.1016/j.midw.2011.08.016

Kupratakul, J., Taneepanichskul, S., Voramongkol, N., \& Phupong, V. (2010). A randomized controlled trial of knowledge sharing practice with empowerment strategies in pregnant women to improve exclusive breastfeeding during the first six months postpartum. J Med Assoc Thai, 93(9), 1009-1018.

La Leche League. (2008). Peer Counsellor Programme. Retrieved 14 November, 2013, from www.pcp.org.nz

Lavender, T., Baker, L., Smyth, R., Collins, S., Spofforth, A., \& Dey, P. (2005a). Breastfeeding expectations versus reality: a cluster randomised controlled trial. BJOG, 112(8), 1047-1053. doi: 10.1111/j.14710528.2005.00644.X

Lavender, T., Thompson, S., \& Wood, L. (2005b). Supporting teenage mothers with breastfeeding guardians. British journal of midwifery, 13(6), 354-359. 
Leger-Leblanc, G., \& Rioux, F. M. (2008). Effect of a prenatal nutritional intervention program on initiation and duration of breastfeeding. Can $J$ Diet Pract Res, 69(2), 101-105.

Li, R., Fein, S., Chen, J., \& Grummer-Strawn, L. (2008). Why mothers stop breastfeeding: mothers' self-reported reasons for stopping during the first year. Pediatrics, 122(Suppl 2), S69 - 76.

Lu, M. C., Prentice, J., Yu, S. M., Inkelas, M., Lange, L. O., \& Halfon, N. (2003). Childbirth education classes: sociodemographic disparities in attendance and the association of attendance with breastfeeding initiation. Matern Child Health J, 7(2), 87-93.

Lumbiganon, P., Martis, R., Laopaiboon, M., Festin, M. R., Ho, J. J., \& Hakimi, M. (2012). Antenatal breastfeeding education for increasing breastfeeding duration. Cochrane Database Syst Rev, 9, CD006425. doi: 10.1002/14651858.CD006425.pub3

Manhire, K. M., Hagan, A. E., \& Floyd, S. A. (2007). A descriptive account of New Zealand mothers' responses to open-ended questions on their breastfeeding experiences. Midwifery, 23(4), 372-381. doi: 10.1016/j.midw.2006.01.002

Mannion, C. A., Hobbs, A. J., McDonald, S. W., \& Tough, S. C. (2013). Maternal perceptions of partner support during breastfeeding. Int Breastfeed $\mathrm{J}$, 8(1), 4. doi: 10.1186/1746-4358-8-4

Marrone, S., Vogeltanz-Holm, N., \& Holm, J. (2008). Attitudes, knowledge, and intentions related to breastfeeding among university undergraduate women and men. Journal of human lactation : official journal of International Lactation Consultant Association, 24(2), 186-192. doi: $10.1177 / 0890334408316072$

Martens, P. J. (2001). The Effect of Breastfeeding Education on Adolescent Beliefs and Attitudes: A Randomized School Intervention in the Canadian Ojibwa Community of Sagkeeng. Journal of Human Lactation, 17(3), 245-255. doi: 10.1177/089033440101700308

Martis, R. (2005). An exploratory study of teenagers and their antenatal education needs in the Palmerston North Region. (Unpublished Masters thesis), Massey University, Palmerston North.

Mattar, C. N., Chong, Y. S., Chan, Y. S., Chew, A., Tan, P., Chan, Y. H., \& Rauff, M. H. (2007). Simple antenatal preparation to improve breastfeeding practice: a randomized controlled trial. Obstet Gynecol, 109(1), 73-80. doi: 10.1097/01.aog.0000249613.15466.26

McBride-Henry, K. (2010). The Influence of the "They": An interpretation of Breastfeeding Culture in New Zealand. Qual Health Res, 20(6), 768-777. 
McCarter-Spaulding, D., \& Gore, R. (2009). Breastfeeding self-efficacy in women of African descent. Journal of obstetric, gynecologic, and neonatal nursing : JOGNN / NAACOG, 38(2), 230-243. doi: 10.1111/j.1552-6909.2009.01011.x

McLeod, D., Pullon, S., \& Cookson, T. (2002). Factors influencing continuation of breastfeeding in a cohort of women. Journal of Human Lactation, 18(4), 335-343.

McQueen, K. A., Dennis, C. L., Stremler, R., \& Norman, C. D. (2011). A pilot randomized controlled trial of a breastfeeding self-efficacy intervention with primiparous mothers. Journal of obstetric, gynecologic, and neonatal nursing : JOGNN / NAACOG, 40(1), 35-46. doi: 10.1111/j.15526909.2010.01210.x

Meedya, S., Fahy, K., \& Kable, A. (2010). Factors that positively influence breastfeeding duration to 6 months: a literature review. Women Birth, 23(4), 135-145. doi: 10.1016/j.wombi.2010.02.002

Ministry of Health. (2006 (revised 2008)). Food and Nutrition Guidelines for Healthy Pregnant and Breastfeeding Women: A background paper.Wellington: Ministry of Health.

Ministry of Health. (2008). Food and Nutrition Guidelines for Health Infants and Toddlers (Aged 0-2) A background paper.Wellington: Ministry of Health Retrieved from http://www.moh.govt.nz/moh.nsf/indexmh/0-2-food-andnutrition-guidelines-may2008.

Ministry of Health. (2009). National Strategic Plan of Action for Breastfeeding 2008-2012. Wellington.

Ministry of Health. (2010). Maternity Factsheet2001-2010 from http://www.health.govt.nz/publication/maternity-factsheet-2001-2010

Molina Torres, M., Davila Torres, R. R., Parrilla Rodriguez, A. M., \& Dennis, C. L. (2003). Translation and validation of the breastfeeding self-efficacy scale into Spanish: data from a Puerto Rican population. Journal of human lactation : official journal of International Lactation Consultant Association, 19(1), 35-42.

Mossman, M., Heaman, M., Dennis, C. L., \& Morris, M. (2008). The influence of adolescent mothers' breastfeeding confidence and attitudes on breastfeeding initiation and duration. Journal of human lactation : official journal of International Lactation Consultant Association, 24(3), 268-277. doi: $10.1177 / 0890334408316075$

National Breastfeeding Advisory Committee of New Zealand. (2007). Protecting, promoting and supporting breastfeeding in Aoteoroa New Zealand. Wellington. 
National Breastfeeding Advisory Committee of New Zealand. (2009). National Strategic Plan of Action for Breastfeeding 2008-2012: National Breastfeeding Advisory Committee of New Zealand's advice to the Director General of Health. Wellington.

Nelson, A. (2009). Adolescent attitudes, beliefs, and concerns regarding breastfeeding. American Journal of maternal and child nursing, 34, 249255.

Nelson, A., \& Sethi, S. (2005). The breastfeeding experiences of Canadian teenage mothers. Journal of obstetric, gynecologic, and neonatal nursing : JOGNN / NAACOG, 34(5), 615-624. doi: 10.1177/0884217505280279

Nesbitt, S. A., Campbell, K. A., Jack, S. M., Robinson, H., Piehl, K., \& Bogdan, J. C. (2012). Canadian adolescent mothers' perceptions of influences on breastfeeding decisions: a qualitative descriptive study. BMC pregnancy and childbirth, 12, 149. doi: 10.1186/1471-2393-12-149

New Zealand Breastfeeding Authority. (2012). Baby Friendly Initiative for Aoteoroa New Zealand: Breastfeeding Data. Retrieved 01 May 2012, from http://www.babyfriendly.org.nz/going-baby-friendly/breastfeedingdata/

New Zealand Crown. (2007). Notice pursuant to section 88 of the New Zealand Public Health and disability act 2000.

New Zealand Parliamentarians' Group on Population and Development. (2007). Youth Sexual Health: "Our Health, Our Issue": Report of NZPGPD 'Open hearing on Youth Sexual and Reproductive Health'. Retrieved 2011, 30 June, from www.fpi.org.nz/Portals/6/NZPPD

Nichols, J., Schutte, N. S., Brown, R. F., Dennis, C. L., \& Price, I. (2009). The impact of a self-efficacy intervention on short-term breast-feeding outcomes. Health Educ Behav, 36(2), 250-258. doi: $10.1177 / 1090198107303362$

Nicoletti, A. (2006). The Breastfeeding Teen. J Pediatr Adolesc Gynecol, 19(2), 131-132. doi: 10.1016/j.jpag.2006.01.010

Noel-Weiss, J. (2005). The effect of prenatal education on maternal breastfeeding self-efficacy and breastfeeding duration. (Master's Science), University of Ottawa, Ottawa,Canada.

Noel-Weiss, J., Bassett, V., \& Cragg, B. (2006a). Developing a prenatal breastfeeding workshop to support maternal breastfeeding self-efficacy. Journal of obstetric, gynecologic, and neonatal nursing : JOGNN / NAACOG, 35(3), 349-357. doi: 10.1111/j.1552-6909.2006.00053.x 
Noel-Weiss, J., Rupp, A., Cragg, B., Bassett, V., \& Woodend, A. K. (2006b). Randomized controlled trial to determine effects of prenatal breastfeeding workshop on maternal breastfeeding self-efficacy and breastfeeding duration. JOGNN: Journal of Obstetric, Gynecologic \& Neonatal Nursing, 35(5), 616-624.

Oliver-Roig, A., d'Anglade-Gonzalez, M. L., Garcia-Garcia, B., Silva-Tubio, J. R., Richart-Martinez, M., \& Dennis, C. L. (2012). The Spanish version of the Breastfeeding Self-Efficacy Scale-Short Form: reliability and validity assessment. Int J Nurs Stud, 49(2), 169-173. doi:

10.1016/j.jinurstu.2011.08.005

Oria, M. O., Ximenes, L. B., de Almeida, P. C., Glick, D. F., \& Dennis, C. L. (2009). Psychometric assessment of the Brazilian version of the Breastfeeding Self-Efficacy Scale. Public Health Nurs, 26(6), 574-583. doi: 10.1111/j.1525-1446.2009.00817.x

Otsuka, K., Dennis, C. L., Tatsuoka, H., \& Jimba, M. (2008). The relationship between breastfeeding self-efficacy and perceived insufficient milk among Japanese mothers. Journal of obstetric, gynecologic, and neonatal nursing : JOGNN / NAACOG, 37(5), 546-555. doi: 10.1111/j.1552-6909.2008.00277.x

Pallant, J. (2011). SPSS Survival Manual: A step by step guide to data analysis using SPSS (4th ed.): Allen and Unwin.

Park, Y. K., Meier, E. R., \& Song, W. O. (2003). Characteristics of teenage mothers and predictors of breastfeeding initiation in the Michigan WIC program in 1995. Journal of Human Lactation, 19(1), 50-56.

Pate, B. L. (2009). Effectiveness of Web-based programs in improving breastfeeding self-efficacy. (Unpublished PhD thesis), University of Arkansas for Medical Sciences. Retrieved from http://search.ebscohost.com/login Available from EBSCOhost rzh database.

Personal Communication (2011). [Whānau].

Pobocik, R., Benavente, J., Schwab, A., Boudreau, N., Morris, C., \&\& Houston, S. (2000). Effect of a breastfeeding education and support program on breastfeeding initiation and duration in a culturally diverse group of adolescents. Journal of Nutrition Education, 32(3), 139-145.

Polit, D., \& Beck, C. (2008). Nursing Research: Generating and Assessing Evidence for Nursing Practice (8th ed.). Philadelphia: Lippincott Williams and Wilkins.

Pollard, D., \& Guill, M. (2011). The relationship between baseline self efficacy and breastfeeding duration. Southern Online Journal of Nursing Research, 9(4). 
Poon, K. (2011). Does in-hospital breastfeeding self-efficacy predict breastfeeding duration? (Unpublished Masters Thesis), Queens University, Ontario.

Rempel, L. A., \& Moore, K. C. (2012). Peer-led prenatal breast-feeding education: a viable alternative to nurse-led education. Midwifery, 28(1), 73-79. doi: 10.1016/j.midw.2010.11.005

Rempel, L. A., \& Rempel, J. K. (2011). The breastfeeding team: the role of involved fathers in the breastfeeding family. Journal of human lactation : official journal of International Lactation Consultant Association, 27(2), 115-121. doi: 10.1177/0890334410390045

Renfrew, M., Dyson, L., Wallace, L., D'Souza, L., McCormick, F., \& Spiby, H. (2005). Promotion of breastfeeding initiation and duration.London: National Institute for Health and Clinical Excellence Retrieved from www.nice.org.uk.

Royal New Zealand Plunket Society. (2010). Plunket Breastfeeding Data:Analysis of 2004-2009 data: Royal New Zealand Plunket Society.

Sandy, J. M., Anisfeld, E., \& Ramirez, E. (2009). Effects of a prenatal intervention on breastfeeding initiation rates in a Latina immigrant sample. Journal of human lactation : official journal of International Lactation Consultant Association, 25(4), 404-411. doi: 10.1177/0890334409337308

Schluter, P. J., Carter, S., \& Percival, T. (2006). Exclusive and any breastfeeding rates of Pacific infants in Auckland: data from the Pacific Islands Families First Two Years of Life Study. Public Health Nutr, 9(6), 692-699.

Silvers, K. M., Frampton, C. M., Wickens, K., Pattemore, P. K., Ingham, T., Fishwick, D., . . . New Zealand Asthma Allergy Cohort Study. (2012). Breastfeeding protects against current asthma up to 6 years of age. $J$ Pediatr, 160(6), 991-996 e991. doi: 10.1016/j.jpeds.2011.11.055

Sipsma, H. L., Magriples, U., Divney, A., Gordon, D., Gabzdyl, E., \& Kershaw, T. (2013). Breastfeeding behavior among adolescents: initiation, duration, and exclusivity. The Journal of adolescent health : official publication of the Society for Adolescent Medicine, 53(3), 394-400. doi: 10.1016/j.jadohealth.2013.04.005

Spear, H. J. (2006). Breastfeeding behaviors and experiences of adolescent mothers. MCN Am J Matern Child Nurs, 31(2), 106-113.

Statistics New Zealand. (2013). New Zealand Income Survey. from www.stats.govt.nz/.../Statistics/.../NZIncomeSurveyJune2013

Stuebe, A. M., \& Bonuck, K. (2011). What predicts intent to breastfeed exclusively? Breastfeeding knowledge, attitudes, and beliefs in a diverse urban population. Breastfeed Med, 6(6), 413-420. doi:

10.1089/bfm.2010.0088 
Su, L. L., Chong, Y. S., Chan, Y. H., Chan, Y. S., Fok, D., Tun, K. T., . . Rauff, M. (2007). Antenatal education and postnatal support strategies for improving rates of exclusive breastfeeding: randomised controlled trial. BMJ, 335(7620), 596. doi: 10.1136/bmj.39279.656343.55

Swanson, V., Power, K., Kaur, B., Carter, H., \& Shepherd, K. (2006). The impact of knowledge and social influences on adolescents' breastfeeding beliefs and intentions. Public Health Nutr, 9(3), 297-305.

Tavakol, M., \& Dennick, R. (2011). Making sense of Cronbach's alpha. International Journal of Medical Education, 2, 53-55. doi: 10.5116/ijme.4dfb.8dfd

Torres de Lacerda, A. C., Lucena de Vasconcelos, M. G., Nascimento de Alencar, E., Osório, M. M., \& Pontes, C. M. (2013). Adolescent fathers: Knowledge of and involvement in the breastfeeding process in Brazil. Midwifery(0). doi: 10.1016/j.midw.2013.01.006

UNFPA. (2005). State of worlds population: Adolescents fact sheet. Retrieved 14 September, 2012, from (www.unfpa.org/swp/2005/presskit/factsheets/facts_adolescents.htm)

UNICEF. (2005). Celebrating the Innocenti Declaration on the protection, promtion and support of breastfeeding. Retrieved 12 September, 2010, from www.unicef.org-irc.org/publications/pdf/1990-2005-gb.pdf.

UNICEF. (2007). Child Poverty in Perspective: An overview of child well being in rich countries. Retrieved 12 September, 2010, from www.unicef.org/media/files/childpoverty/pdf

Uzun, A. K., Orhon, F. S., Baskan, S., \& Ulukol, B. (2013). A comparison between adolescent mothers and adult mothers in terms of maternal and infant outcomes at follow-ups. J Matern Fetal Neonatal Med, 26(5), 454458. doi: $10.3109 / 14767058.2012 .733748$

van Rossem, L., Oenema, A., Steegers, E. A., Moll, H. A., Jaddoe, V. W., Hofman, A., ... Raat, H. (2009). Are starting and continuing breastfeeding related to educational background? The generation $R$ study. Pediatrics, 123(6), e1017-1027. doi: 10.1542/peds.2008-2663

Vogel, A., Hutchison, B. L., \& Mitchell, E. A. (1999). Factors associated with the duration of breastfeeding. Acta Pædiatrica, 88(12), 1320-1326. doi: 10.1111/j.1651-2227.1999.tb01044.x

Volpe, E. (2002). Breastfeeding by adolescent mothers. A strategy that works. Advance nurse practitioners, 10(10), 67-70.

Volpe, E. M., \& Bear, M. (2000). Enhancing breastfeeding initiation in adolescent mothers through the Breastfeeding Educated and Supported Teen (BEST) Club. Journal of Human Lactation, 16(3), 196-200. 
Wambach, K., \& Cole, C. (2000). Breastfeeding and adolescents. Journal of obstetric, gynecologic, and neonatal nursing : JOGNN / NAACOG, 29(3), 282-294.

Wambach, K. A., Aaronson, L., Breedlove, G., Domian, E. W., Rojjanasrirat, W., \& Yeh, H.-W. (2011). A randomized controlled trial of breastfeeding support and education for adolescent mothers. Western journal of nursing research, 33(4), 486-505. doi: 10.1542/peds.2004-2491

Wambach, K. A., \& Cohen, S. M. (2009). Breastfeeding experiences of urban adolescent mothers. Journal of pediatric nursing, 24(4), 244-254. doi: 10.1016/j.pedn.2008.03.002

Wambach, K. A., \& Koehn, M. (2004). Experiences of infant-feeding decisionmaking among urban economically disadvantaged pregnant adolescents. J Adv Nurs, 48(4), 361-370. doi: 10.1111/j.1365-2648.2004.03205.x

Wilhelm, S. L., Rodehorst, T. K., Stepans, M. B., Hertzog, M., \& Berens, C. (2008). Influence of intention and self-efficacy levels on duration of breastfeeding for midwest rural mothers. Appl Nurs Res, 21(3), 123-130. doi: 10.1016/j.apnr.2006.10.005

World Health Organisation and Unicef. (2003). Global strategy on infant and young child feeding Retrieved from www.who.itl

Yi, C. M., \& Man, H. S. (2011). The effectiveness of breastfeeding education on maternal breastfeeding self-efficacy and breastfeeding duration: a systematic review (Vol. 9).

Zubaran, C., Foresti, K., Schumacher, M., Thorell, M. R., Amoretti, A., Muller, L., \& Dennis, C. L. (2010). The Portuguese version of the Breastfeeding Self-Efficacy Scale-Short Form. Journal of human lactation : official journal of International Lactation Consultant Association, 26(3), 297-303. doi: 10.1177/0890334409359916 